\title{
Modeling and Depletion Simulations for a High Flux Isotope Reactor Cycle with a Representative Experiment Loading
}

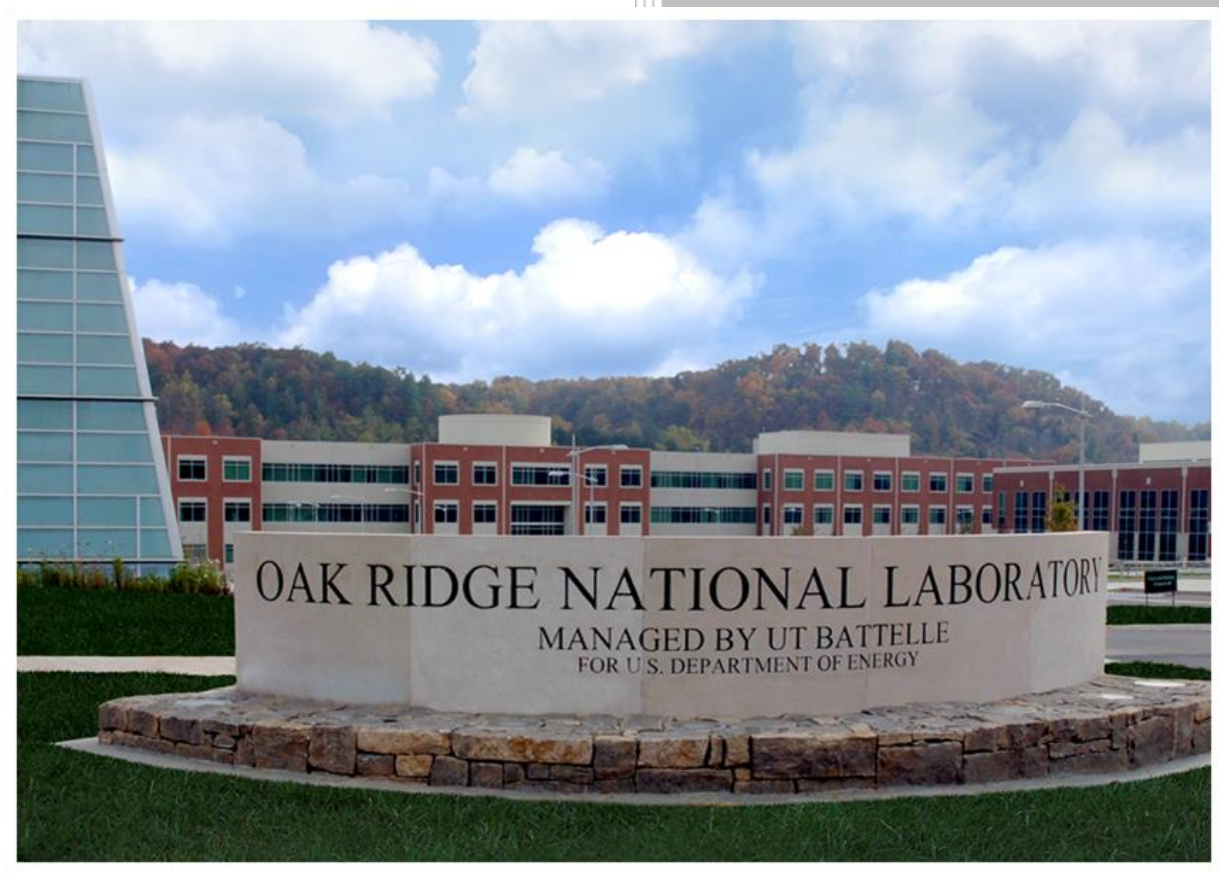

David Chandler Ben Betzler Greg Hirtz Germina llas Eva Sunny

September 2016 


\section{DOCUMENT AVAILABILITY}

Reports produced after January 1, 1996, are generally available free via US Department of Energy (DOE) SciTech Connect.

Website http://www.osti.gov/scitech/

Reports produced before January 1, 1996, may be purchased by members of the public from the following source:

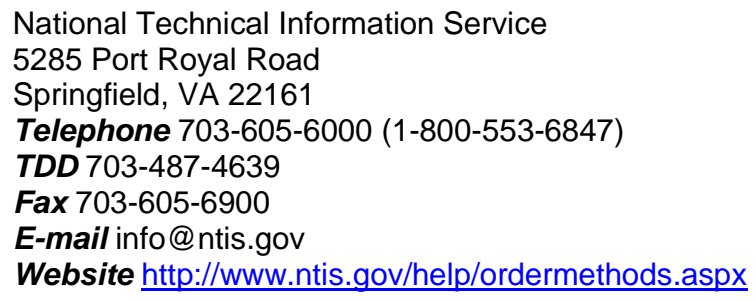

Reports are available to DOE employees, DOE contractors, Energy Technology Data Exchange representatives, and International Nuclear Information System representatives from the following source:

Office of Scientific and Technical Information

PO Box 62

Oak Ridge, TN 37831

Telephone 865-576-8401

Fax 865-576-5728

E-mail reports@osti.gov

Website http://www.osti.gov/contact.html

This report was prepared as an account of work sponsored by an agency of the United States Government. Neither the United States Government nor any agency thereof, nor any of their employees, makes any warranty, express or implied, or assumes any legal liability or responsibility for the accuracy, completeness, or usefulness of any information, apparatus, product, or process disclosed, or represents that its use would not infringe privately owned rights. Reference herein to any specific commercial product, process, or service by trade name, trademark, manufacturer, or otherwise, does not necessarily constitute or imply its endorsement, recommendation, or favoring by the United States Government or any agency thereof. The views and opinions of authors expressed herein do not necessarily state or reflect those of the United States Government or any agency thereof. 
Research Reactors Division

Reactor and Nuclear Systems Division

\title{
MODELING AND DEPLETION SIMULATIONS FOR A HIGH FLUX ISOTOPE REACTOR CYCLE WITH A REPRESENTATIVE EXPERIMENT LOADING
}

\author{
David Chandler \\ Ben Betzler \\ Greg Hirtz \\ Germina Ilas \\ Eva Sunny
}

Date Published: September 2016

Prepared by

OAK RIDGE NATIONAL LABORATORY

Oak Ridge, TN 37831-6283

managed by

UT-BATTELLE, LLC

for the

US DEPARTMENT OF ENERGY

under contract DE-AC05-00OR22725 



\section{CONTENTS}

Page

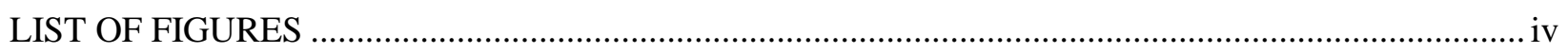

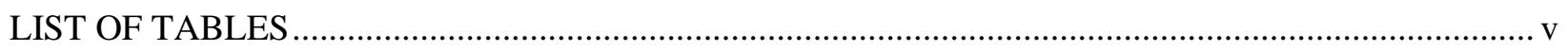

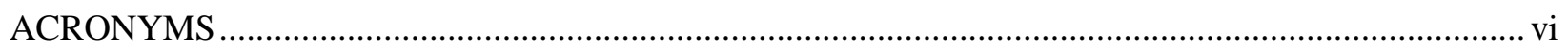

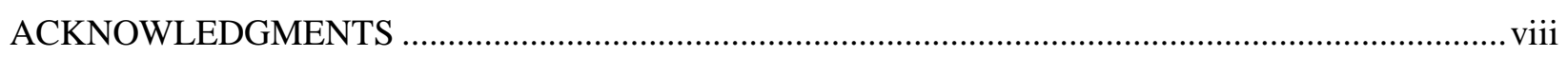

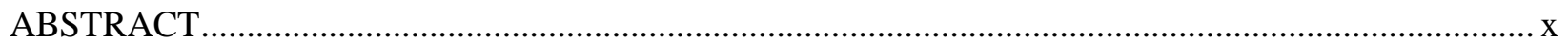

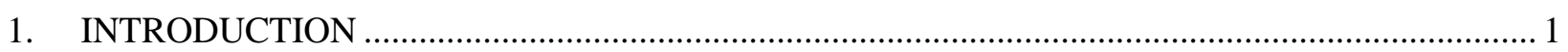

2. OVERVIEW OF HFIR IRRADIATION EXPERIMENT FACILITIES ........................................ 2

3. MODELING OF THE FLUX TRAP TARGET REGION .......................................................... 4

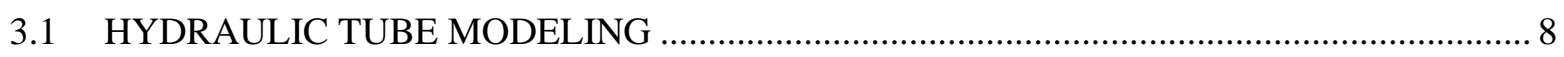

3.2 SHROUDED DUMMY ALUMINUM TARGET MODELING ......................................... 10

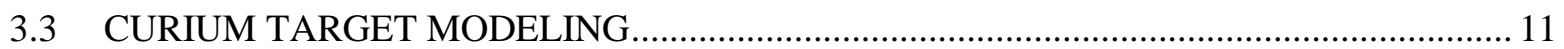

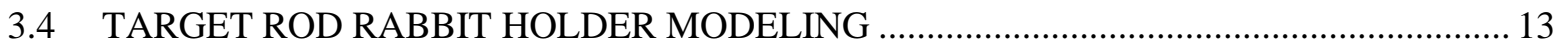

3.5 PERIPHERAL TARGET POSITION MODELING …...................................................... 18

4. MODELING OF THE BERYLLIUM REFLECTOR EXPERIMENTS …..................................... 24

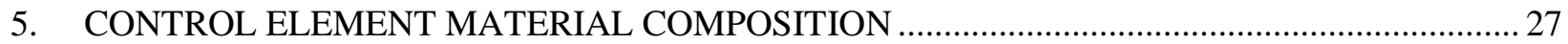

6. HIGH-FIDELITY FUEL ELEMENT SIDE PLATE MODELING ….......................................... 30

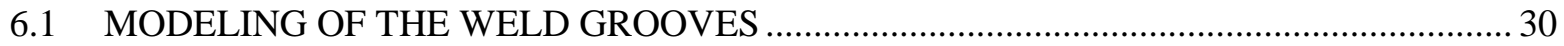

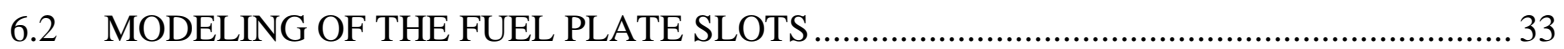

6.3 MODELING OF THE SHOULDERS AND EXTENSIONS ….......................................... 34

7. EXPLICIT AND SIMPLIFIED MODELING OF THE FUEL ELEMENTS ...................................... 36

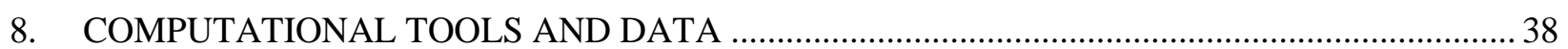

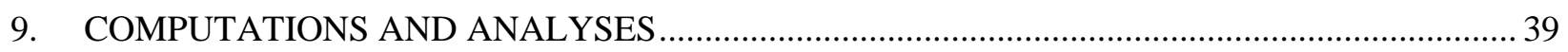

9.1 SYMMETRICAL CONTROL ELEMENT POSITIONS AND CYCLE LENGTH ................ 39

9.1.1 Cycle Length Estimate for the Explicit Fuel Model ................................................ 39

9.1.2 Cycle Length Estimate for the Simplified Fuel Model ............................................. 43

9.2 ISOTOPIC COMPOSITION OF IRRADIATED FUEL ................................................. 46

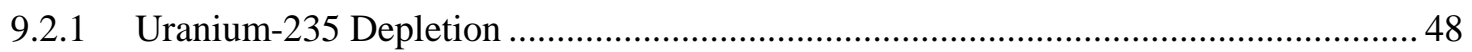

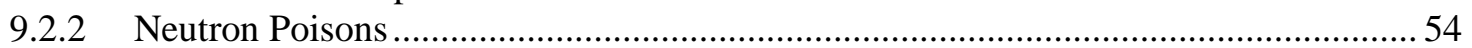

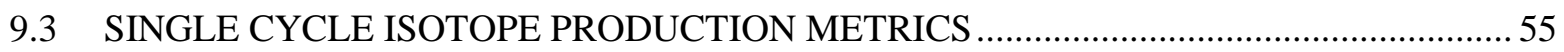

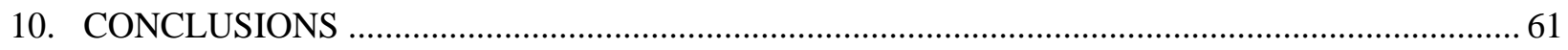

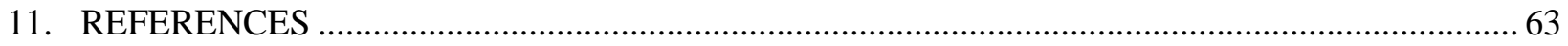




\section{LIST OF FIGURES}

Figure

Figure 1. Illustration of High Flux Isotope Reactor irradiation experiment locations.............................. 2

Figure 2. Cross-section of flux trap target region at the core midplane: (a) target position map, (b)

Cycle 400 HEU model, (c) model for LEU studies prior to 2015, and (d) new,

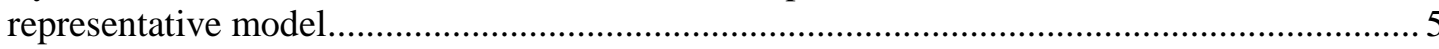

Figure 3. Illustration of the representative model flux trap loading map........................................... 6

Figure 4. Illustrations of (a) $x-z$ and (b) $y-z$ cross-sections through the flux trap of the representative model on the core centerline $(-39.69 /+49.21 \mathrm{~cm}$ with respect to core axial midplane shown).

Figure 5. Illustration of the hydraulic tube including two pusher rabbits, four dummy rabbits, and

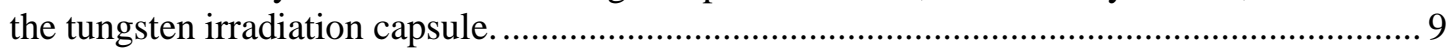

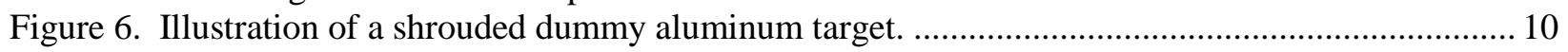

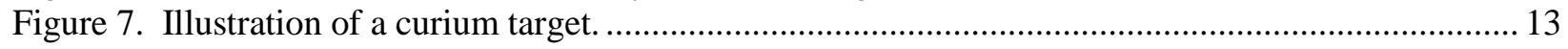

Figure 8. Illustration of target rod rabbit holders.......................................................................... 14

Figure 9. Illustration of peripheral target position targets: (a) PTP Generic 1 and (b) PTP Generic 2..... 19

Figure 10. Illustration of fully loaded plutonium-238 production targets in vertical experiment

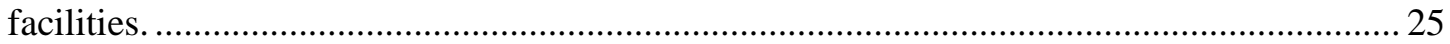

Figure 11. Cross-section of the as-modeled representative core configuration at the horizontal

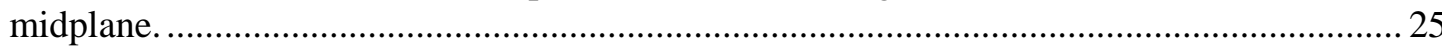

Figure 12. An r-z cross-section of the fuel element assembly as-modeled geometry.............................. 31

Figure 13. An r-z cross-section of the upper five as-modeled weld grooves of the inner fuel

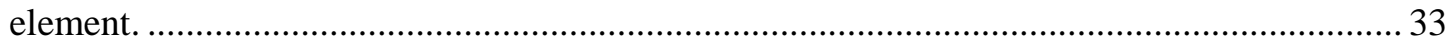

Figure 14. An x-y cross-section of fuel plate and slot as-modeled geometry...................................... 34

Figure 15. Modeling of the fuel elements in the simplified MCNP model.............................................. 36

Figure 16. Modeling of the fuel elements in the explicit MCNP model................................................ 37

Figure 17. Approximation of the involute-shaped inner fuel element (top) and outer fuel element

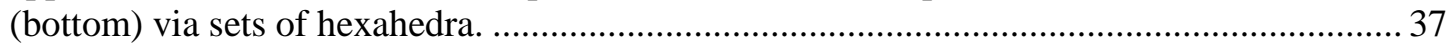

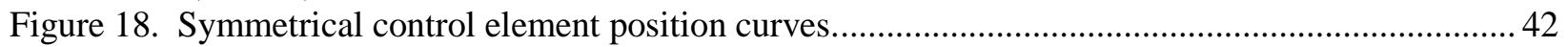

Figure 19. Variation of calculated $k_{\text {eff }}$ with irradiation time and control element position. ..................... 43

Figure 20. U-235 depletion and $\mathrm{Pu}-239$ production vs. irradiation time for explicit model..................... 48

Figure 21. Variation of enrichment $\left({ }^{235} \mathrm{U} / \mathrm{U}\right)$ with irradiation time for explicit model. ............................ 49

Figure 22. End-of-cycle U-235 depletion distribution for explicit model. ........................................... 50

Figure 23. End-of-cycle U-235 depletion - radial and axial profiles for explicit model.......................... 51

Figure 24. Variation of inner fuel element B-10 poison with time for explicit model. …........................ 54

Figure 25. Buildup of Xe-135 and Sm-149 fission product poisons with time for explicit model........... 55

Figure 26. Single cycle W-188 and Re-188 production curves for explicit model..................................56

Figure 27. Single cycle Cf-252 and Bk-249 production curves for explicit model. ...............................57

Figure 28. Single cycle $\mathrm{Pu}-238$ production curves for explicit model....................................................58

Figure 29. Single cycle $\mathrm{Pu}-238$ production target metrics for explicit model. ........................................ 59

Figure 30. Single cycle target fission power curves for explicit model................................................. 60 


\section{LIST OF TABLES}

Table

Page

Table 1. Peripheral target position generic capsule loading .............................................................. 7

Table 2. Flux trap target region experiment loading summary (interior targets) .................................... 8

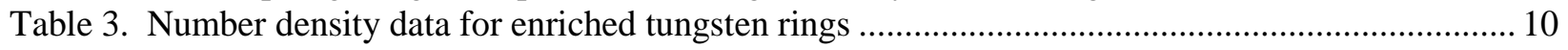

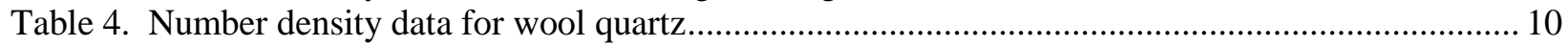

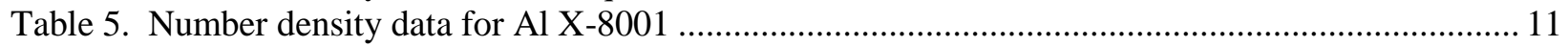

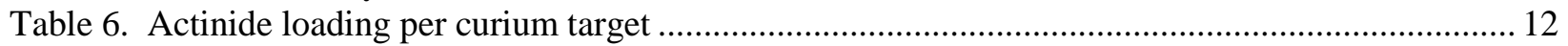

Table 7. Number density data for curium oxide in aluminum pellets................................................... 12

Table 8. Number density data for $\mathrm{Nb}+\mathrm{Fe}$ target rod rabbit holder irradiation capsule ............................. 15

Table 9. Number density data for $\mathrm{V}+\mathrm{Ni}$ target rod rabbit holder irradiation capsule ................................ 16

Table 10. Number density data for Mo target rod rabbit holder irradiation capsule................................. 17

Table 11. Number density data for Se target rod rabbit holder irradiation capsule .................................. 18

Table 12. Number density data for $\mathrm{Ni}+$ Se target rod rabbit holder irradiation capsule ............................ 18

Table 13. Number density data for $\mathrm{Nb}$ peripheral target position irradiation capsule ............................. 20

Table 14. Number density data for Mo peripheral target position irradiation capsule ............................ 21

Table 15. Number density data for $\mathrm{V}$ peripheral target position irradiation capsule ................................ 22

Table 16. Number density data for Fe peripheral target position irradiation capsule ............................. 23

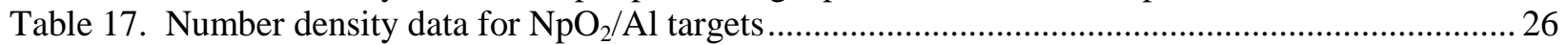

Table 18. Material composition data for reduced-tantalum inner control element gray material

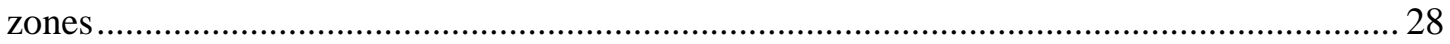

Table 19. Material composition data for reduced-tantalum outer control element gray material

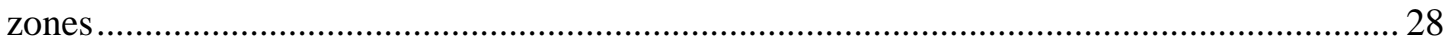

Table 20. Material composition data for reduced-tantalum inner control element black material

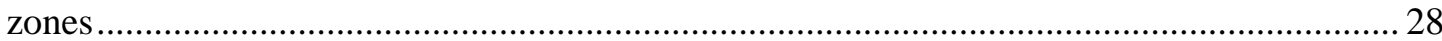

Table 21. Material composition data for reduced-tantalum outer control element black material

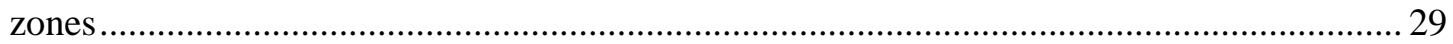

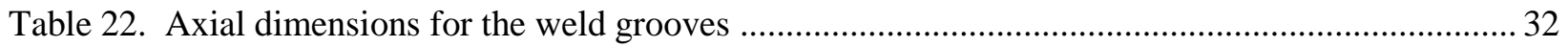

Table 23. Explicit model symmetrical control element position and $\mathrm{k}_{\mathrm{eff}}$ as-calculated with VESTA and the critical search script 40

Table 24. Simplified model symmetrical control element position and $\mathrm{k}_{\text {eff }}$ as-calculated with VESTA and the critical search script .....

Table 25. Explicit model $k_{\text {eff }}$ values with elements fully withdrawn ................................................. 43

Table 26. Simplified model $k_{\text {eff }}$ values with elements fully withdrawn.................................................. 44

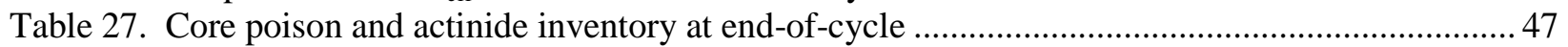

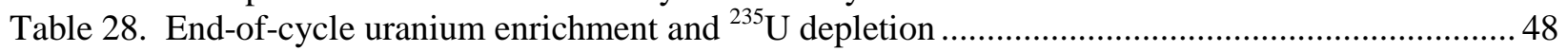

Table 29. Explicit model end-of-cycle U-235 depletion (\%) distribution .............................................52

Table 30. Simplified model end-of-cycle U-235 depletion (\%) distribution ..........................................53

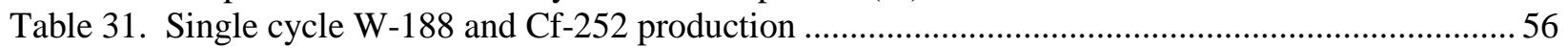

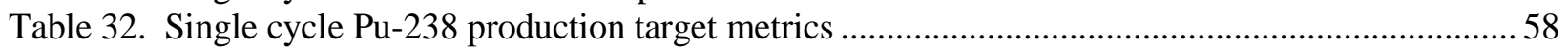

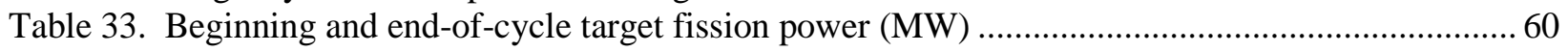




\section{ACRONYMS}

$\begin{array}{ll}\text { BOC } & \text { beginning-of-cycle } \\ \text { CE } & \text { control element } \\ \text { CRAP } & \text { control rod access plug } \\ \text { DOE } & \text { Department of Energy } \\ \text { EF } & \text { engineering facility } \\ \text { EFPD } & \text { effective full power day } \\ \text { EOC } & \text { end-of-cycle } \\ \text { ESCCEP } & \text { estimated symmetrical critical control element position } \\ \text { FTT } & \text { flux trap target } \\ \text { HB } & \text { horizontal beam (tube) } \\ \text { HEU } & \text { high-enriched uranium } \\ \text { HFIR } & \text { High Flux Isotope Reactor } \\ \text { HT } & \text { hydraulic tube } \\ \text { ID } & \text { inner diameter } \\ \text { IFE } & \text { inner fuel element } \\ \text { ISVXF } & \text { inner small vertical experiment facility } \\ \text { LEU } & \text { low-enriched uranium } \\ \text { LVXF } & \text { large vertical experiment facility } \\ \text { MCNP } & \text { Monte Carlo N-Particle } \\ \text { NAA } & \text { neutron activation analysis } \\ \text { NASA } & \text { National Aeronautics and Space Administration } \\ \text { NIST } & \text { National Institute of Standards and Technology } \\ \text { NS\&EA } & \text { Nuclear Safety \& Experiment Analysis } \\ \text { OD } & \text { outer diameter } \\ \text { OFE } & \text { outer fuel element } \\ \text { ORNL } & \text { Oak Ridge National Laboratory } \\ \text { OSVXF } & \text { outer small vertical experiment facility } \\ \text { PB } & \text { permanent beryllium reflector } \\ \text { PT } & \text { pneumatic tube } \\ \text { PTP } & \text { peripheral target position } \\ \text { RB } & \text { removable beryllium reflector } \\ \text { RNSD } & \text { Reactor and Nuclear Systems Division } \\ \text { RRD } & \text { Research Reactors Division } \\ \text { SAR } & \text { safety analysis report } \\ \text { SCCEP } & \text { symmetrical critical control element position } \\ \text { SPB } & \text { semi-permanent beryllium reflector } \\ \text { TRRH } & \text { target rod rabbit holder } \\ \text { VXF } & \text { vertical experiment facility } \\ & \end{array}$





\section{ACKNOWLEDGMENTS}

The authors would like to acknowledge the support for this work provided by the Office of Material Management and Minimization of the US Department of Energy's National Nuclear Security Administration and the Oak Ridge National Laboratory's (ORNL) Research Reactors Division. The authors would like to acknowledge R. W. Hobbs, C. D. Bryan, and S. L. Hogle, all of ORNL, for their assistance in defining a representative experiment loading. Reviews of the manuscript by C. R. Daily, D. G. Renfro, and C. D. Carathers, all of ORNL, are appreciated. The authors would also like to thank K. A. Smith and D. G. Renfro for supporting this work and M. L. Wells for her help with the formatting of this manuscript. 



\begin{abstract}
The purpose of this report is to document a high-fidelity VESTA/MCNP High Flux Isotope Reactor (HFIR) core model that features a new, representative experiment loading. This model, which represents the current, high-enriched uranium fuel core, will serve as a reference for low-enriched uranium conversion studies, safety-basis calculations, and other research activities. A new experiment loading model was developed to better represent current, typical experiment loadings, in comparison to the experiment loading included in the model for Cycle 400 (operated in 2004). The new experiment loading model for the flux trap target region includes full length ${ }^{252} \mathrm{Cf}$ production targets, ${ }^{75} \mathrm{Se}$ production capsules, ${ }^{63} \mathrm{Ni}$ production capsules, a ${ }^{188} \mathrm{~W}$ production capsule, and various materials irradiation targets. Fully loaded ${ }^{238} \mathrm{Pu}$ production targets are modeled in eleven vertical experiment facilities located in the beryllium reflector. Other changes compared to the Cycle 400 model are the high-fidelity modeling of the fuel element side plates and the material composition of the control elements. Results obtained from the depletion simulations with the new model are presented, with a focus on time-dependent isotopic composition of irradiated fuel and single cycle isotope production metrics.
\end{abstract}





\section{INTRODUCTION}

The High Flux Isotope Reactor (HFIR) is a versatile research reactor that is operated at the Oak Ridge National Laboratory (ORNL) and serves a broad range of science and technology communities. Neutrons produced in HFIR are used to support cold and thermal neutron scattering experiments, materials irradiation research, and isotope production. The reactor operates at $85 \mathrm{MW}$ power and its fuel is highenriched uranium (HEU) with an enrichment of $\sim 93 \mathrm{wt} . \%{ }^{235} \mathrm{U}$. Design studies are ongoing to support the conversion of HFIR from HEU fuel to low-enriched uranium (LEU) fuel [1, 2].

The purpose of the work described in this report was to develop and analyze a high-fidelity VESTA/MCNP model of HFIR with a representative experiment loading. MCNP models for HFIR Cycle $400[3,4]$ have been used extensively for HFIR research-based and safety-based neutronics studies since 2005, with model improvements continuing over the years to take advantage of the available state-of-theart modeling and simulations methods and codes. The latest major revision of this MCNP model was completed in 2015 [4] and included a high-fidelity, explicit representation of the involute fuel plate geometry that is characteristic to HFIR, along with development and documentation of a new VESTA depletion model that is based on the explicit fuel model [4]. However, the Cycle 400 experiment loading is not typical of current HFIR operation. Further improvements were needed to the latest advances in the Cycle 400 model to better reflect the experiment loadings of current and future HFIR cycles.

The work performed and documented in this report was driven by the HEU to LEU conversion project, which is sponsored by the US Department of Energy's (DOE) National Nuclear Security Administration Office of Material Management and Minimization. At this time, the primary objective of the HFIR LEU conversion project is to produce a safety basis documenting one or more acceptable LEU fuel designs based on combining recent alternate design studies [1] and up-to-date high fidelity models of the HFIR [4, 5, 6]. Following the conversion of HFIR from HEU to LEU fuel, (1) the ability of HFIR to perform its scientific missions must not be diminished, (2) the cycle length should be no shorter than that with the current HEU fuel, and (3) all safety requirements must be met. In order to ensure these goals are met, detailed modeling and simulations must be performed with consistent core models of the HEU fuel design and the proposed LEU fuel design(s).

The comparisons between the HEU fuel design and the analyzed LEU fuel designs, as documented to date, have not been performed with completely consistent models - the Cycle 400 model [3] has been used for the HEU core, and a modified version of the Cycle 400 model [1,2] has been used for the LEU studied cores. Other than the fuel material and geometry, the primary difference between these models was the experiment loading in the flux trap target region. A recent, enhanced LEU depletion model for HFIR has been developed [6] with an explicit representation of the fuel plate geometry and similar to the new Cycle 400 model [4] in most aspects of the core configuration except for the experiment loading and a higher fidelity modeling of the fuel element side plates. However, the experiment loading for this new LEU model is not typical of current HFIR operation and needs to be improved. A new, representative experiment loading model was needed for both HEU and LEU core models.

The development of a representative MCNP model for HFIR provides the ability to perform consistent physics comparisons between the HEU and LEU cores including, but not limited to, neutron fluxes to experiments and scattering instruments, cycle length, safety margins, reactivity coefficients, and production of key isotopes. Additionally, ongoing and future research- and safety-based neutronics studies will benefit from the availability of a core model that better reflects a current, typical experiment loading. 


\section{OVERVIEW OF HFIR IRRADIATION EXPERIMENT FACILITIES}

A brief overview of HFIR, with an emphasis on the irradiation experiment facilities, is provided here for completeness. HFIR is fueled by two concentric fuel annuli referred to as the inner fuel element (IFE) and the outer fuel element (OFE). The IFE and OFE contain 171 and 369 fuel plates, respectively. Thus, combined, the two elements are composed of 540 involute-shaped fuel plates that contain fuel meat in the form of $\mathrm{U}_{3} \mathrm{O}_{8}$ - $\mathrm{Al}$, encapsulated in aluminum clad. The fuel is $\mathrm{HEU}$ enriched to $\sim 93 \mathrm{wt} . \%{ }^{235} \mathrm{U}$ and approximately $2.6,6.8$, and $9.4 \mathrm{~kg}$ of ${ }^{235} \mathrm{U}$ are respectively loaded into the IFE, OFE, and IFE plus OFE combined. Neutrons that are generated from fission events in the fuel are used for neutron scattering, isotope production, and materials irradiation applications.

A central flux trap, located inside the IFE, provides 37 target positions as illustrated in Figure 1: 31 interior vertical target irradiation facilities and six peripheral target positions (PTPs). A hydraulic tube (HT) facility, located in interior position B3, allows for irradiation capsules to be transported to and from the core on demand. The PTPs are typically occupied by material irradiation experiments (e.g., capsules containing graphite, $\mathrm{SiC}$, steel) that require high fast neutron fluxes because the fast fluxes in these locations are the highest accessible in the reactor. The interior flux trap target (FTT) positions are occupied by capsules containing materials for isotope production and materials irradiation experiments. Experiments requiring high thermal neutron fluxes are placed near the center of the flux trap where the highest thermal fluxes in the core exist. For example, irradiation experiments containing materials to produce ${ }^{252} \mathrm{Cf}$ (neutron source for reactor startups, nondestructive examination of welds, stress analysis, explosives detection, cancer treatments, etc.), ${ }^{63} \mathrm{Ni}$ (electron capture technology for drug and explosives detection), ${ }^{75} \mathrm{Se}$ (gamma radiography for nondestructive examinations), and ${ }^{188} \mathrm{~W} / \mathrm{Re}$ (radioisotope generators used in nuclear medicine to treat cancer, arthritis, and prevent restenosis) are typically irradiated in the central regions of the flux trap.

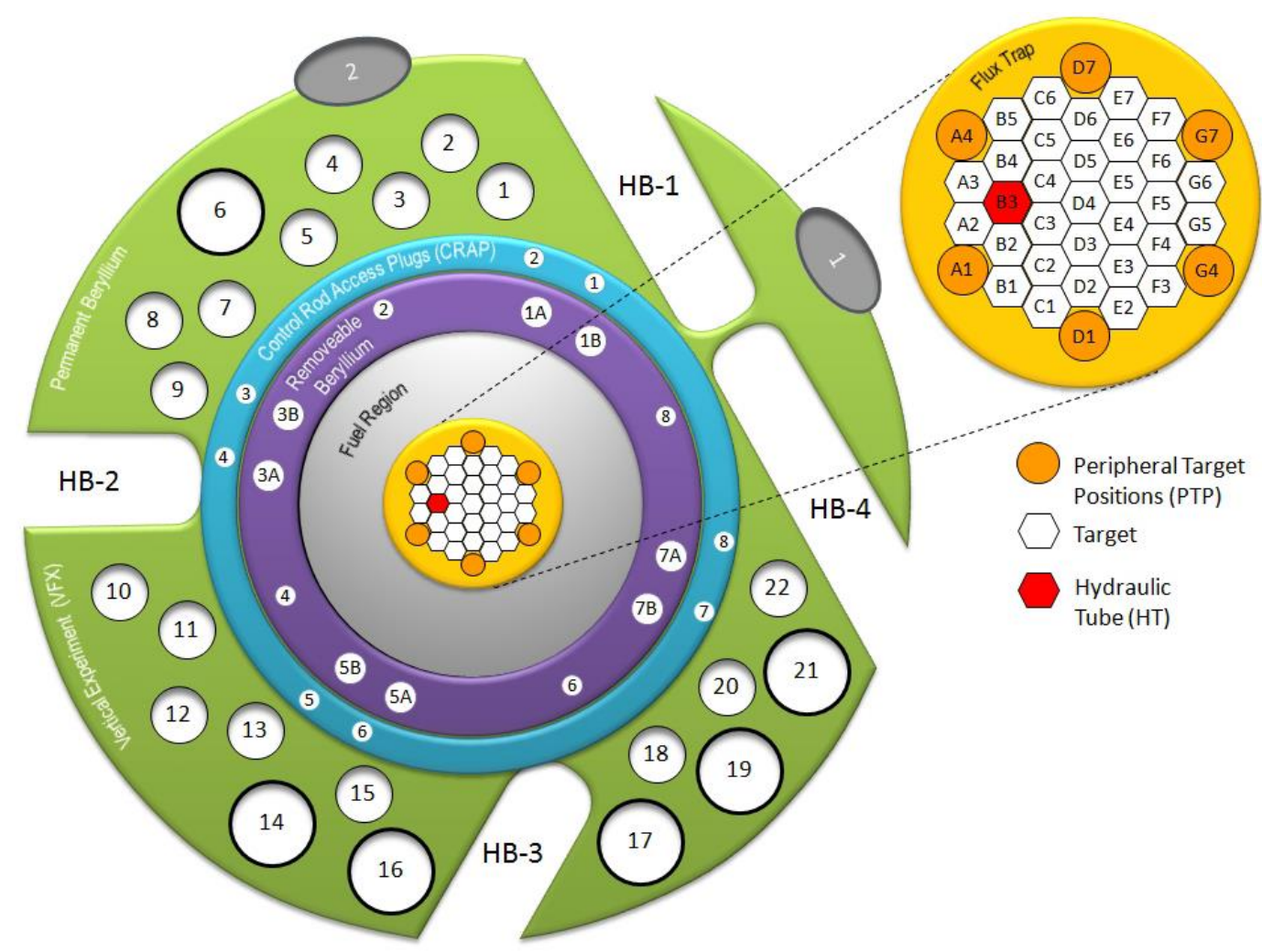

Figure 1. Illustration of High Flux Isotope Reactor irradiation experiment locations. 
A large concentric ring of beryllium reflector surrounding the fuel elements is subdivided into three regions, each providing numerous target irradiation facilities, as illustrated in Figure 1. These three regions are, in the order of their distance with respect to the core centerline: the removable beryllium reflector $(\mathrm{RB})$, the semi-permanent beryllium reflector (SPB), and the permanent beryllium reflector (PB).

The $\mathrm{RB}$ is penetrated by eight large aluminum-lined $\mathrm{RB}$ facilities (designated RB-1A, RB-1B, RB3A, RB-3B, RB-5A, RB-5B, RB-7A, and RB-7B) and four small unlined RB facilities (designated RB-2, RB-4, RB-6, and RB-8). The large RB facilities can be instrumented or uninstrumented; and when used, they typically accommodate experiments for fusion materials irradiation, high-temperature gas-cooled reactor fuel irradiation, or radioisotope production. Materials irradiated in the large RBs are often shielded (e.g., $\mathrm{Eu}_{2} \mathrm{O}_{3}$ liner) to tailor the neutron flux spectrum. When unused, the large and small $\mathrm{RB}$ facilities contain either beryllium plugs or aluminum plugs, depending on the beryllium plug inventory.

The SPB is composed of four control rod access plugs (CRAPs), each providing two small unlined CRAP irradiation facilities. The eight CRAP irradiation facilities are designated CR-1 to CR-8. When these facilities are not being used for materials irradiation or isotope production, they are typically loaded with aluminum dummy plugs.

The $\mathrm{PB}$, which is the largest of the three reflector regions, is penetrated by 22 vertical experiment facilities (VXFs), four horizontal beam tubes (HBs), and two engineering slant facility tubes (EFs). The VXFs are designated VXF-1 to VXF-22, and depending on their size and location with respect to the core centerline, they are referred to as inner small VXFs (ISVXF), outer small VXFs (OSVXF), or large VXFs (LVXF). In the last several years, the VXFs have been used to irradiate ${ }^{238} \mathrm{Pu}$-producing targets as part of an effort to reestablish a domestic ${ }^{238} \mathrm{Pu}$ supply chain for the National Aeronautics and Space Administration (NASA). This ${ }^{238} \mathrm{Pu}$ will be the power source for multi-mission radioisotope thermoelectric generators used in deep-space missions [7]. Additionally, the VXF locations have been used to irradiate $\mathrm{SiC}$-clad fuel pins containing $\mathrm{UO}_{2}$ fuel pellets to examine the compatibility of the $\mathrm{SiC}$ cladding technology with $\mathrm{UO}_{2}$ light water reactor fuel, and metal coupons for post-irradiation weld testing. Two pneumatic tubes (PT), designated PT-1 and PT-2, are located in VXF-7 and EF-2, respectively, and are used for neutron activation analysis (NAA) activities with application to nuclear and criminal forensics, impurity analysis, and environmental studies. Four HB tubes that extend outward from the reactor core at the midplane of the reactor transport cold and thermal neutrons to 15 scattering instruments used for experiments with application in biology, physics, chemistry, materials science, engineering, and other areas of interest. 


\section{MODELING OF THE FLUX TRAP TARGET REGION}

As previously discussed, the FTT experiment loading in the Cycle 400 HEU model $[3,4]$ and that in the previous LEU models [1,2] differ significantly. Figure 2 illustrates the as-modeled flux trap region for the Cycle 400 model, old LEU models, and the newly developed HEU representative model. The FTT holder in the Cycle 400 model (Figure 2(b)) contains: 7 solid aluminum dummy targets (in locations $\mathrm{C} 2$, C5, D3, D4, E5, E6, and F5), 2 stainless steel JP targets (large outer diameter (OD) targets in locations C6 and E2), the hydraulic tube filled with aluminum capsules in location B3, 21 shrouded aluminum dummy targets filled with aluminum slugs (small OD targets in the remaining interior basket locations), and 6 PTP sites loaded with various irradiation experiment capsules. The FTT holder as modeled in the LEU models prior to 2015 (Figure 2(c)) contains 30 shrouded aluminum target holders loaded with curium oxide pellets, the hydraulic tube filled with aluminum capsules, and 6 PTP sites filled with water. The contents of the FTT holder as modeled in the new HEU representative model (Figure 2(d)) were decided upon following a detailed analysis of recent, typical cycle loadings. A loading map describing the targets in the new representative model is provided in Figure 3 and described in detail in the following sections. Furthermore, $\mathrm{x}-\mathrm{z}$ and $\mathrm{y}-\mathrm{z}$ cross-sections through the representative model for the flux trap are provided in Figure 4.

The flux trap loading in the representative model is based on discussions within the ORNL Research Reactors Division (RRD), Nuclear Safety and Experiment Analysis (NS\&EA) Group as well as a detailed analysis of recent cycle flux trap loadings. Conclusions drawn from discussions within the group include:

1. Five full length $\mathrm{Cm}$ targets used for ${ }^{252} \mathrm{Cf}$ production should be modeled in ring 1 (see Figure 3 ) of the FTT region.

- HFIR was designed with the mission of producing ${ }^{252} \mathrm{Cf}$ and this mission is still critical to HFIR operations today.

- The most recent campaign consisted of five ${ }^{252} \mathrm{Cf}$ production targets (i.e., five targets from Campaign 75 were removed following Cycle 457 shutdown); five targets will be typical of future campaigns.

- $\quad{ }^{252} \mathrm{Cf}$ production is a key performance metric for comparing the HEU and LEU core designs.

2. Selenium-75 production capsules should be modeled in the center position (D4) of the FTT region.

- HFIR routinely irradiates selenium.

- ${ }^{75}$ Se production rate will be a metric for comparing the HEU and LEU core designs.

3. Nickel-63 production capsules should be modeled in ring 1 of the FTT region.

- HFIR routinely irradiates nickel.

- ${ }^{63} \mathrm{Ni}$ production rate will be a metric for comparing the HEU and LEU core designs.

4. $\mathrm{A}^{188} \mathrm{~W} / \mathrm{Re}$ production capsule in the hydraulic tube should be modeled in the midplane position (i.e., position 5) of the tube.

- It is common to irradiate this irradiation capsule, whether loaded with sintered tungsten pellets or rings, in the hydraulic tube.

- ${ }^{188} \mathrm{~W}$ production rate will be a metric for comparing the HEU and LEU core designs.

- Previous irradiation data exists and may be used for validation purposes.

- The capsule containing tungsten rings is to be modeled. Multiple capsules with this design were irradiated in Cycle 458. This design is preferred because it produces greater specific activities than the design with tungsten pellets due to self-shielding.

- Aluminum pusher rabbits are to be modeled in positions 1 and 7 of the hydraulic tube.

- Perforated finned dummy aluminum rabbits are to be modeled in positions 2, 3, 4, and 6 of the hydraulic tube.

5. An analysis should be performed with data from recent cycles to derive the loading of the PTPs and other flux trap positions. 


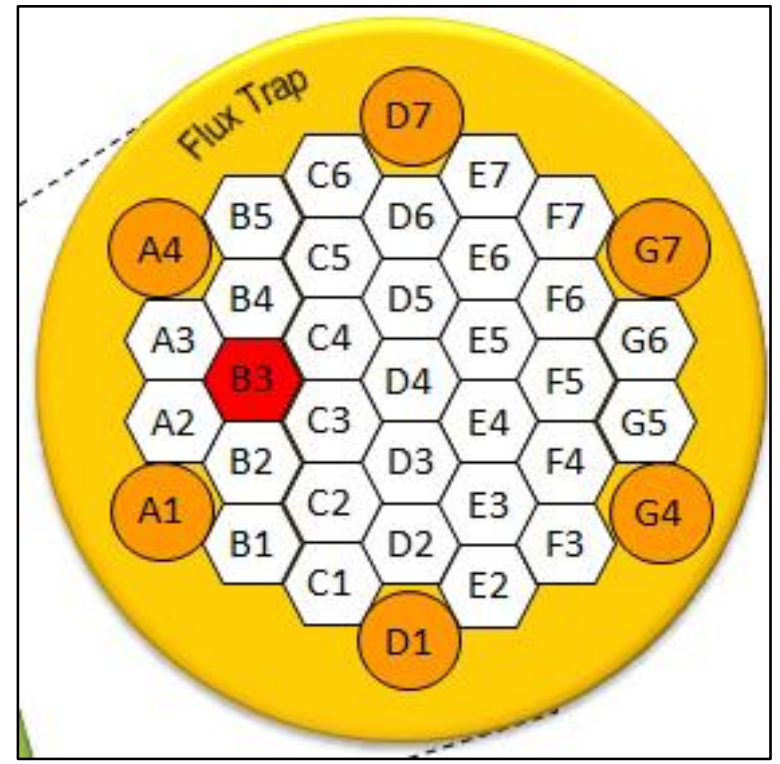

(a)

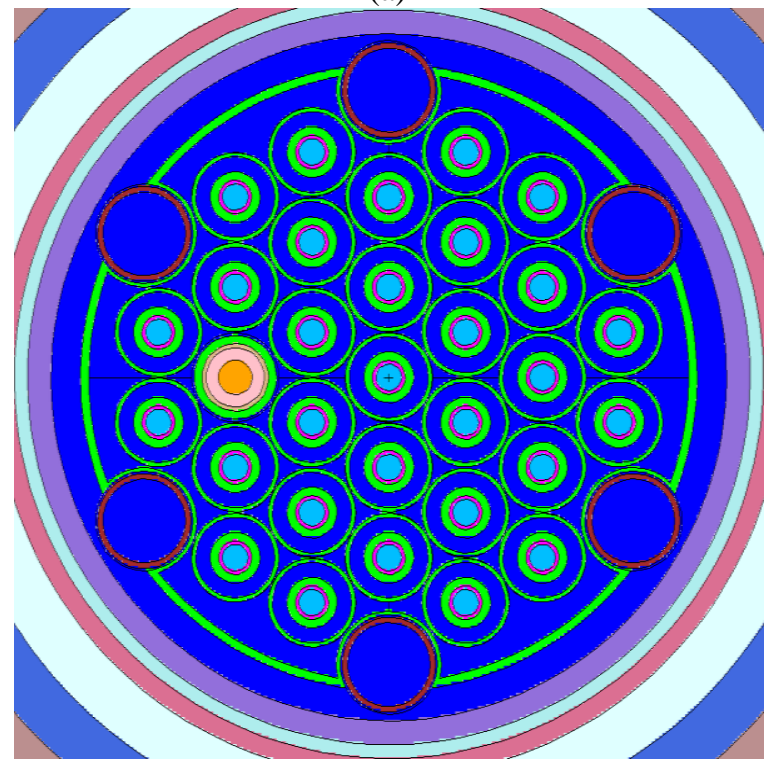

(c)

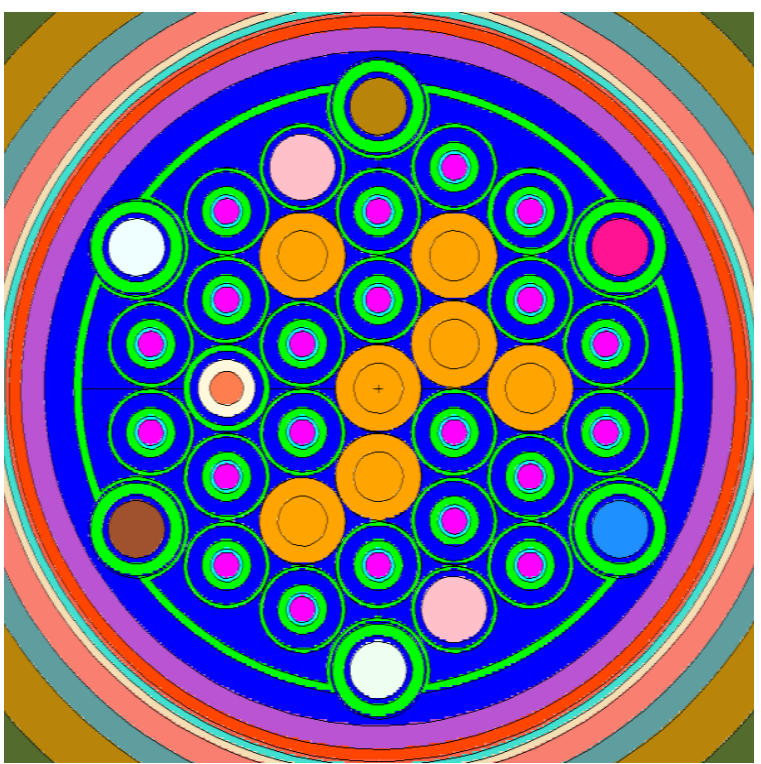

(b)

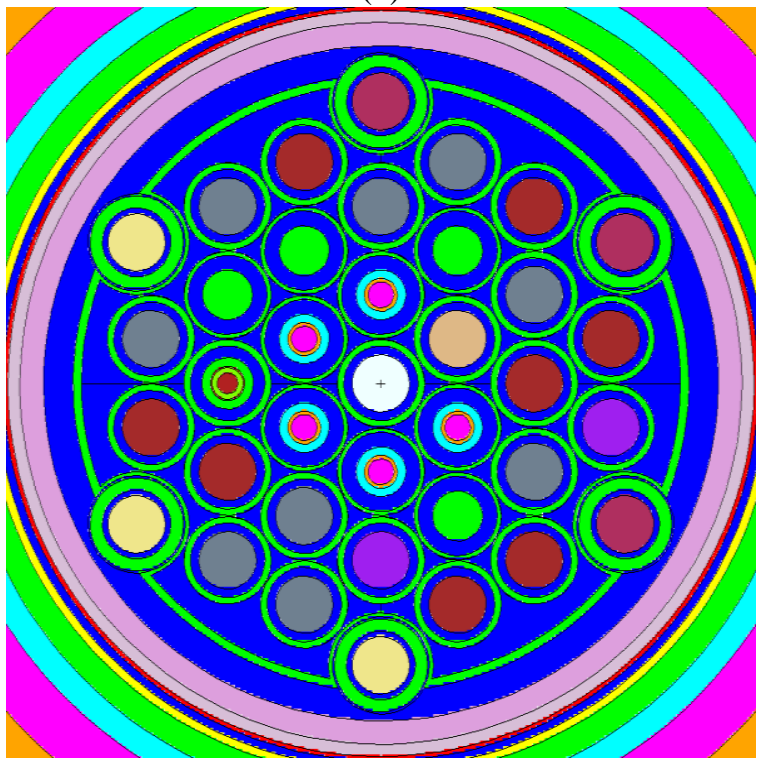

(d)

Figure 2. Cross-section of flux trap target region at the core midplane: (a) target position map, (b) Cycle 400 HEU model, (c) model for LEU studies prior to 2015, and (d) new, representative model. 


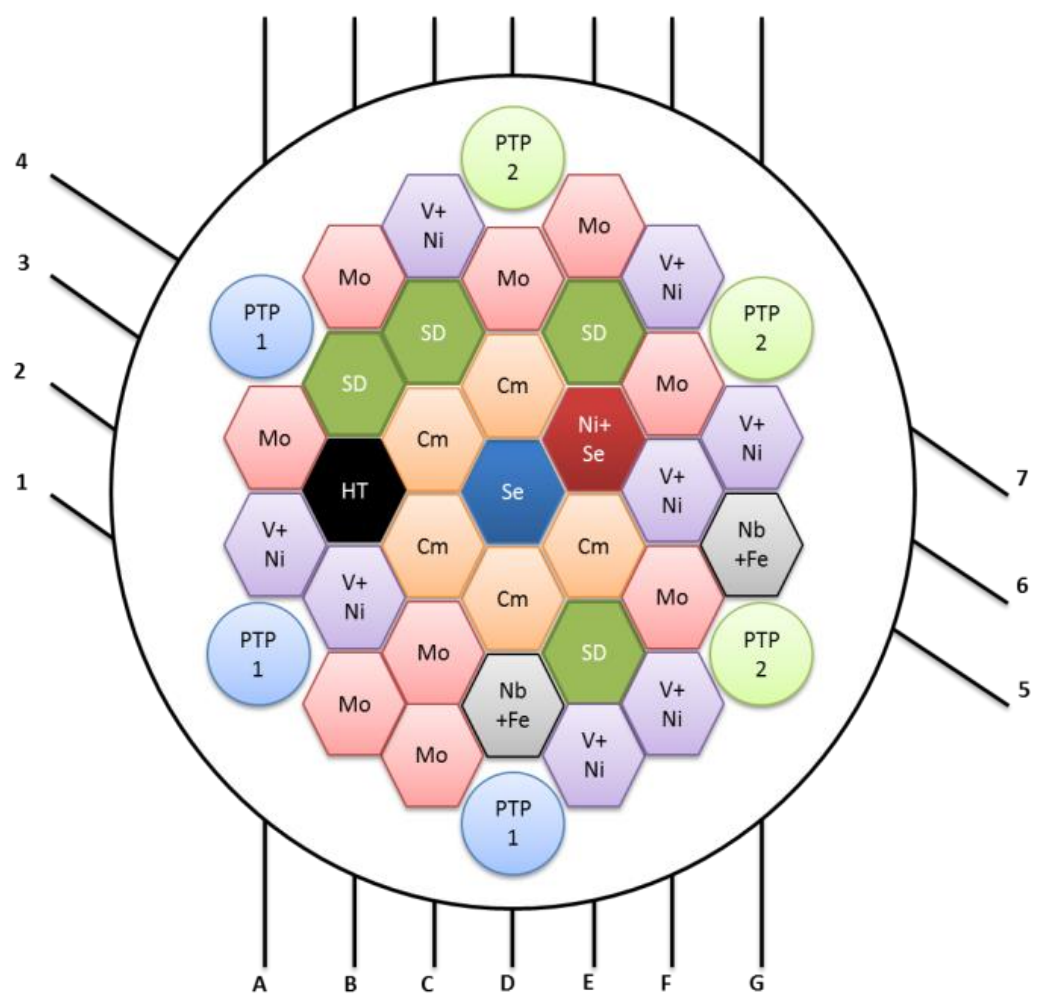

Figure 3. Illustration of the representative model flux trap loading map.

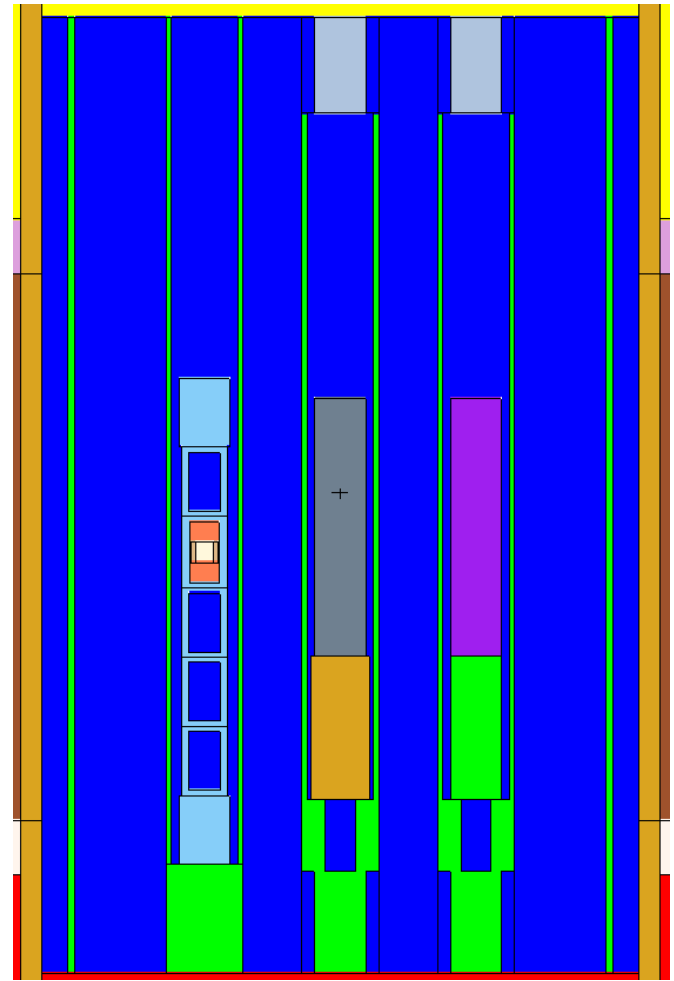

(a)

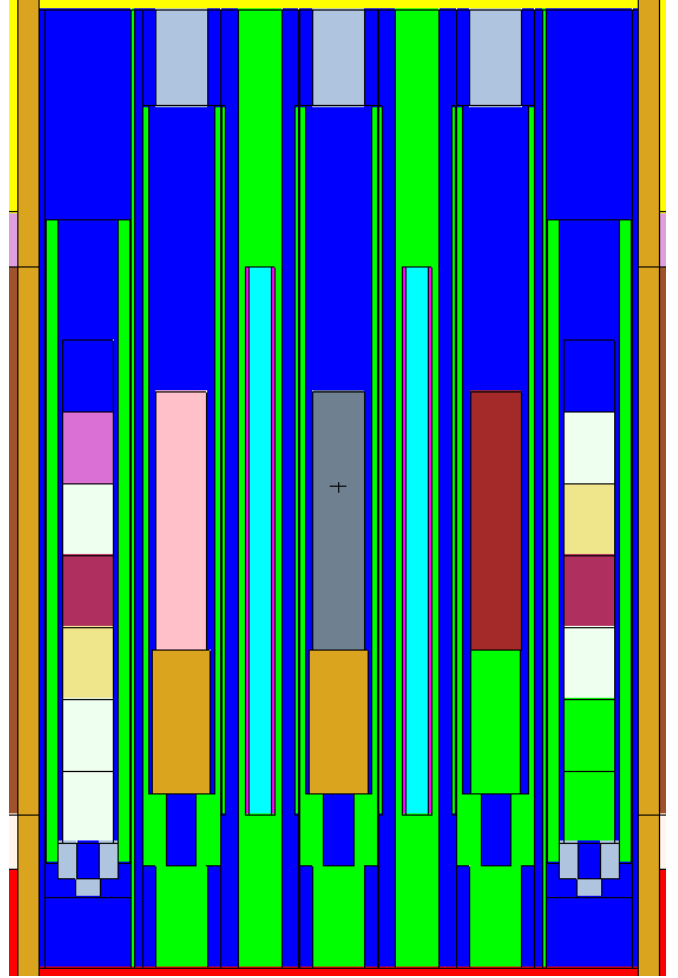

(b)

Figure 4. Illustrations of (a) $x-z$ and (b) $y-z$ cross-sections through the flux trap of the representative model on the core centerline $(-39.69 /+49.21 \mathrm{~cm}$ with respect to core axial midplane shown). 
Records in the form of Excel spreadsheets that contain the FTT loadings are maintained. For each cycle, a matrix of the capsule identifiers is generated, organized by position within the flux trap (see Figure 1 or Figure 2(a)) and axial location within the target holder. Furthermore, the elemental masses making up the capsules and their contents are listed. A maximum of eight standard irradiation capsules are loaded into target rod rabbit holders (TRRH) and a maximum of seven irradiation capsules are loaded into the PTPs. Typically, the majority of these positions are occupied by materials irradiation capsules. The specimens being studied are generally various types of steel, graphite, and/or silicon carbide. These specimens are often encapsulated in vanadium or molybdenum holders. Other components (e.g., springs, thermometry, centering thimbles, spacers) composed of various elements can also be found in typical aluminum irradiation capsules.

A detailed analysis was performed to determine what the contents of a representative cycle's FTT loading should look like, with the previously drawn conclusions in mind. First, thousands of as-built capsules from the past $\sim 50$ cycles (between 2007 and 2015) were categorized into several types and identified by the element in the capsule with the greatest mass: $\mathrm{Fe}, \mathrm{Mo}, \mathrm{V}, \mathrm{Nb}$, and $\mathrm{Ni}$. Note that ${ }^{63} \mathrm{Ni}$ and $\mathrm{Ni}$ will be used to differentiate between the ${ }^{63} \mathrm{Ni}$ production capsules, which are enriched in ${ }^{62} \mathrm{Ni}$, and the generic $\mathrm{Ni}$ (natural) bearing irradiation capsules. Loading maps from the last 11 cycles (i.e., cycles 448 458, operated between June 2013 and February 2015) were constructed and the number of each generic capsule type per position and per cycle were tallied. The PTPs were assessed first and then the flux trap positions were assessed from the outermost ring inwards.

The irradiation capsules loaded in the PTPs are modeled as seven individual capsules and the capsule housing and contents are homogenized together such that one cylinder is defined per capsule. The irradiation capsules loaded in the interior flux trap positions are also modeled as homogenized cylinders. Experimenters usually want their irradiation capsules located near the core horizontal midplane where the neutron flux is the greatest; thus, the majority of the irradiation capsules are loaded near the midplane. Beryllium and aluminum spacers are used to adjust the axial location of the irradiation capsules and empty positions above the irradiation capsules are occupied by water coolant flowing down through the target region.

Based on the PTP assessment, two generic PTP loading schemes were identified: PTP Generic 1, to be modeled in positions D1, A1, and A4, and PTP Generic 2, to be loaded in positions D7, G7, and G4. The seven capsules loaded in the two PTP types are listed in Table 1. The as-modeled PTP Generic 1 and 2 targets are illustrated in Figure 4 (b) as the left-most and right-most targets shown, respectively, and are described in more detail in a later section.

Table 1. Peripheral target position generic capsule loading

\begin{tabular}{lll}
\hline Position & PTP Generic 1 & PTP Generic 2 \\
\hline 7 (top) & water (empty) & water (empty) \\
6 & $\mathrm{Fe}$ & $\mathrm{Nb}$ \\
5 & $\mathrm{Nb}$ & $\mathrm{Mo}$ \\
4 & $\mathrm{~V}$ & $\mathrm{~V}$ \\
3 & $\mathrm{Mo}$ & $\mathrm{Nb}$ \\
2 & $\mathrm{Nb}$ & $\mathrm{Al}$ spacer \\
1 (bottom) & $\mathrm{Nb}$ & $\mathrm{Al}$ spacer \\
\hline
\end{tabular}

The loading maps generated for each position in ring 4 (A2, A3, B1, B5, C1, C6, E2, E7, F3, F7, G5, and G6) were used to determine the average number of each capsule type loaded in ring 4 per cycle. The same averaging approach was used for ring 3 (B2, B4, D2, D6, F4, and F6) and ring 2 (C2, C5, E3, E6, and F5). The ring 1 positions (C3, C4, D3, D5, E4, and E5) and the center position (D4) were also assessed to obtain average ${ }^{63} \mathrm{Ni}, \mathrm{Cm}$, and Se target loadings, as well as to help balance the overall FTT holder loading.

Per this analysis, an average of $~ 3.6$ irradiation capsules are loaded into a TRRH and approximately four full length shrouded dummy aluminum targets are present in the flux trap per cycle. Five curium 
targets, four shrouded dummy aluminum targets, one target containing ${ }^{75}$ Se production capsules, one target containing ${ }^{63} \mathrm{Ni}$ and ${ }^{75} \mathrm{Se}$ production capsules, and the hydraulic tube are included in the model. Thus, 19 positions containing TRRHs remain to be filled. On average, about 4.36, 23.45, 32.00, 2.73, and $6.00 \mathrm{Nb}, \mathrm{V}, \mathrm{Mo}, \mathrm{Fe}$, and Ni type rabbits, respectively, are loaded in the non-PTP flux trap positions.

Each of the 21 TRRHs modeled, including the two containing the ${ }^{63} \mathrm{Ni}$ and ${ }^{75} \mathrm{Se}$ production capsules, are loaded with either aluminum or beryllium spacers in the bottom two positions (i.e., positions 1 and 2), irradiation capsules in positions $3-5.6$, and water in positions 5.6-8. Within each of these TRRHs, the two spacers are modeled as one homogenized cylinder and the 3.6 irradiation capsules are modeled as one homogenized cylinder. Several TRRHs could have been modeled with 3 irradiation capsules while others could have been modeled with 4 such that the average number of irradiation capsules per TRRH was approximately 3.6, but it was decided that modelling all TRRHs with 3.6 irradiation capsules was adequate for a representative model.

Thus, on average, there are $~ 1.21,6.51,8.89,0.76$, and 1.67 TRRHs with $\mathrm{Nb}, \mathrm{V}, \mathrm{Mo}, \mathrm{Fe}$, and Ni type irradiation capsules, respectively, per cycle under the assumptions made. Because of the minimal number of $\mathrm{Nb}, \mathrm{Fe}$, and $\mathrm{Ni}$ targets, it was decided to combine the $\mathrm{Nb}$ and $\mathrm{Fe}$ capsules (because these capsules have similar contents and neutron cross-sections) and to combine the $\mathrm{V}$ and $\mathrm{Ni}$ capsules (because these capsules have similar neutron cross-sections). Therefore, there are $\sim 1.97 \mathrm{Nb}+\mathrm{Fe}$-bearing TRRHs and $8.18 \mathrm{~V}+\mathrm{Ni}$-bearing TRRHs per cycle. Based on this analysis, the remaining $19 \mathrm{TRRHs}$ to be modeled comprise of $9 \mathrm{Mo}-, 2 \mathrm{Nb}+\mathrm{Fe}-$, and $8 \mathrm{~V}+\mathrm{Ni}$-bearing TRRHs. A summary of the experiments modeled in the flux trap region, as illustrated in Figures 2 - 4, is provided in Table 2.

Table 2. Flux trap target region experiment loading summary (interior targets)

\begin{tabular}{llc}
\hline Target ID & Target description & Number of targets \\
\hline $\mathrm{HT}$ & Hydraulic tube & 1 \\
$\mathrm{SD}$ & Full length shrouded dummy Al targets & 4 \\
$\mathrm{Cm}$ & Full length curium targets & 5 \\
$\mathrm{Se}$ & TRRH with selenium production capsules and Be spacers & 1 \\
$\mathrm{Ni}+\mathrm{Se}$ & TRRH with ${ }^{63} \mathrm{Ni}$ and ${ }^{75} \mathrm{Se}$ production capsules and Be spacers & 1 \\
$\mathrm{Nb}+\mathrm{Fe}$ & TRRH with $\mathrm{Nb}+\mathrm{Fe}$ type capsules and Be spacers & 2 \\
$\mathrm{~V}+\mathrm{Ni}$ & TRRH with $\mathrm{V}+\mathrm{Ni}$ type capsules and Al spacers & 8 \\
$\mathrm{Mo}$ & TRRH with Mo type capsules and Al spacers & 9 \\
Sum of above targets & 31 \\
\hline
\end{tabular}

\subsection{HYDRAULIC TUBE MODELING}

A maximum of nine rabbits (capsules) is permitted in the rabbit train to be irradiated in the hydraulic tube, which is located in position B3 of the flux trap bundle. An illustration of the as-modeled hydraulic tube and stack of rabbits is provided in Figure 5. The rabbit stack modeled in the hydraulic tube (flux trap position B3) consists of rabbit pushers in positions 1 and 7, dummy capsules in positions 2, 3, 4 and 6, a ${ }^{188} \mathrm{~W} / \mathrm{Re}$ production capsule in position 5 , and water coolant in positions 8 and 9 (empty positions). This configuration is typical of routine HFIR irradiations for this location. The hydraulic tube is modeled as represented by the HFIR rabbit facility drawings. The nominal tube inner diameter (ID) and OD are 0.560 and 0.657 in $(0.656+0.002 /-0.00$ in $)$, respectively. The bottom of the rabbit stack, referred to as the rabbit stop, was adjusted to an elevation of 11.596 in below the core midplane to reflect the dimensions listed in the drawings. Per these drawings, the distance from the core midplane to the bottom of the bottom hydraulic tube tip is 15.846 in and the length of the tip and of the impact area are 3.875 and 0.375 in, respectively. 


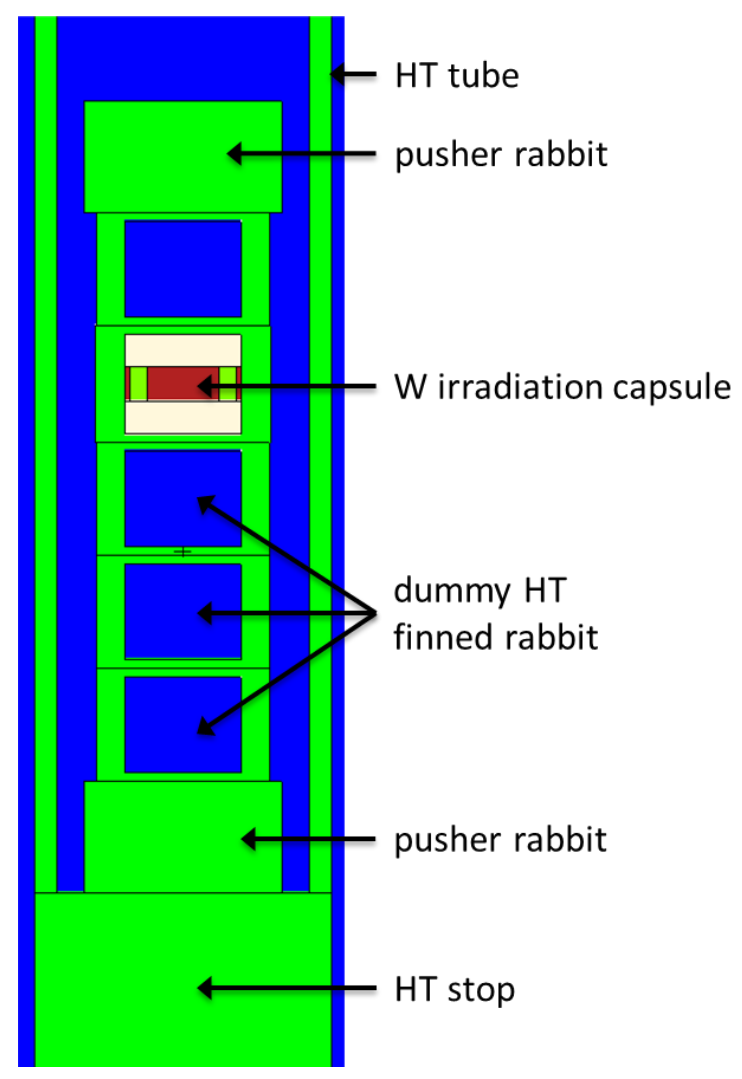

Figure 5. Illustration of the hydraulic tube including two pusher rabbits, four dummy rabbits, and the tungsten irradiation capsule.

Solid aluminum (Al-6061) rabbit pushers are modeled as solid, large OD capsules that help insert and eject the rabbit stack into and out of the hydraulic tube. The rabbit pusher has a nominal length and OD of 2.500 and $0.438 \mathrm{in}$, respectively. The nominal length and ID of the perforated, finned dummy Al-6061 capsules, as taken from its corresponding drawing, are 2.53125 in and 0.260 in, respectively. An OD of 0.385915 in, which was calculated to approximately conserve the total aluminum volume, including the body, caps, fins, and flow holes, was modeled.

The Al-6061 finned irradiation capsule containing the enriched tungsten rings was modeled according to the HFIR hydraulic tube irradiation capsule assembly and details drawing and based on discussions within the NS\&EA Group. The nominal irradiation capsule length and ID of 2.625 and 0.258 in, respectively, were modeled, and an OD of 0.387667 in was calculated to approximately conserve the aluminum volume. A tungsten ring stack length of $1.9523 \mathrm{~cm}$ was calculated based on the following data: a post-sintered tungsten density of $15 \mathrm{~g} / \mathrm{cm}^{3}$ [8], a total tungsten mass loading of 4.6 grams, a ring ID of $4 \mathrm{~mm}$, and a ring OD of $6 \mathrm{~mm}$. The stack was centered within the target capsule; quartz wool $\left(\mathrm{SiO}_{2}\right)$ at $0.006 \mathrm{~g} / \mathrm{cm}^{3}$ [8] density was modeled above and below the ring stack. Helium fill gas was modeled around the ring stack.

The modeled isotopic composition for the tungsten material includes $96 \mathrm{wt} . \%{ }^{186} \mathrm{~W}$ and $4 \mathrm{wt} . \%$ of other isotopes that occur in the natural isotopic composition of $\mathrm{W}-{ }^{180} \mathrm{~W},{ }^{182} \mathrm{~W},{ }^{183} \mathrm{~W}$, and ${ }^{184} \mathrm{~W}$. The relative amounts of these latter four $\mathrm{W}$ isotopes in the $4 \mathrm{wt} . \%$ of tungsten material were the same as their relative weights in W's natural isotopic composition. Because ${ }^{180} \mathrm{~W}$ does not have ENDF/B-VII.0 crosssections [9], the content of this isotope was distributed among the other isotopes $\left({ }^{182} \mathrm{~W},{ }^{183} \mathrm{~W}\right.$, and $\left.{ }^{184} \mathrm{~W}\right)$. Note that the content of ${ }^{180} \mathrm{~W}$ in the tungsten target material is very small $(\sim 0.007 \mathrm{wt} . \%)$. Atomic masses and composition data are based on National Institute of Standards and Technology (NIST) data [10]. The isotopic compositions for the tungsten rings and the wool quartz as used in the MCNP model are listed in Table 3 and Table 4, respectively. 
Table 3. Number density data for enriched tungsten rings

\begin{tabular}{cccc}
\hline Element & Isotope & $\begin{array}{c}\text { Isotope } \\
\text { identifier }\end{array}$ & $\begin{array}{c}\text { Number density } \\
\text { (at/b-cm) }\end{array}$ \\
\hline W & W-182 & 74182 & $7.32299 \mathrm{E}-04$ \\
W & W-183 & 74183 & $3.95442 \mathrm{E}-04$ \\
W & W-184 & 74184 & $8.46704 \mathrm{E}-04$ \\
W & W-186 & 74186 & $4.66345 \mathrm{E}-02$ \\
total & & & $4.86089 \mathrm{E}-02$ \\
\hline
\end{tabular}

Table 4. Number density data for wool quartz

\begin{tabular}{cccc}
\hline Element & Isotope & $\begin{array}{c}\text { Isotope } \\
\text { identifier }\end{array}$ & $\begin{array}{c}\text { Number density } \\
\text { (at/b-cm) }\end{array}$ \\
\hline $\mathrm{O}$ & $\mathrm{O}-16$ & 8016 & $1.20274 \mathrm{E}-04$ \\
$\mathrm{Si}$ & $\mathrm{Si}-28$ & 14028 & $5.54601 \mathrm{E}-05$ \\
$\mathrm{Si}$ & $\mathrm{Si}-29$ & 14029 & $2.81741 \mathrm{E}-06$ \\
$\mathrm{Si}$ & $\mathrm{Si}-30$ & 14030 & $1.85943 \mathrm{E}-06$ \\
total & & & $1.80411 \mathrm{E}-04$ \\
\hline
\end{tabular}

\subsection{SHROUDED DUMMY ALUMINUM TARGET MODELING}

Aluminum dummy target assemblies, also referred to as shrouded dummy aluminum targets, were modeled based on their associated HFIR drawings. The four Al-6061 shrouded targets modeled in the B4, C5, E3, and E6 positions of the HFIR representative model are full length targets. They are solid, finned aluminum tubes located within a shroud (see Figure 6) to reflect the design currently being used at HFIR. These models for the shrouded dummy targets differ from those in the Cycle 400 model where the tubes are hollow and filled with aluminum slugs at $80 \%$ theoretical density.

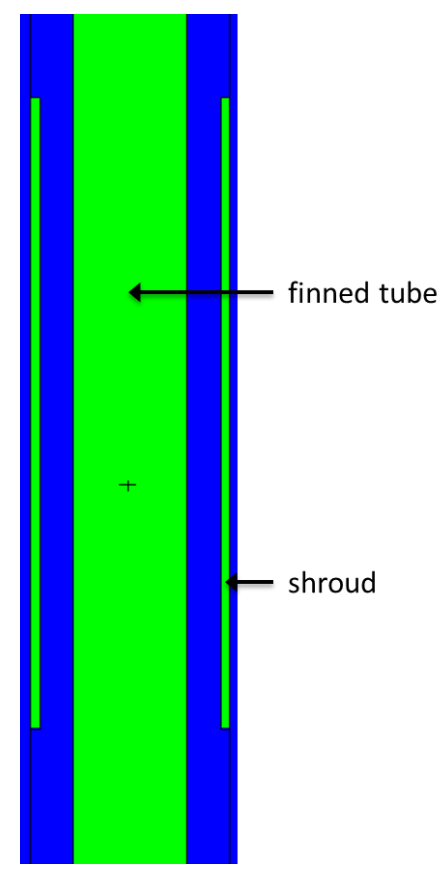

Figure 6. Illustration of a shrouded dummy aluminum target. 


\subsection{CURIUM TARGET MODELING}

The curium targets used for ${ }^{252} \mathrm{Cf}$ production are modeled based on relevant target drawings. The target tube is similar to the shrouded dummy target in the Cycle 400 model $[3,4]$ and to the curium target tube modeled in previous LEU models [1,2]. However, the curium target tubes are made out of $\mathrm{Al} \mathrm{X-}$ 8001; whereas, the shrouds are made from Al-6061. The elemental composition of the Al X-8001 material was taken from [11], the isotopic compositions and atomic masses based on NIST data [10] were used, and a density of $2.7 \mathrm{~g} / \mathrm{cm}^{3}$ was considered. The number densities for the Al X-8001 material are listed in Table 5.

Table 5. Number density data for Al X-8001

\begin{tabular}{cccc}
\hline Element & Isotope & $\begin{array}{c}\text { Isotope } \\
\text { identifier }\end{array}$ & $\begin{array}{c}\text { Number density } \\
\text { (at/b-cm) }\end{array}$ \\
\hline $\mathrm{Al}$ & $\mathrm{Al}-27$ & 13027 & $5.92044 \mathrm{E}-02$ \\
$\mathrm{Si}$ & $\mathrm{Si}-28$ & 14028 & $3.20349 \mathrm{E}-05$ \\
$\mathrm{Si}$ & $\mathrm{Si}-29$ & 14029 & $1.62740 \mathrm{E}-06$ \\
$\mathrm{Si}$ & $\mathrm{Si}-30$ & 14030 & $1.07405 \mathrm{E}-06$ \\
$\mathrm{Fe}$ & $\mathrm{Fe}-54$ & 26054 & $8.16874 \mathrm{E}-06$ \\
$\mathrm{Fe}$ & $\mathrm{Fe}-56$ & 26056 & $1.28232 \mathrm{E}-04$ \\
$\mathrm{Fe}$ & $\mathrm{Fe}-57$ & 26057 & $2.96143 \mathrm{E}-06$ \\
$\mathrm{Fe}$ & $\mathrm{Fe}-58$ & 26058 & $3.94112 \mathrm{E}-07$ \\
$\mathrm{Ni}$ & $\mathrm{Ni}-58$ & 28058 & $2.24426 \mathrm{E}-04$ \\
$\mathrm{Ni}$ & $\mathrm{Ni}-60$ & 28060 & $8.64483 \mathrm{E}-05$ \\
$\mathrm{Ni}$ & $\mathrm{Ni}-61$ & 28061 & $3.75785 \mathrm{E}-06$ \\
$\mathrm{Ni}$ & $\mathrm{Ni}-62$ & 28062 & $1.19817 \mathrm{E}-05$ \\
$\mathrm{Ni}$ & $\mathrm{Ni}-64$ & 28064 & $3.05138 \mathrm{E}-06$ \\
$\mathrm{Cu}$ & $\mathrm{Cu}-63$ & 29063 & $4.60036 \mathrm{E}-06$ \\
$\mathrm{Cu}$ & $\mathrm{Cu}-65$ & 29065 & $2.05237 \mathrm{E}-06$ \\
total & & & $5.97152 \mathrm{E}-02$ \\
\hline
\end{tabular}

The pellet, comprising of curium oxide $(\mathrm{CmO})$ and aluminum, has a nominal length of 0.471 in and a nominal OD and 0.195 in. Each pellet is cladded with Al-1100 tubing on its radial surface (0.249 in OD) and compacted $\mathrm{Al}$ powder on its axial surfaces ( 0.05 in thick). Therefore, the total length of a pellet including axial cladding is $0.571 \mathrm{in.}$ A total of 35 pellets are loaded into the target tubes, and thus the total stack length is 19.985 in. For modeling purposes, the actinide mass and axial cladding regions are modeled as a single homogenized material spanning the length of the active core height of $20 \mathrm{in}$. The actinide loading from an as-built Campaign 75 target is provided in Table 6. Composition data provided with the actinide mass loading included: there were $1.71 \mathrm{O}$ atoms per actinide atom in $\mathrm{CmO}$, there were 1.8 grams of $\mathrm{Al}$ per gram of $\mathrm{CmO}$, and impurities (mostly $\mathrm{Al}_{2} \mathrm{O}_{3}, \mathrm{CaO}$, and $\mathrm{Fe}_{2} \mathrm{O}_{3}$ ) were present at $\sim 12$ vol.\% of the $\mathrm{CmO}$. For calculation of the target isotopic content based on the provided data, the following assumptions were used: (a) 20 vol.\% void in the $\mathrm{CmO} / \mathrm{Al}$ pellets [12]; (b) three impurities were included in the $\mathrm{CmO}$ mix, namely $\mathrm{Al}_{2} \mathrm{O}_{3}, \mathrm{CaO}$, and $\mathrm{Fe}_{2} \mathrm{O}_{3}$, and (c) each of the impurities occupies $1 / 3$ (or 4 vol.\%) of the total impurities volume in $\mathrm{CmO}$. The $\mathrm{CmO} / \mathrm{Al}$ number density data, as used in the MCNP model, is provided in Table 7 . Figure 7 shows an as-modeled curium target including the finned tube, pellet liner, actinide pellet stack, and shroud. 
Table 6. Actinide loading per curium target

\begin{tabular}{cccc}
\hline Element & Isotope & $\begin{array}{c}\text { Isotope } \\
\text { identifier }\end{array}$ & $\begin{array}{c}\text { Mass } \\
\text { (grams) }\end{array}$ \\
\hline $\mathrm{Pu}$ & $\mathrm{Pu}-238$ & 94238 & $7.20 \mathrm{E}-03$ \\
$\mathrm{Pu}$ & $\mathrm{Pu}-239$ & 94239 & $6.44 \mathrm{E}-04$ \\
$\mathrm{Pu}$ & $\mathrm{Pu}-240$ & 94240 & $1.37 \mathrm{E}-01$ \\
$\mathrm{Pu}$ & $\mathrm{Pu}-241$ & 94241 & $4.40 \mathrm{E}-05$ \\
$\mathrm{Pu}$ & $\mathrm{Pu}-242$ & 94242 & $1.82 \mathrm{E}-03$ \\
$\mathrm{Am}$ & $\mathrm{Am}-241$ & 95241 & $1.29 \mathrm{E}-01$ \\
$\mathrm{Am}$ & $\mathrm{Am}-242 \mathrm{~m}$ & 95242 & $5.25 \mathrm{E}-04$ \\
$\mathrm{Am}$ & $\mathrm{Am}-243$ & 95243 & $4.67 \mathrm{E}-01$ \\
$\mathrm{Cm}$ & $\mathrm{Cm}-242$ & 96242 & $1.46 \mathrm{E}-04$ \\
$\mathrm{Cm}$ & $\mathrm{Cm}-243$ & 96243 & $1.03 \mathrm{E}-03$ \\
$\mathrm{Cm}$ & $\mathrm{Cm}-244$ & 96244 & $1.43 \mathrm{E}+00$ \\
$\mathrm{Cm}$ & $\mathrm{Cm}-245$ & 96245 & $3.36 \mathrm{E}-02$ \\
$\mathrm{Cm}$ & $\mathrm{Cm}-246$ & 96246 & $4.45 \mathrm{E}+00$ \\
$\mathrm{Cm}$ & $\mathrm{Cm}-247$ & 96247 & $1.26 \mathrm{E}-01$ \\
$\mathrm{Cm}$ & $\mathrm{Cm}-248$ & 96248 & $9.94 \mathrm{E}-01$ \\
total & & & $7.78 \mathrm{E}+00$ \\
\hline
\end{tabular}

Table 7. Number density data for curium oxide in aluminum pellets

\begin{tabular}{cccccccc}
\hline Element & Isotope & $\begin{array}{c}\text { Isotope } \\
\text { identifier }\end{array}$ & $\begin{array}{c}\text { Number density } \\
\text { (at/b-cm) }\end{array}$ & Element & Isotope & $\begin{array}{c}\text { Isotope } \\
\text { identifier }\end{array}$ & $\begin{array}{c}\text { Number density } \\
\text { (at/b-cm) }\end{array}$ \\
\hline $\mathrm{O}$ & $\mathrm{O}-16$ & 8016 & $3.68187 \mathrm{E}-03$ & $\mathrm{Pu}$ & $\mathrm{Pu}-240$ & 94240 & $3.51134 \mathrm{E}-05$ \\
$\mathrm{Al}$ & $\mathrm{Al}-27$ & 13027 & $4.72376 \mathrm{E}-02$ & $\mathrm{Pu}$ & $\mathrm{Pu}-241$ & 94241 & $1.12304 \mathrm{E}-08$ \\
$\mathrm{Ca}$ & $\mathrm{Ca}-40$ & 20040 & $7.38242 \mathrm{E}-05$ & $\mathrm{Pu}$ & $\mathrm{Pu}-242$ & 94242 & $4.62606 \mathrm{E}-07$ \\
$\mathrm{Ca}$ & $\mathrm{Ca}-42$ & 20042 & $4.69276 \mathrm{E}-07$ & $\mathrm{Am}$ & $\mathrm{Am}-241$ & 95241 & $3.29254 \mathrm{E}-05$ \\
$\mathrm{Ca}$ & $\mathrm{Ca}-43$ & 20043 & $9.56372 \mathrm{E}-08$ & $\mathrm{Am}$ & $\mathrm{Am}-242 \mathrm{~m}$ & 95242 & $1.33444 \mathrm{E}-07$ \\
$\mathrm{Ca}$ & $\mathrm{Ca}-44$ & 20044 & $1.44426 \mathrm{E}-06$ & $\mathrm{Am}$ & $\mathrm{Am}-243$ & 95243 & $1.18212 \mathrm{E}-04$ \\
$\mathrm{Ca}$ & $\mathrm{Ca}-46$ & 20046 & $2.64902 \mathrm{E}-09$ & $\mathrm{Cm}$ & $\mathrm{Cm}-242$ & 96242 & $3.71101 \mathrm{E}-08$ \\
$\mathrm{Ca}$ & $\mathrm{Ca}-48$ & 20048 & $1.18679 \mathrm{E}-07$ & $\mathrm{Cm}$ & $\mathrm{Cm}-243$ & 96243 & $2.60725 \mathrm{E}-07$ \\
$\mathrm{Fe}$ & $\mathrm{Fe}-54$ & 26054 & $5.06325 \mathrm{E}-06$ & $\mathrm{Cm}$ & $\mathrm{Cm}-244$ & 96244 & $3.60492 \mathrm{E}-04$ \\
$\mathrm{Fe}$ & $\mathrm{Fe}-56$ & 26056 & $7.66470 \mathrm{E}-05$ & $\mathrm{Cm}$ & $\mathrm{Cm}-245$ & 96245 & $8.43563 \mathrm{E}-06$ \\
$\mathrm{Fe}$ & $\mathrm{Fe}-57$ & 26057 & $1.73901 \mathrm{E}-06$ & $\mathrm{Cm}$ & $\mathrm{Cm}-246$ & 96246 & $1.11267 \mathrm{E}-03$ \\
$\mathrm{Fe}$ & $\mathrm{Fe}-58$ & 26058 & $2.27444 \mathrm{E}-07$ & $\mathrm{Cm}$ & $\mathrm{Cm}-247$ & 96247 & $3.13769 \mathrm{E}-05$ \\
$\mathrm{Pu}$ & $\mathrm{Pu}-238$ & 94238 & $1.86091 \mathrm{E}-06$ & $\mathrm{Cm}$ & $\mathrm{Cm}-248$ & 96248 & $2.46529 \mathrm{E}-04$ \\
$\mathrm{Pu}$ & $\mathrm{Pu}-239$ & 94239 & $1.65750 \mathrm{E}-07$ & total & & & $5.30278 \mathrm{E}-02$ \\
\hline
\end{tabular}




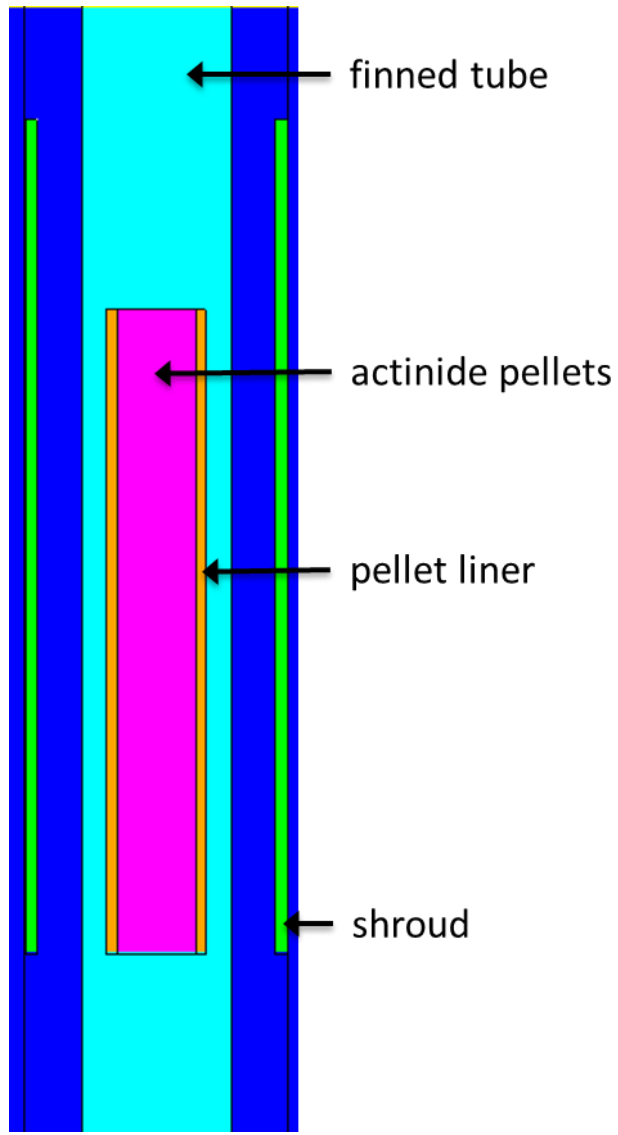

Figure 7. Illustration of a curium target.

\subsection{TARGET ROD RABBIT HOLDER MODELING}

The target rod rabbit holders are modeled with an ID and OD of 0.560 and 0.656 in, respectively, as obtained from the relevant HFIR drawings. The aluminum bottom plug and stainless steel threaded top plug are modeled below and above the target tube, respectively.

Irradiation capsules loaded in the TRRHs are modeled as homogenized cylinders as discussed previously, with the length and OD of the irradiation capsules being 2.625 and 0.4315 in. The OD of the aluminum and beryllium spacers is 0.420 and 0.4895 in, respectively, and the length of these spacers is 2.625 in. An illustration of two TRRHs, one using aluminum spacers and one using beryllium spacers, is provided in Figure 8.

The number densities for the generic $\mathrm{Nb}+\mathrm{Fe}, \mathrm{V}+\mathrm{Ni}, \mathrm{Mo}, \mathrm{Se}$, and $\mathrm{Ni}+\mathrm{Se}$ irradiation capsules in the target rod rabbit holders, as previously discussed, are listed in Table 8 - Table 12. The Ni in the Ni+Se irradiation capsule is $96.46 \mathrm{wt} . \%{ }^{62} \mathrm{Ni}$, as specified in [13]; whereas, the naturally occurring isotopic composition of $\mathrm{Ni}$ is used in the $\mathrm{V}+\mathrm{Ni}$ irradiation capsules. Also, the selenium composition in the Se and $\mathrm{Ni}+\mathrm{Se}$ capsules, as provided by experiment records, includes $99.97 \mathrm{wt} . \%{ }^{74} \mathrm{Se}$, with the remaining being ${ }^{76} \mathrm{Se}$. 


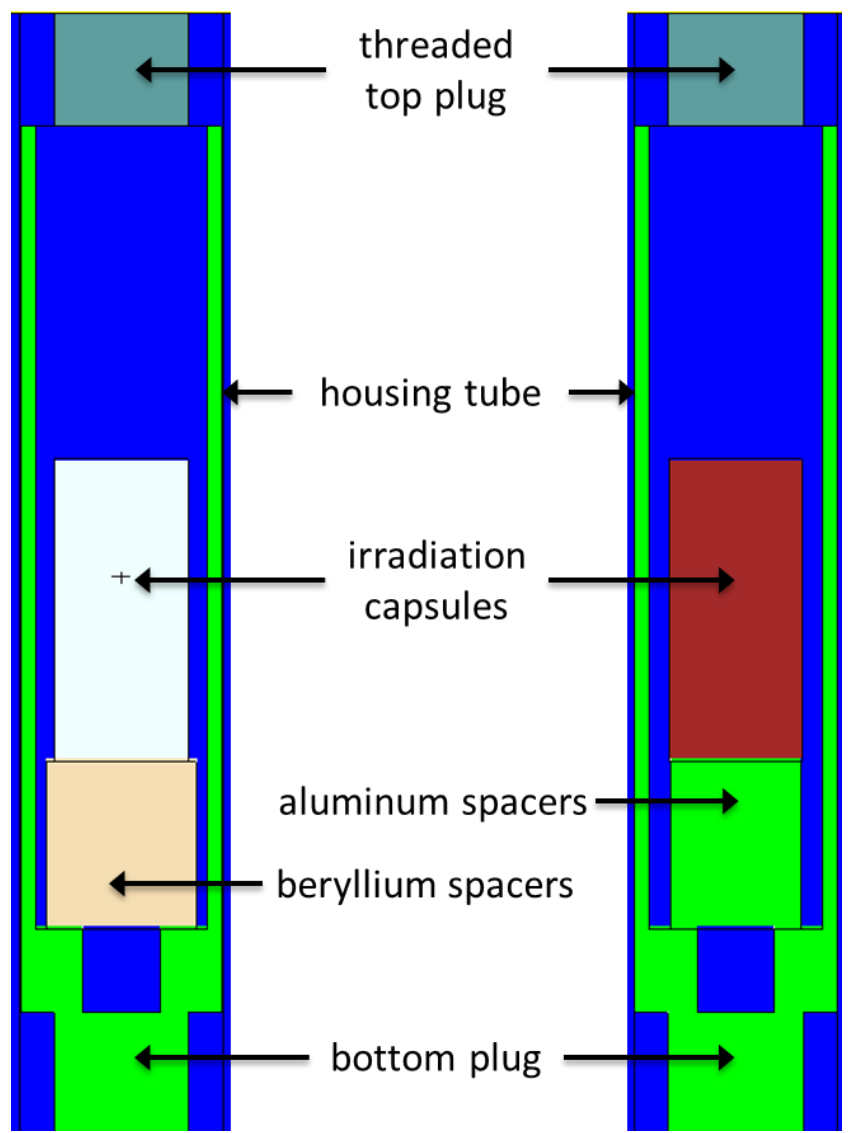

Figure 8. Illustration of target rod rabbit holders. 
Table 8. Number density data for $\mathrm{Nb}+\mathrm{Fe}$ target rod rabbit holder irradiation capsule

\begin{tabular}{cccccccc}
\hline Element & Isotope & $\begin{array}{c}\text { Isotope } \\
\text { identifier }\end{array}$ & $\begin{array}{c}\text { Number } \\
\text { density } \\
\text { (at/b-cm) }\end{array}$ & Element & Isotope & $\begin{array}{c}\text { Isotope } \\
\text { identifier }\end{array}$ & $\begin{array}{c}\text { Number } \\
\text { density } \\
\text { (at/b-cm) }\end{array}$ \\
\hline $\mathrm{C}$ & $\mathrm{C}$ & 6000 & $1.02798 \mathrm{E}-02$ & $\mathrm{Ni}$ & $\mathrm{Ni} 62$ & 28062 & $4.27107 \mathrm{E}-06$ \\
$\mathrm{Mg}$ & $\mathrm{Mg}-24$ & 12024 & $1.74500 \mathrm{E}-04$ & $\mathrm{Ni}$ & $\mathrm{Ni} 64$ & 28064 & $1.08771 \mathrm{E}-06$ \\
$\mathrm{Mg}$ & $\mathrm{Mg}-25$ & 12025 & $2.20913 \mathrm{E}-05$ & $\mathrm{Co}$ & $\mathrm{Co5} 9$ & 27059 & $1.43097 \mathrm{E}-06$ \\
$\mathrm{Mg}$ & $\mathrm{Mg}-26$ & 12026 & $2.43226 \mathrm{E}-05$ & $\mathrm{Cu}$ & $\mathrm{Cu} 63$ & 29063 & $3.51762 \mathrm{E}-05$ \\
$\mathrm{Al}$ & $\mathrm{Al}-27$ & 13027 & $2.25095 \mathrm{E}-02$ & $\mathrm{Cu}$ & $\mathrm{Cu} 65$ & 29065 & $1.56932 \mathrm{E}-05$ \\
$\mathrm{Si}$ & $\mathrm{Si}-28$ & 14028 & $5.93887 \mathrm{E}-03$ & $\mathrm{Zn}$ & $\mathrm{Zn}$ & 30000 & $7.93104 \mathrm{E}-07$ \\
$\mathrm{Si}$ & $\mathrm{Si}-29$ & 14029 & $3.01699 \mathrm{E}-04$ & $\mathrm{Zr}$ & $\mathrm{Zr} 90$ & 40090 & $4.61440 \mathrm{E}-06$ \\
$\mathrm{Si}$ & $\mathrm{Si}-30$ & 14030 & $1.99115 \mathrm{E}-04$ & $\mathrm{Zr}$ & $\mathrm{Zr} 91$ & 40091 & $1.00629 \mathrm{E}-06$ \\
$\mathrm{Ti}$ & $\mathrm{Ti}-46$ & 22046 & $4.60805 \mathrm{E}-05$ & $\mathrm{Zr}$ & $\mathrm{Zr} 92$ & 40092 & $1.53813 \mathrm{E}-06$ \\
$\mathrm{Ti}$ & $\mathrm{Ti}-47$ & 22047 & $4.15562 \mathrm{E}-05$ & $\mathrm{Zr}$ & $\mathrm{Zr} 94$ & 40094 & $1.55876 \mathrm{E}-06$ \\
$\mathrm{Ti}$ & $\mathrm{Ti}-48$ & 22048 & $4.11764 \mathrm{E}-04$ & $\mathrm{Zr}$ & $\mathrm{Zr} 96$ & 40096 & $2.51124 \mathrm{E}-07$ \\
$\mathrm{Ti}$ & $\mathrm{Ti}-49$ & 22049 & $3.02176 \mathrm{E}-05$ & $\mathrm{Nb}$ & $\mathrm{Nb} 93$ & 41093 & $9.00127 \mathrm{E}-04$ \\
$\mathrm{Ti}$ & $\mathrm{Ti}-50$ & 22050 & $2.89329 \mathrm{E}-05$ & $\mathrm{Mo}$ & $\mathrm{Mo} 92$ & 42092 & $4.30798 \mathrm{E}-05$ \\
$\mathrm{~V}$ & $\mathrm{~V}$ & 23000 & $1.02679 \mathrm{E}-02$ & $\mathrm{Mo}$ & $\mathrm{Mo} 94$ & 42094 & $2.69212 \mathrm{E}-05$ \\
$\mathrm{Cr}$ & $\mathrm{Cr} 50$ & 24050 & $4.28420 \mathrm{E}-05$ & $\mathrm{Mo}$ & $\mathrm{Mo} 95$ & 42095 & $4.63757 \mathrm{E}-05$ \\
$\mathrm{Cr}$ & $\mathrm{Cr} 52$ & 24052 & $8.26165 \mathrm{E}-04$ & $\mathrm{Mo}$ & $\mathrm{Mo} 96$ & 42096 & $4.86507 \mathrm{E}-05$ \\
$\mathrm{Cr}$ & $\mathrm{Cr} 53$ & 24053 & $9.36804 \mathrm{E}-05$ & $\mathrm{Mo}$ & $\mathrm{Mo} 97$ & 42097 & $2.78837 \mathrm{E}-05$ \\
$\mathrm{Cr}$ & $\mathrm{Cr} 54$ & 24054 & $2.33190 \mathrm{E}-05$ & $\mathrm{Mo}$ & $\mathrm{Mo} 98$ & 42098 & $7.05552 \mathrm{E}-05$ \\
$\mathrm{Mn}$ & $\mathrm{Mn} 55$ & 25055 & $2.54672 \mathrm{E}-05$ & $\mathrm{Mo}$ & $\mathrm{Mo} 100$ & 42100 & $2.82046 \mathrm{E}-05$ \\
$\mathrm{Fe}$ & $\mathrm{Fe} 54$ & 26054 & $2.19030 \mathrm{E}-04$ & $\mathrm{Ho}$ & $\mathrm{Ho} 165$ & 67165 & $4.16219 \mathrm{E}-06$ \\
$\mathrm{Fe}$ & $\mathrm{Fe} 56$ & 26056 & $3.43830 \mathrm{E}-03$ & $\mathrm{Ta}$ & $\mathrm{Ta}-181$ & 73181 & $2.83146 \mathrm{E}-05$ \\
$\mathrm{Fe}$ & $\mathrm{Fe} 57$ & 26057 & $7.94055 \mathrm{E}-05$ & $\mathrm{~W}$ & $\mathrm{~W} 182$ & 74182 & $4.04097 \mathrm{E}-05$ \\
$\mathrm{Fe}$ & $\mathrm{Fe} 58$ & 26058 & $1.05674 \mathrm{E}-05$ & $\mathrm{~W}$ & $\mathrm{~W} 183$ & 74183 & $2.18212 \mathrm{E}-05$ \\
$\mathrm{Ni}$ & $\mathrm{Ni58}$ & 28058 & $8.00003 \mathrm{E}-05$ & $\mathrm{~W}$ & $\mathrm{~W} 184$ & 74184 & $4.67227 \mathrm{E}-05$ \\
$\mathrm{Ni}$ & $\mathrm{Ni60}$ & 28060 & $3.08160 \mathrm{E}-05$ & $\mathrm{~W}$ & $\mathrm{~W} 186$ & 74186 & $4.33527 \mathrm{E}-05$ \\
$\mathrm{Ni}$ & $\mathrm{Ni61}$ & 28061 & $1.33955 \mathrm{E}-06$ & total & & & $5.65913 \mathrm{E}-02$ \\
\hline
\end{tabular}


Table 9. Number density data for $\mathrm{V}+\mathrm{Ni}$ target rod rabbit holder irradiation capsule

\begin{tabular}{|c|c|c|c|c|c|c|c|}
\hline Element & Isotope & $\begin{array}{l}\text { Isotope } \\
\text { identifier }\end{array}$ & $\begin{array}{c}\text { Number } \\
\text { density } \\
\text { (at/b-cm) }\end{array}$ & Element & Isotope & $\begin{array}{c}\text { Isotope } \\
\text { identifier }\end{array}$ & $\begin{array}{c}\text { Number } \\
\text { density } \\
\text { (at/b-cm) }\end{array}$ \\
\hline $\mathrm{C}$ & $\mathrm{C}$ & 6000 & $1.67917 \mathrm{E}-02$ & $\mathrm{Ni}$ & Ni64 & 28064 & 7.50604E-06 \\
\hline $\mathrm{Mg}$ & $\mathrm{Mg}-24$ & 12024 & $2.01380 \mathrm{E}-04$ & Co & Co59 & 27059 & 1.10604E-05 \\
\hline $\mathrm{Mg}$ & $\mathrm{Mg}-25$ & 12025 & $2.54944 \mathrm{E}-05$ & $\mathrm{Cu}$ & $\mathrm{Cu} 63$ & 29063 & 2.02630E-05 \\
\hline $\mathrm{Mg}$ & $\mathrm{Mg}-26$ & 12026 & $2.80694 \mathrm{E}-05$ & $\mathrm{Cu}$ & $\mathrm{Cu} 65$ & 29065 & $9.03998 \mathrm{E}-06$ \\
\hline $\mathrm{Al}$ & Al-27 & 13027 & $2.17843 \mathrm{E}-02$ & $\mathrm{Zn}$ & $\mathrm{Zn}$ & 30000 & $8.15996 \mathrm{E}-07$ \\
\hline $\mathrm{Si}$ & $\mathrm{Si}-28$ & 14028 & $2.99180 \mathrm{E}-03$ & $\mathrm{Nb}$ & $\mathrm{Nb} 93$ & 41093 & 6.99009E-06 \\
\hline $\mathrm{Si}$ & $\mathrm{Si}-29$ & 14029 & $1.51986 \mathrm{E}-04$ & Mo & Mo92 & 42092 & $1.15942 \mathrm{E}-04$ \\
\hline $\mathrm{Si}$ & $\mathrm{Si}-30$ & 14030 & $1.00307 \mathrm{E}-04$ & Mo & Mo94 & 42094 & 7.24539E-05 \\
\hline $\mathrm{Ti}$ & Ti-46 & 22046 & $9.05032 \mathrm{E}-05$ & Mo & Mo95 & 42095 & $1.24812 \mathrm{E}-04$ \\
\hline $\mathrm{Ti}$ & Ti-47 & 22047 & $8.16174 \mathrm{E}-05$ & Mo & Mo96 & 42096 & 1.30935E-04 \\
\hline $\mathrm{Ti}$ & Ti-48 & 22048 & $8.08714 \mathrm{E}-04$ & Mo & Mo97 & 42097 & 7.50444E-05 \\
\hline $\mathrm{Ti}$ & Ti-49 & 22049 & 5.93481E-05 & Mo & Mo98 & 42098 & $1.89887 \mathrm{E}-04$ \\
\hline $\mathrm{Ti}$ & $\mathrm{Ti}-50$ & 22050 & $5.68250 \mathrm{E}-05$ & Mo & Mo100 & 42100 & 7.59078E-05 \\
\hline $\mathrm{V}$ & V & 23000 & $1.13260 \mathrm{E}-02$ & $\mathrm{Gd}$ & Gd152 & 64152 & $2.80350 \mathrm{E}-11$ \\
\hline $\mathrm{Cr}$ & Cr50 & 24050 & $3.58165 \mathrm{E}-05$ & $\mathrm{Gd}$ & Gd154 & 64154 & $3.05581 \mathrm{E}-10$ \\
\hline $\mathrm{Cr}$ & $\mathrm{Cr} 52$ & 24052 & $6.90686 \mathrm{E}-04$ & Gd & Gd155 & 64155 & 2.07459E-09 \\
\hline $\mathrm{Cr}$ & Cr53 & 24053 & $7.83183 \mathrm{E}-05$ & $\mathrm{Gd}$ & Gd156 & 64156 & 2.86938E-09 \\
\hline $\mathrm{Cr}$ & Cr54 & 24054 & $1.94951 \mathrm{E}-05$ & $\mathrm{Gd}$ & Gd157 & 64157 & 2.19374E-09 \\
\hline Mn & Mn55 & 25055 & $2.16936 \mathrm{E}-05$ & Gd & Gd158 & 64158 & 3.48194E-09 \\
\hline $\mathrm{Fe}$ & $\mathrm{Fe} 54$ & 26054 & $2.42289 \mathrm{E}-05$ & $\mathrm{Gd}$ & Gd160 & 64160 & 3.06422E-09 \\
\hline $\mathrm{Fe}$ & $\mathrm{Fe} 56$ & 26056 & $3.80342 \mathrm{E}-04$ & $\mathrm{Ta}$ & Та-181 & 73181 & $2.54774 \mathrm{E}-09$ \\
\hline $\mathrm{Fe}$ & $\mathrm{Fe} 57$ & 26057 & 8.78376E-06 & W & W182 & 74182 & $1.40296 \mathrm{E}-08$ \\
\hline $\mathrm{Fe}$ & Fe58 & 26058 & $1.16896 \mathrm{E}-06$ & $\mathrm{~W}$ & W183 & 74183 & 7.57599E-09 \\
\hline $\mathrm{Ni}$ & Ni58 & 28058 & $5.52062 \mathrm{E}-04$ & W & W184 & 74184 & $1.62214 \mathrm{E}-08$ \\
\hline $\mathrm{Ni}$ & Ni60 & 28060 & $2.12653 \mathrm{E}-04$ & W & W186 & 74186 & $1.50514 \mathrm{E}-08$ \\
\hline $\mathrm{Ni}$ & Ni61 & 28061 & $9.24389 \mathrm{E}-06$ & & & & \\
\hline $\mathrm{Ni}$ & $\mathrm{Ni} 62$ & 28062 & $2.94736 \mathrm{E}-05$ & total & & & $5.74028 \mathrm{E}-02$ \\
\hline
\end{tabular}


Table 10. Number density data for Mo target rod rabbit holder irradiation capsule

\begin{tabular}{cccccccc}
\hline Element & Isotope & $\begin{array}{c}\text { Isotope } \\
\text { identifier }\end{array}$ & $\begin{array}{c}\text { Number } \\
\text { density } \\
\text { (at/b-cm) }\end{array}$ & Element & Isotope & $\begin{array}{c}\text { Isotope } \\
\text { identifier }\end{array}$ & $\begin{array}{c}\text { Number } \\
\text { density } \\
\text { (at/b-cm) }\end{array}$ \\
\hline $\mathrm{C}$ & $\mathrm{C}$ & 6000 & $1.71148 \mathrm{E}-02$ & $\mathrm{Ni}$ & $\mathrm{Ni} 60$ & 28060 & $1.89382 \mathrm{E}-06$ \\
$\mathrm{Mg}$ & $\mathrm{Mg}-24$ & 12024 & $1.35846 \mathrm{E}-04$ & $\mathrm{Ni}$ & $\mathrm{Ni} 61$ & 28061 & $8.23232 \mathrm{E}-08$ \\
$\mathrm{Mg}$ & $\mathrm{Mg}-25$ & 12025 & $1.71978 \mathrm{E}-05$ & $\mathrm{Ni}$ & $\mathrm{Ni} 62$ & 28062 & $2.62482 \mathrm{E}-07$ \\
$\mathrm{Mg}$ & $\mathrm{Mg}-26$ & 12026 & $1.89348 \mathrm{E}-05$ & $\mathrm{Ni}$ & $\mathrm{Ni64}$ & 28064 & $6.68465 \mathrm{E}-08$ \\
$\mathrm{Al}$ & $\mathrm{Al}-27$ & 13027 & $1.64749 \mathrm{E}-02$ & $\mathrm{Co}$ & $\mathrm{Co5} 9$ & 27059 & $8.37725 \mathrm{E}-08$ \\
$\mathrm{Si}$ & $\mathrm{Si}-28$ & 14028 & $4.94327 \mathrm{E}-03$ & $\mathrm{Cu}$ & $\mathrm{Cu} 63$ & 29063 & $1.29138 \mathrm{E}-05$ \\
$\mathrm{Si}$ & $\mathrm{Si}-29$ & 14029 & $2.51122 \mathrm{E}-04$ & $\mathrm{Cu}$ & $\mathrm{Cu} 65$ & 29065 & $5.76127 \mathrm{E}-06$ \\
$\mathrm{Si}$ & $\mathrm{Si}-30$ & 14030 & $1.65735 \mathrm{E}-04$ & $\mathrm{Zn}$ & $\mathrm{Zn}$ & 30000 & $9.17839 \mathrm{E}-07$ \\
$\mathrm{Ti}$ & $\mathrm{Ti}-46$ & 22046 & $9.48017 \mathrm{E}-06$ & $\mathrm{Mo}$ & $\mathrm{Mo} 92$ & 42092 & $2.20696 \mathrm{E}-03$ \\
$\mathrm{Ti}$ & $\mathrm{Ti}-47$ & 22047 & $8.54939 \mathrm{E}-06$ & $\mathrm{Mo}$ & $\mathrm{Mo} 94$ & 42094 & $1.37916 \mathrm{E}-03$ \\
$\mathrm{Ti}$ & $\mathrm{Ti}-48$ & 22048 & $8.47125 \mathrm{E}-05$ & $\mathrm{Mo}$ & $\mathrm{Mo} 95$ & 42095 & $2.37581 \mathrm{E}-03$ \\
$\mathrm{Ti}$ & $\mathrm{Ti}-49$ & 22049 & $6.21670 \mathrm{E}-06$ & $\mathrm{Mo}$ & $\mathrm{Mo} 96$ & 42096 & $2.49236 \mathrm{E}-03$ \\
$\mathrm{Ti}$ & $\mathrm{Ti}-50$ & 22050 & $5.95240 \mathrm{E}-06$ & $\mathrm{Mo}$ & $\mathrm{Mo} 97$ & 42097 & $1.42847 \mathrm{E}-03$ \\
$\mathrm{~V}$ & $\mathrm{~V}$ & 23000 & $6.18271 \mathrm{E}-04$ & $\mathrm{Mo}$ & $\mathrm{Mo} 98$ & 42098 & $3.61452 \mathrm{E}-03$ \\
$\mathrm{Cr}$ & $\mathrm{Cr} 50$ & 24050 & $2.80681 \mathrm{E}-06$ & $\mathrm{Mo}$ & $\mathrm{Mo} 100$ & 42100 & $1.44491 \mathrm{E}-03$ \\
$\mathrm{Cr}$ & $\mathrm{Cr} 52$ & 24052 & $5.41265 \mathrm{E}-05$ & $\mathrm{Ta}$ & $\mathrm{Ta}-181$ & 73181 & $6.20533 \mathrm{E}-12$ \\
$\mathrm{Cr}$ & $\mathrm{Cr} 53$ & 24053 & $6.13751 \mathrm{E}-06$ & $\mathrm{~W}$ & $\mathrm{~W} 182$ & 74182 & $5.42551 \mathrm{E}-06$ \\
$\mathrm{Cr}$ & $\mathrm{Cr} 54$ & 24054 & $1.52776 \mathrm{E}-06$ & $\mathrm{~W}$ & $\mathrm{~W} 183$ & 74183 & $2.92978 \mathrm{E}-06$ \\
$\mathrm{Mn}$ & $\mathrm{Mn} 55$ & 25055 & $3.00814 \mathrm{E}-06$ & $\mathrm{~W}$ & $\mathrm{~W} 184$ & 74184 & $6.27312 \mathrm{E}-06$ \\
$\mathrm{Fe}$ & $\mathrm{Fe} 54$ & 26054 & $4.07233 \mathrm{E}-06$ & $\mathrm{~W}$ & $\mathrm{~W} 186$ & 74186 & $5.82066 \mathrm{E}-06$ \\
$\mathrm{Fe}$ & $\mathrm{Fe} 56$ & 26056 & $6.39268 \mathrm{E}-05$ & $\mathrm{Re}$ & $\mathrm{Re} 185$ & 75185 & $8.48438 \mathrm{E}-08$ \\
$\mathrm{Fe}$ & $\mathrm{Fe} 57$ & 26057 & $1.47635 \mathrm{E}-06$ & $\mathrm{Re}$ & $\mathrm{Re} 187$ & 75187 & $1.42011 \mathrm{E}-07$ \\
$\mathrm{Fe}$ & $\mathrm{Fe} 58$ & 26058 & $1.96475 \mathrm{E}-07$ & & & & \\
$\mathrm{Ni}$ & $\mathrm{Ni58}$ & 28058 & $4.91649 \mathrm{E}-06$ & total & & & $5.49820 \mathrm{E}-02$ \\
\hline & & & & & & &
\end{tabular}


Table 11. Number density data for Se target rod rabbit holder irradiation capsule

\begin{tabular}{cccccccc}
\hline Element & Isotope & $\begin{array}{c}\text { Isotope } \\
\text { identifier }\end{array}$ & $\begin{array}{c}\text { Number density (at/b- } \\
\mathbf{c m})\end{array}$ & Element & Isotope & $\begin{array}{c}\text { Isotope } \\
\text { identifier }\end{array}$ & $\begin{array}{c}\text { Number } \\
\text { density (at/b- } \\
\text { cm) }\end{array}$ \\
\hline $\mathrm{Al}$ & $\mathrm{Al}-27$ & 13027 & $4.46513 \mathrm{E}-02$ & $\mathrm{Ti}$ & $\mathrm{Ti}-50$ & 22050 & $5.09382 \mathrm{E}-06$ \\
$\mathrm{Ti}$ & $\mathrm{Ti}-46$ & 22046 & $8.11274 \mathrm{E}-06$ & $\mathrm{~V}$ & $\mathrm{~V}$ & 23000 & $8.63844 \mathrm{E}-03$ \\
$\mathrm{Ti}$ & $\mathrm{Ti}-47$ & 22047 & $7.31622 \mathrm{E}-06$ & $\mathrm{Se}$ & $\mathrm{Se} 74$ & 34074 & $2.30813 \mathrm{E}-03$ \\
$\mathrm{Ti}$ & $\mathrm{Ti}-48$ & 22048 & $7.24935 \mathrm{E}-05$ & $\mathrm{Se}$ & $\mathrm{Se} 76$ & 34076 & $6.74430 \mathrm{E}-07$ \\
$\mathrm{Ti}$ & $\mathrm{Ti}-49$ & 22049 & $5.31999 \mathrm{E}-06$ & total & & & $5.56969 \mathrm{E}-02$ \\
\hline
\end{tabular}

Table 12. Number density data for Ni+Se target rod rabbit holder irradiation capsule

\begin{tabular}{cccccccc}
\hline Element & Isotope & $\begin{array}{c}\text { Isotope } \\
\text { identifier }\end{array}$ & $\begin{array}{c}\text { Number } \\
\text { density } \\
\text { (at/b-cm) }\end{array}$ & Element & Isotope & $\begin{array}{c}\text { Isotope } \\
\text { identifier }\end{array}$ & $\begin{array}{c}\text { Number } \\
\text { density } \\
\text { (at/b-cm) }\end{array}$ \\
\hline $\mathrm{Al}$ & $\mathrm{Al}-27$ & 13027 & $3.57536 \mathrm{E}-02$ & $\mathrm{Ni}$ & $\mathrm{Ni} 6$ & 28060 & $1.64907 \mathrm{E}-04$ \\
$\mathrm{Ti}$ & $\mathrm{Ti}-46$ & 22046 & $2.25354 \mathrm{E}-06$ & $\mathrm{Ni}$ & $\mathrm{Ni} 11$ & 28061 & $2.33470 \mathrm{E}-05$ \\
$\mathrm{Ti}$ & $\mathrm{Ti}-47$ & 22047 & $2.03228 \mathrm{E}-06$ & $\mathrm{Ni}$ & $\mathrm{Ni} 62$ & 28062 & $1.16620 \mathrm{E}-02$ \\
$\mathrm{Ti}$ & $\mathrm{Ti}-48$ & 22048 & $2.01371 \mathrm{E}-05$ & $\mathrm{Ni}$ & $\mathrm{Ni} 64$ & 28064 & $1.87389 \mathrm{E}-05$ \\
$\mathrm{Ti}$ & $\mathrm{Ti}-49$ & 22049 & $1.47778 \mathrm{E}-06$ & $\mathrm{Se}$ & $\mathrm{Se} 74$ & 34074 & $6.41148 \mathrm{E}-04$ \\
$\mathrm{Ti}$ & $\mathrm{Ti}-50$ & 22050 & $1.41495 \mathrm{E}-06$ & $\mathrm{Se}$ & $\mathrm{Se} 76$ & 34076 & $1.87342 \mathrm{E}-07$ \\
$\mathrm{~V}$ & $\mathrm{~V}$ & 23000 & $2.39957 \mathrm{E}-03$ & & & & \\
$\mathrm{Ni}$ & $\mathrm{Ni} 58$ & 28058 & $2.41665 \mathrm{E}-04$ & total & & & $5.09325 \mathrm{E}-02$ \\
\hline
\end{tabular}

\subsection{PERIPHERAL TARGET POSITION MODELING}

The PTPs and the irradiation capsules loaded in the PTPs are modeled according to data from appropriate HFIR drawings. The aluminum housing tube is modeled with an OD and wall thickness of 0.700 and 0.092 in, respectively, and the stainless steel lower plug is modeled with a length of 2.000 in. A target lower axial bound of -13.03125 in is modeled based on the 12.87500 in distance from the core midplane to the top of the target holder adapter ring and the 0.15625 in lower plug tip length. An illustration of the two PTP types modeled, PTP Generic 1 and PTP Generic 2, is provided in Figure 9. The number densities for the generic $\mathrm{Nb}, \mathrm{Mo}, \mathrm{V}$, and Fe irradiation capsules in the PTPs, as previously discussed, are listed in Table 13 - Table 16. 


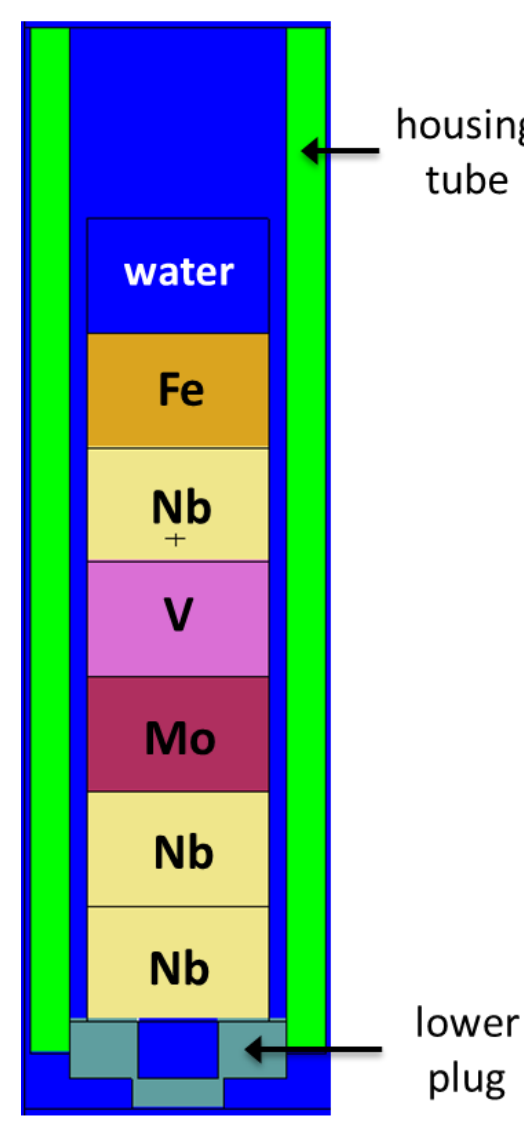

(a)

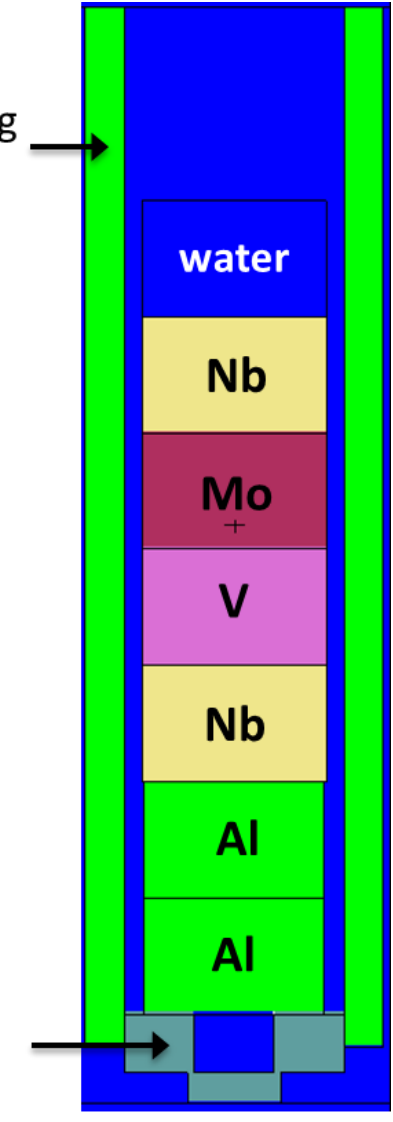

(b)

Figure 9. Illustration of peripheral target position targets: (a) PTP Generic 1 and (b) PTP Generic 2. 
Table 13. Number density data for $\mathrm{Nb}$ peripheral target position irradiation capsule

\begin{tabular}{cccccccc}
\hline Element & Isotope & $\begin{array}{c}\text { Isotope } \\
\text { identifier }\end{array}$ & $\begin{array}{c}\text { Number } \\
\text { density } \\
\text { (at/b-cm) }\end{array}$ & Element & Isotope & $\begin{array}{c}\text { Isotope } \\
\text { identifier }\end{array}$ & $\begin{array}{c}\text { Number } \\
\text { density } \\
\text { (at/b-cm) }\end{array}$ \\
\hline $\mathrm{C}$ & $\mathrm{C}$ & 6000 & $1.63792 \mathrm{E}-02$ & $\mathrm{Ni}$ & $\mathrm{Ni} 58$ & 28058 & $4.09915 \mathrm{E}-05$ \\
$\mathrm{Mg}$ & $\mathrm{Mg}-24$ & 12024 & $1.20339 \mathrm{E}-04$ & $\mathrm{Ni}$ & $\mathrm{Ni60}$ & 28060 & $1.57898 \mathrm{E}-05$ \\
$\mathrm{Mg}$ & $\mathrm{Mg}-25$ & 12025 & $1.52347 \mathrm{E}-05$ & $\mathrm{Ni}$ & $\mathrm{Ni61}$ & 28061 & $6.86373 \mathrm{E}-07$ \\
$\mathrm{Mg}$ & $\mathrm{Mg}-26$ & 12026 & $1.67734 \mathrm{E}-05$ & $\mathrm{Ni}$ & $\mathrm{Ni62}$ & 28062 & $2.18846 \mathrm{E}-06$ \\
$\mathrm{Al}$ & $\mathrm{Al}-27$ & 13027 & $1.68465 \mathrm{E}-02$ & $\mathrm{Ni}$ & $\mathrm{Ni64}$ & 28064 & $5.57336 \mathrm{E}-07$ \\
$\mathrm{Si}$ & $\mathrm{Si}-28$ & 14028 & $9.19532 \mathrm{E}-03$ & $\mathrm{Cu}$ & $\mathrm{Cu} 63$ & 29063 & $1.12402 \mathrm{E}-05$ \\
$\mathrm{Si}$ & $\mathrm{Si}-29$ & 14029 & $4.67129 \mathrm{E}-04$ & $\mathrm{Cu}$ & $\mathrm{Cu} 65$ & 29065 & $5.01463 \mathrm{E}-06$ \\
$\mathrm{Si}$ & $\mathrm{Si}-30$ & 14030 & $3.08295 \mathrm{E}-04$ & $\mathrm{Zn}$ & $\mathrm{Zn}$ & 30000 & $6.31080 \mathrm{E}-07$ \\
$\mathrm{Ti}$ & $\mathrm{Ti}-46$ & 22046 & $5.35348 \mathrm{E}-05$ & $\mathrm{Zr}$ & $\mathrm{Zr} 90$ & 40090 & $7.49841 \mathrm{E}-06$ \\
$\mathrm{Ti}$ & $\mathrm{Ti}-47$ & 22047 & $4.82787 \mathrm{E}-05$ & $\mathrm{Zr}$ & $\mathrm{Zr} 91$ & 40091 & $1.63522 \mathrm{E}-06$ \\
$\mathrm{Ti}$ & $\mathrm{Ti}-48$ & 22048 & $4.78374 \mathrm{E}-04$ & $\mathrm{Zr}$ & $\mathrm{Zr} 92$ & 40092 & $2.49947 \mathrm{E}-06$ \\
$\mathrm{Ti}$ & $\mathrm{Ti}-49$ & 22049 & $3.51059 \mathrm{E}-05$ & $\mathrm{Zr}$ & $\mathrm{Zr} 94$ & 40094 & $2.53299 \mathrm{E}-06$ \\
$\mathrm{Ti}$ & $\mathrm{Ti}-50$ & 22050 & $3.36134 \mathrm{E}-05$ & $\mathrm{Zr}$ & $\mathrm{Zr} 96$ & 40096 & $4.08077 \mathrm{E}-07$ \\
$\mathrm{~V}$ & $\mathrm{~V}$ & 23000 & $1.41925 \mathrm{E}-02$ & $\mathrm{Nb}$ & $\mathrm{Nb} 93$ & 41093 & $1.46271 \mathrm{E}-03$ \\
$\mathrm{Cr}$ & $\mathrm{Cr} 50$ & 24050 & $2.87685 \mathrm{E}-05$ & $\mathrm{Mo}$ & $\mathrm{Mo92}$ & 42092 & $3.64877 \mathrm{E}-05$ \\
$\mathrm{Cr}$ & $\mathrm{Cr} 52$ & 24052 & $5.54772 \mathrm{E}-04$ & $\mathrm{Mo}$ & $\mathrm{Mo} 94$ & 42094 & $2.28017 \mathrm{E}-05$ \\
$\mathrm{Cr}$ & $\mathrm{Cr} 53$ & 24053 & $6.29067 \mathrm{E}-05$ & $\mathrm{Mo}$ & $\mathrm{Mo} 95$ & 42095 & $3.92792 \mathrm{E}-05$ \\
$\mathrm{Cr}$ & $\mathrm{Cr} 54$ & 24054 & $1.56588 \mathrm{E}-05$ & $\mathrm{Mo}$ & $\mathrm{Mo} 96$ & 42096 & $4.12061 \mathrm{E}-05$ \\
$\mathrm{Mn}$ & $\mathrm{Mn} 55$ & 25055 & $1.47172 \mathrm{E}-05$ & $\mathrm{Mo}$ & $\mathrm{Mo97}$ & 42097 & $2.36169 \mathrm{E}-05$ \\
$\mathrm{Fe}$ & $\mathrm{Fe} 54$ & 26054 & $3.37550 \mathrm{E}-05$ & $\mathrm{Mo}$ & $\mathrm{Mo9}$ & 42098 & $5.97587 \mathrm{E}-05$ \\
$\mathrm{Fe}$ & $\mathrm{Fe} 56$ & 26056 & $5.29881 \mathrm{E}-04$ & $\mathrm{Mo}$ & $\mathrm{Mo} 100$ & 42100 & $2.38887 \mathrm{E}-05$ \\
$\mathrm{Fe}$ & $\mathrm{Fe} 57$ & 26057 & $1.22373 \mathrm{E}-05$ & $\mathrm{Ho}$ & $\mathrm{Ho} 165$ & 67165 & $6.76356 \mathrm{E}-06$ \\
$\mathrm{Fe}$ & $\mathrm{Fe} 58$ & 26058 & $1.62855 \mathrm{E}-06$ & total & & & $6.12527 \mathrm{E}-02$ \\
\hline
\end{tabular}


Table 14. Number density data for Mo peripheral target position irradiation capsule

\begin{tabular}{cccccccc}
\hline Element & Isotope & $\begin{array}{c}\text { Isotope } \\
\text { identifier }\end{array}$ & $\begin{array}{c}\text { Number } \\
\text { density } \\
\text { (at/b-cm) }\end{array}$ & Element & Isotope & $\begin{array}{c}\text { Isotope } \\
\text { identifier }\end{array}$ & $\begin{array}{c}\text { Number } \\
\text { density } \\
\text { (at/b-cm) }\end{array}$ \\
\hline $\mathrm{C}$ & $\mathrm{C}$ & 6000 & $1.71148 \mathrm{E}-02$ & $\mathrm{Ni}$ & $\mathrm{Ni} 60$ & 28060 & $1.89382 \mathrm{E}-06$ \\
$\mathrm{Mg}$ & $\mathrm{Mg}-24$ & 12024 & $1.35846 \mathrm{E}-04$ & $\mathrm{Ni}$ & $\mathrm{Ni} 61$ & 28061 & $8.23232 \mathrm{E}-08$ \\
$\mathrm{Mg}$ & $\mathrm{Mg}-25$ & 12025 & $1.71978 \mathrm{E}-05$ & $\mathrm{Ni}$ & $\mathrm{Ni} 62$ & 28062 & $2.62482 \mathrm{E}-07$ \\
$\mathrm{Mg}$ & $\mathrm{Mg}-26$ & 12026 & $1.89348 \mathrm{E}-05$ & $\mathrm{Ni}$ & $\mathrm{Ni64}$ & 28064 & $6.68465 \mathrm{E}-08$ \\
$\mathrm{Al}$ & $\mathrm{Al}-27$ & 13027 & $1.64749 \mathrm{E}-02$ & $\mathrm{Co}$ & $\mathrm{Co5} 9$ & 27059 & $8.37725 \mathrm{E}-08$ \\
$\mathrm{Si}$ & $\mathrm{Si}-28$ & 14028 & $4.94327 \mathrm{E}-03$ & $\mathrm{Cu}$ & $\mathrm{Cu} 63$ & 29063 & $1.29138 \mathrm{E}-05$ \\
$\mathrm{Si}$ & $\mathrm{Si}-29$ & 14029 & $2.51122 \mathrm{E}-04$ & $\mathrm{Cu}$ & $\mathrm{Cu} 65$ & 29065 & $5.76127 \mathrm{E}-06$ \\
$\mathrm{Si}$ & $\mathrm{Si}-30$ & 14030 & $1.65735 \mathrm{E}-04$ & $\mathrm{Zn}$ & $\mathrm{Zn}$ & 30000 & $9.17839 \mathrm{E}-07$ \\
$\mathrm{Ti}$ & $\mathrm{Ti}-46$ & 22046 & $9.48017 \mathrm{E}-06$ & $\mathrm{Mo}$ & $\mathrm{Mo} 92$ & 42092 & $2.20696 \mathrm{E}-03$ \\
$\mathrm{Ti}$ & $\mathrm{Ti}-47$ & 22047 & $8.54939 \mathrm{E}-06$ & $\mathrm{Mo}$ & $\mathrm{Mo} 94$ & 42094 & $1.37916 \mathrm{E}-03$ \\
$\mathrm{Ti}$ & $\mathrm{Ti}-48$ & 22048 & $8.47125 \mathrm{E}-05$ & $\mathrm{Mo}$ & $\mathrm{Mo} 95$ & 42095 & $2.37581 \mathrm{E}-03$ \\
$\mathrm{Ti}$ & $\mathrm{Ti}-49$ & 22049 & $6.21670 \mathrm{E}-06$ & $\mathrm{Mo}$ & $\mathrm{Mo} 96$ & 42096 & $2.49236 \mathrm{E}-03$ \\
$\mathrm{Ti}$ & $\mathrm{Ti}-50$ & 22050 & $5.95240 \mathrm{E}-06$ & $\mathrm{Mo}$ & $\mathrm{Mo} 97$ & 42097 & $1.42847 \mathrm{E}-03$ \\
$\mathrm{~V}$ & $\mathrm{~V}$ & 23000 & $6.18271 \mathrm{E}-04$ & $\mathrm{Mo}$ & $\mathrm{Mo} 98$ & 42098 & $3.61452 \mathrm{E}-03$ \\
$\mathrm{Cr}$ & $\mathrm{Cr} 50$ & 24050 & $2.80681 \mathrm{E}-06$ & $\mathrm{Mo}$ & $\mathrm{Mo} 100$ & 42100 & $1.44491 \mathrm{E}-03$ \\
$\mathrm{Cr}$ & $\mathrm{Cr} 52$ & 24052 & $5.41265 \mathrm{E}-05$ & $\mathrm{Ta}$ & $\mathrm{Ta}-181$ & 73181 & $6.20533 \mathrm{E}-12$ \\
$\mathrm{Cr}$ & $\mathrm{Cr} 53$ & 24053 & $6.13751 \mathrm{E}-06$ & $\mathrm{~W}$ & $\mathrm{~W} 182$ & 74182 & $5.42551 \mathrm{E}-06$ \\
$\mathrm{Cr}$ & $\mathrm{Cr} 54$ & 24054 & $1.52776 \mathrm{E}-06$ & $\mathrm{~W}$ & $\mathrm{~W} 183$ & 74183 & $2.92978 \mathrm{E}-06$ \\
$\mathrm{Mn}$ & $\mathrm{Mn} 55$ & 25055 & $3.00814 \mathrm{E}-06$ & $\mathrm{~W}$ & $\mathrm{~W} 184$ & 74184 & $6.27312 \mathrm{E}-06$ \\
$\mathrm{Fe}$ & $\mathrm{Fe} 54$ & 26054 & $4.07233 \mathrm{E}-06$ & $\mathrm{~W}$ & $\mathrm{~W} 186$ & 74186 & $5.82066 \mathrm{E}-06$ \\
$\mathrm{Fe}$ & $\mathrm{Fe} 56$ & 26056 & $6.39268 \mathrm{E}-05$ & $\mathrm{Re}$ & $\mathrm{Re} 185$ & 75185 & $8.48438 \mathrm{E}-08$ \\
$\mathrm{Fe}$ & $\mathrm{Fe} 57$ & 26057 & $1.47635 \mathrm{E}-06$ & $\mathrm{Re}$ & $\mathrm{Re} 187$ & 75187 & $1.42011 \mathrm{E}-07$ \\
$\mathrm{Fe}$ & $\mathrm{Fe} 58$ & 26058 & $1.96475 \mathrm{E}-07$ & & & & \\
$\mathrm{Ni}$ & $\mathrm{Ni58}$ & 28058 & $4.91649 \mathrm{E}-06$ & total & & & $5.49820 \mathrm{E}-02$ \\
\hline
\end{tabular}


Table 15. Number density data for $V$ peripheral target position irradiation capsule

\begin{tabular}{|c|c|c|c|c|c|c|c|}
\hline Element & Isotope & $\begin{array}{c}\text { Isotope } \\
\text { identifier }\end{array}$ & $\begin{array}{c}\text { Number } \\
\text { density } \\
\text { (at/b-cm) }\end{array}$ & Element & Isotope & $\begin{array}{l}\text { Isotope } \\
\text { identifier }\end{array}$ & $\begin{array}{c}\text { Number } \\
\text { density } \\
\text { (at/b-cm) }\end{array}$ \\
\hline $\mathrm{C}$ & $\mathrm{C}$ & 6000 & $2.10276 \mathrm{E}-02$ & $\mathrm{Ni}$ & Ni62 & 28062 & 1.60204E-07 \\
\hline $\mathrm{Mg}$ & $\mathrm{Mg}-24$ & 12024 & $1.35367 \mathrm{E}-04$ & $\mathrm{Ni}$ & Ni64 & 28064 & 4.07992E-08 \\
\hline $\mathrm{Mg}$ & $\mathrm{Mg}-25$ & 12025 & $1.71372 \mathrm{E}-05$ & Co & Co59 & 27059 & $5.11522 \mathrm{E}-08$ \\
\hline $\mathrm{Mg}$ & $M g-26$ & 12026 & $1.88681 \mathrm{E}-05$ & $\mathrm{Cu}$ & $\mathrm{Cu} 63$ & 29063 & $1.29015 \mathrm{E}-05$ \\
\hline $\mathrm{Al}$ & Al-27 & 13027 & $1.66776 \mathrm{E}-02$ & $\mathrm{Cu}$ & $\mathrm{Cu} 65$ & 29065 & 5.75577E-06 \\
\hline $\mathrm{Si}$ & $\mathrm{Si}-28$ & 14028 & $3.55890 \mathrm{E}-03$ & $\mathrm{Zn}$ & $\mathrm{Zn}$ & 30000 & $8.29885 \mathrm{E}-07$ \\
\hline $\mathrm{Si}$ & $\mathrm{Si}-29$ & 14029 & $1.80795 \mathrm{E}-04$ & Mo & Mo92 & 42092 & $1.45602 \mathrm{E}-04$ \\
\hline $\mathrm{Si}$ & $\mathrm{Si}-30$ & 14030 & $1.19321 \mathrm{E}-04$ & Mo & Mo94 & 42094 & $9.09886 \mathrm{E}-05$ \\
\hline $\mathrm{Ti}$ & Ti-46 & 22046 & $1.10108 \mathrm{E}-04$ & Mo & Mo95 & 42095 & $1.56741 \mathrm{E}-04$ \\
\hline $\mathrm{Ti}$ & Ti-47 & 22047 & 9.92971E-05 & Mo & Mo96 & 42096 & $1.64430 \mathrm{E}-04$ \\
\hline $\mathrm{Ti}$ & Ti-48 & 22048 & $9.83895 \mathrm{E}-04$ & Mo & Mo97 & 42097 & $9.42418 \mathrm{E}-05$ \\
\hline $\mathrm{Ti}$ & Ti-49 & 22049 & $7.22039 \mathrm{E}-05$ & Mo & Mo98 & 42098 & 2.38463E-04 \\
\hline $\mathrm{Ti}$ & Ti-50 & 22050 & $6.91342 \mathrm{E}-05$ & Mo & Mo100 & 42100 & $9.53261 \mathrm{E}-05$ \\
\hline V & V & 23000 & 1.42234E-02 & $\mathrm{Gd}$ & Gd152 & 64152 & 3.52067E-11 \\
\hline $\mathrm{Cr}$ & $\mathrm{Cr} 50$ & 24050 & $2.92609 \mathrm{E}-05$ & $\mathrm{Gd}$ & Gd154 & 64154 & $3.83753 \mathrm{E}-10$ \\
\hline $\mathrm{Cr}$ & Cr52 & 24052 & $5.64268 \mathrm{E}-04$ & $\mathrm{Gd}$ & Gd155 & 64155 & $2.60530 \mathrm{E}-09$ \\
\hline $\mathrm{Cr}$ & $\mathrm{Cr} 53$ & 24053 & $6.39834 \mathrm{E}-05$ & Gd & Gd156 & 64156 & $3.60341 \mathrm{E}-09$ \\
\hline $\mathrm{Cr}$ & $\mathrm{Cr} 54$ & 24054 & $1.59268 \mathrm{E}-05$ & $\mathrm{Gd}$ & Gd157 & 64157 & 2.75493E-09 \\
\hline Mn & Mn55 & 25055 & $2.36346 \mathrm{E}-06$ & $\mathrm{Gd}$ & Gd158 & 64158 & 4.37267E-09 \\
\hline $\mathrm{Fe}$ & $\mathrm{Fe} 54$ & 26054 & 4.79022E-06 & Gd & Gd160 & 64160 & 3.84809E-09 \\
\hline $\mathrm{Fe}$ & Fe56 & 26056 & $7.51961 \mathrm{E}-05$ & $\mathrm{Ta}$ & Тa-181 & 73181 & 3.19949E-09 \\
\hline $\mathrm{Fe}$ & $\mathrm{Fe} 57$ & 26057 & $1.73661 \mathrm{E}-06$ & $\mathrm{~W}$ & W182 & 74182 & $1.76186 \mathrm{E}-08$ \\
\hline $\mathrm{Fe}$ & $\mathrm{Fe} 58$ & 26058 & $2.31110 \mathrm{E}-07$ & $\mathrm{~W}$ & W183 & 74183 & 9.51403E-09 \\
\hline $\mathrm{Ni}$ & Ni58 & 28058 & $3.00074 \mathrm{E}-06$ & $\mathrm{~W}$ & W184 & 74184 & $2.03711 \mathrm{E}-08$ \\
\hline $\mathrm{Ni}$ & Ni60 & 28060 & $1.15588 \mathrm{E}-06$ & $\mathrm{~W}$ & W186 & 74186 & $1.89017 \mathrm{E}-08$ \\
\hline $\mathrm{Ni}$ & Ni61 & 28061 & $5.02453 \mathrm{E}-08$ & total & & & $5.90612 \mathrm{E}-02$ \\
\hline
\end{tabular}


Table 16. Number density data for Fe peripheral target position irradiation capsule

\begin{tabular}{|c|c|c|c|c|c|c|c|}
\hline Element & Isotope & $\begin{array}{l}\text { Isotope } \\
\text { identifier }\end{array}$ & $\begin{array}{c}\text { Number } \\
\text { density } \\
\text { (at/b-cm) }\end{array}$ & Element & Isotope & $\begin{array}{l}\text { Isotope } \\
\text { identifier }\end{array}$ & $\begin{array}{c}\text { Number } \\
\text { density } \\
\text { (at/b-cm) }\end{array}$ \\
\hline $\mathrm{C}$ & $\mathrm{C}$ & 6000 & $5.20934 \mathrm{E}-04$ & $\mathrm{Ni}$ & $\mathrm{Ni} 58$ & 28058 & $1.42414 \mathrm{E}-04$ \\
\hline $\mathrm{Mg}$ & $\mathrm{Mg}-24$ & 12024 & $2.61156 \mathrm{E}-04$ & $\mathrm{Ni}$ & Ni60 & 28060 & 5.48577E-05 \\
\hline $\mathrm{Mg}$ & $\mathrm{Mg}-25$ & 12025 & $3.30620 \mathrm{E}-05$ & $\mathrm{Ni}$ & Ni61 & 28061 & 2.38463E-06 \\
\hline $\mathrm{Mg}$ & $\mathrm{Mg}-26$ & 12026 & $3.64012 \mathrm{E}-05$ & $\mathrm{Ni}$ & $\mathrm{Ni62}$ & 28062 & 7.60324E-06 \\
\hline $\mathrm{Al}$ & $\mathrm{Al}-27$ & 13027 & $3.15701 \mathrm{E}-02$ & $\mathrm{Ni}$ & Ni64 & 28064 & 1.93632E-06 \\
\hline $\mathrm{Si}$ & $\mathrm{Si}-28$ & 14028 & $7.28540 \mathrm{E}-04$ & Co & Co59 & 27059 & 3.72053E-06 \\
\hline $\mathrm{Si}$ & $\mathrm{Si}-29$ & 14029 & 3.70104E-05 & $\mathrm{Cu}$ & $\mathrm{Cu} 63$ & 29063 & 7.34737E-05 \\
\hline $\mathrm{Si}$ & $\mathrm{Si}-30$ & 14030 & 2.44261E-05 & $\mathrm{Cu}$ & $\mathrm{Cu} 65$ & 29065 & $3.27789 \mathrm{E}-05$ \\
\hline $\mathrm{Ti}$ & Ti-46 & 22046 & $3.41535 \mathrm{E}-05$ & $\mathrm{Zn}$ & $\mathrm{Zn}$ & 30000 & 1.05234E-06 \\
\hline $\mathrm{Ti}$ & Ti-47 & 22047 & $3.08002 \mathrm{E}-05$ & Mo & Mo92 & 42092 & $5.36272 \mathrm{E}-05$ \\
\hline $\mathrm{Ti}$ & $\mathrm{Ti}-48$ & 22048 & $3.05187 \mathrm{E}-04$ & Mo & Mo94 & 42094 & 3.35125E-05 \\
\hline $\mathrm{Ti}$ & Ti-49 & 22049 & $2.23964 \mathrm{E}-05$ & Mo & Mo95 & 42095 & $5.77300 \mathrm{E}-05$ \\
\hline $\mathrm{Ti}$ & Ti-50 & 22050 & $2.14443 \mathrm{E}-05$ & Mo & Mo96 & 42096 & $6.05621 \mathrm{E}-05$ \\
\hline V & V & 23000 & $3.98854 \mathrm{E}-03$ & Mo & Mo97 & 42097 & $3.47106 \mathrm{E}-05$ \\
\hline $\mathrm{Cr}$ & $\mathrm{Cr} 50$ & 24050 & $6.53595 \mathrm{E}-05$ & Mo & Mo98 & 42098 & 8.78295E-05 \\
\hline $\mathrm{Cr}$ & $\mathrm{Cr} 52$ & 24052 & $1.26039 \mathrm{E}-03$ & Mo & Mo100 & 42100 & $3.51100 \mathrm{E}-05$ \\
\hline $\mathrm{Cr}$ & $\mathrm{Cr} 53$ & 24053 & $1.42918 \mathrm{E}-04$ & $\mathrm{Ta}$ & Ta-181 & 73181 & 7.36180E-05 \\
\hline $\mathrm{Cr}$ & $\mathrm{Cr} 54$ & 24054 & $3.55754 \mathrm{E}-05$ & $\mathrm{~W}$ & W182 & 74182 & $1.05065 \mathrm{E}-04$ \\
\hline Mn & Mn55 & 25055 & $4.26671 \mathrm{E}-05$ & $\mathrm{~W}$ & W183 & 74183 & 5.67352E-05 \\
\hline $\mathrm{Fe}$ & $\mathrm{Fe} 54$ & 26054 & $5.15470 \mathrm{E}-04$ & $\mathrm{~W}$ & W184 & 74184 & $1.21479 \mathrm{E}-04$ \\
\hline $\mathrm{Fe}$ & $\mathrm{Fe} 56$ & 26056 & 8.09178E-03 & $\mathrm{W}$ & W186 & 74186 & $1.12717 \mathrm{E}-04$ \\
\hline $\mathrm{Fe}$ & $\mathrm{Fe} 57$ & 26057 & $1.86875 \mathrm{E}-04$ & & & & \\
\hline $\mathrm{Fe}$ & $\mathrm{Fe} 58$ & 26058 & $2.48696 \mathrm{E}-05$ & total & & & 4.91330E-02 \\
\hline
\end{tabular}




\section{MODELING OF THE BERYLLIUM REFLECTOR EXPERIMENTS}

In recent past years, the RB and SPB experiment facilities have largely been occupied by dummy $\mathrm{Al}$ or Be plugs. Occasionally, shielded or unshielded materials irradiations are performed in a large RB facility. However, since lately, these locations have been loaded with dummy plugs more often than experiments. Therefore, it was previously decided to model Be plugs loaded in all of the RBs (large and small). In the new representative model presented in this report, all RB and VXF experiment locations that do not include irradiation experiments are modeled as containing Be plugs. Because RRD has recently purchased a large beryllium billet and has begun to fabricate reflectors and plugs out of it, it is anticipated that the beryllium plug inventory will be restored and unused RB and VXF positions will be loaded with them. Currently, unused RBs contain dummy Be plugs (an Al plug or two are often used), unused large VXFs contain beryllium plugs, and the unused small VXFs contain stainless steel liners/orifices and water.

All of the small RB facilities are modeled with dummy Be plugs and the large RB facilities are modeled with Be plugs in aluminum liners. Thus, the $\mathrm{Eu}_{2} \mathrm{O}_{3}$ lined experiment and the three $\mathrm{Al}$ plugs present in the large RBs within the Cycle 400 model are replaced with Be plugs. These changes alone are expected to increase the cycle length, with respect to the Cycle 400 model, by $\sim 1.5-2$ days. The modeling of the CRAP facilities remains unchanged from that in the Cycle 400 model.

As part of the US DOE's task to reestablish the domestic production of ${ }^{238} \mathrm{Pu}$, a technology demonstration sub-project has been initiated $[7,14] .{ }^{238} \mathrm{Pu}$ production will become a key mission at HFIR, and this mission expansion will need to be assessed for the LEU core. Based on discussions within the NS\&EA Group and near future mission needs expected to be about 500 grams ${ }^{238} \mathrm{Pu}$ per year, it was decided to model 11 of the VXFs with fully loaded ${ }^{238} \mathrm{Pu}$ production targets: five ISVXFs, three OSVXFs, and three LVXFs. All other VXFs, except for VXF-7, which contains a PT facility for NAA, are modeled with dummy beryllium plugs. The production rate is expected to increase to about one kilogram per year in 2023.

The fully loaded ${ }^{238} \mathrm{Pu}$ production target assemblies contain a stack of $52 \mathrm{NpO}_{2} / \mathrm{Al}$ cermet pellets. These pellets are positioned within a finned, thin-walled Al-6061 housing tube such that the midplane of the pellet stack is located on the core horizontal midplane. The cermet pellets are nominally 20 vol.\% $\mathrm{NpO}_{2}, 70$ vol.\% Al-1100, and 10 vol.\% void. Each of the 52 pellets has an OD of 0.2500 in (OR = $0.3175 \mathrm{~cm})$ and a length of 0.3780 in $(0.9601 \mathrm{~cm})$. Thus, the pellet stack has a length of $19.6560 \mathrm{in}$ $(49.9262 \mathrm{~cm})$ and a volume of $0.9649 \mathrm{in}^{3}\left(15.8112 \mathrm{~cm}^{3}\right)$. Aluminum-6061 dummy pellets and stainless steel expansion sleeves with roll pins are located above and below the stack of pellets.

A seven-hole target holder assembly that is an Al-6061 tube with an OD of 1.5500 in $(3.9370 \mathrm{~cm})$ is loaded into one of the small VXFs. One target hole is centrally located within the target holder assembly and the other six target holes are positioned on a bolt circle of 0.9640 in diameter $(r=1.2243 \mathrm{~cm})$. A large VXF fully loaded target holder drawing has not been developed yet, but the large VXFs will likely be loaded with 19 fully loaded targets. The locations of the 19 vertical positions within the holder and the OD of the holder were assumed to be the same as they were modeled in [14]. In the 19-hole holder, one target hole is centrally located, six target holes are located on a bolt circle with 1.1000 in diameter $(\mathrm{r}=$ $1.3970 \mathrm{~cm})$, and 12 target holes are located on a bolt circle with 2.2000 in diameter $(\mathrm{r}=2.7940 \mathrm{~cm})$. The OD of the vertical experiment target holes in both holders is 0.4180 in $(r=0.5309 \mathrm{~cm})$. An $x-y$ crosssection of the fully loaded targets in VXFs 12, 13, and 14 and an $\mathrm{x}-\mathrm{z}$ cross-section of a fully loaded target are illustrated in Figure 10.

For depletion purposes, one $\mathrm{NpO}_{2} / \mathrm{Al}$ material is modeled per VXF type (inner small, outer small, and large). More $\mathrm{NpO}_{2} / \mathrm{Al}$ depletion materials can be defined per VXF or per target pin if the analyst needs to assess spatially dependent production rates. Inner small VXFs 3, 5, 13, 15, and 20 each contain seven fully loaded targets. Outer small VXFs 2, 4, and 12 each contain seven fully loaded targets. Large VXFs 6,14 , and 19 each contain 19 fully loaded targets. These VXFs were selected because they are not adjacent to the HB tubes; thus, the irradiation of targets in these VXFs will have little-to-no impact on the neutron fluxes at the neutron scattering instruments. An illustration of the as-modeled core and experiments including the ${ }^{238} \mathrm{Pu}$ targets is provided in Figure 11. It almost appears that six inner small VXFs are loaded with fully loaded ${ }^{238} \mathrm{Pu}$ production targets in this figure; however, VXF-7 (see Figure 1 
for location) contains a PT facility consisting of piping that is used to insert and remove samples for neutron activation analysis activities. The MCNP model does not use universes for individual target pins to allow the ability, if detailed analyses are needed in the future, of modeling each stack of pellets within each VXF type as a unique material. The number densities for the $\mathrm{NpO}_{2} / \mathrm{Al}$ materials are listed in Table 17. The material compositions from $[14,15]$, for the fresh, unirradiated $\mathrm{NpO}_{2} / \mathrm{Al}$ pellets, are used.
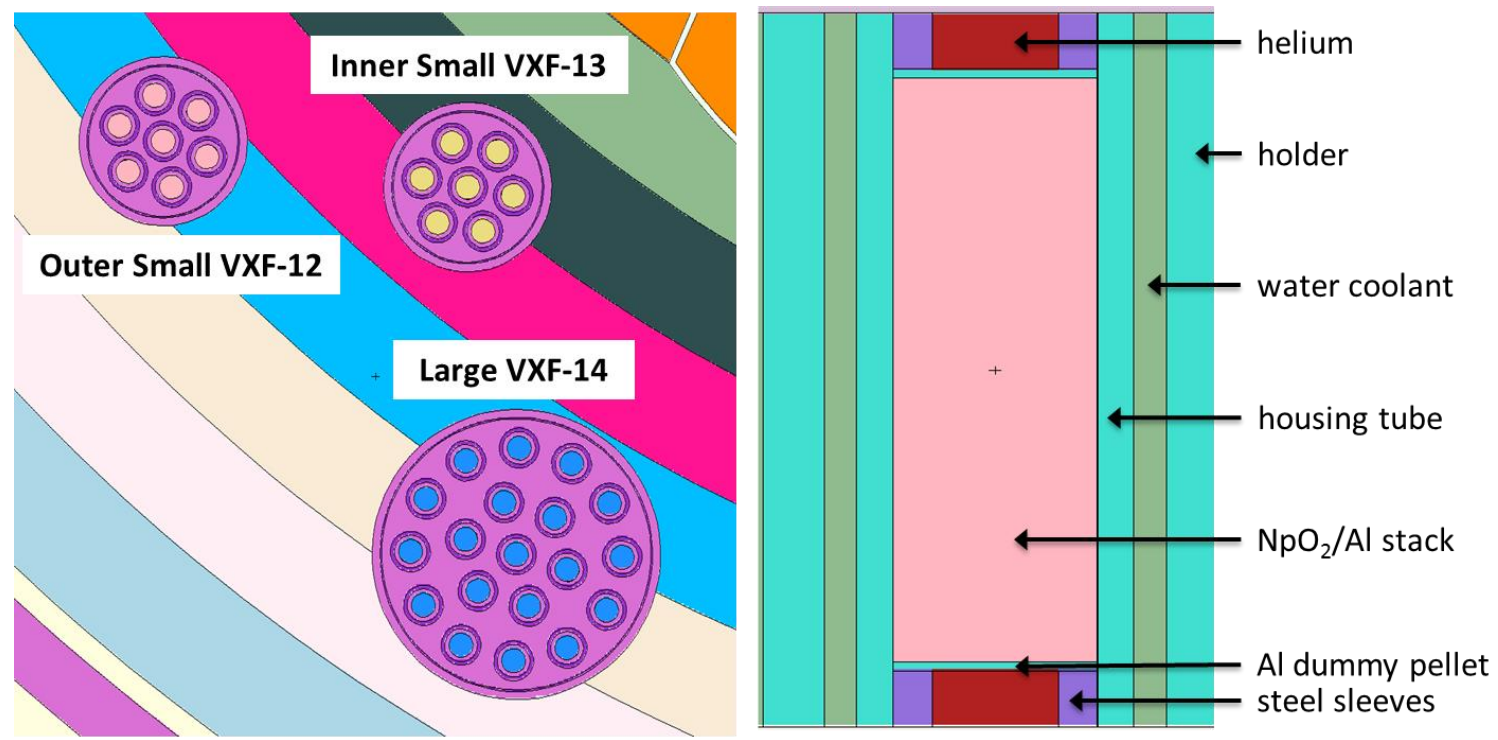

Figure 10. Illustration of fully loaded plutonium-238 production targets in vertical experiment facilities.

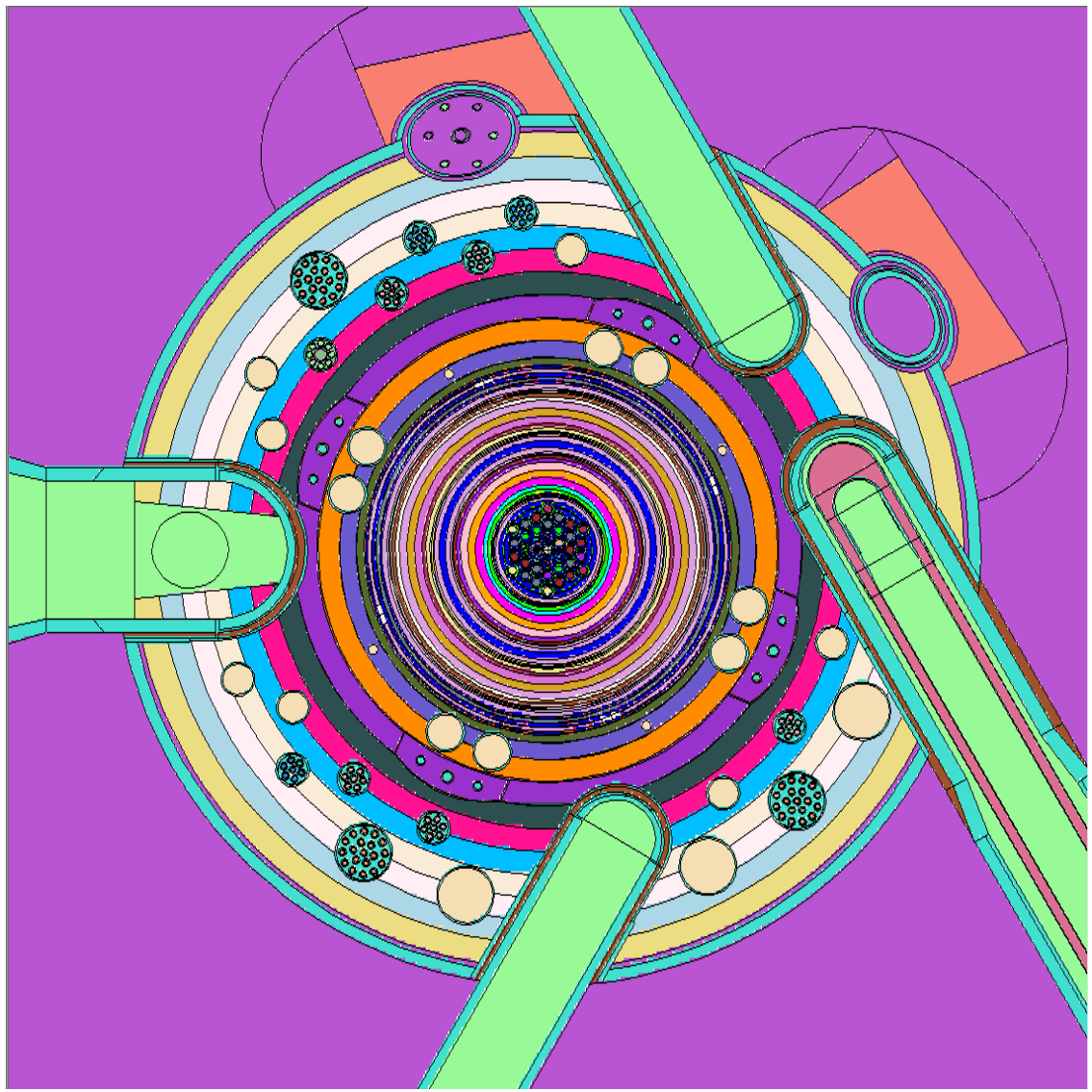

Figure 11. Cross-section of the as-modeled representative core configuration at the horizontal midplane. 
Table 17. Number density data for $\mathrm{NpO}_{2} / \mathrm{Al}$ targets

\begin{tabular}{cccccccc}
\hline Element & Isotope & $\begin{array}{c}\text { Isotope } \\
\text { identifier }\end{array}$ & $\begin{array}{c}\text { Number } \\
\text { density } \\
\text { (at/b-cm) }\end{array}$ & Element & Isotope & $\begin{array}{c}\text { Isotope } \\
\text { identifier }\end{array}$ & $\begin{array}{c}\text { Number } \\
\text { density } \\
\text { (at/b-cm) }\end{array}$ \\
\hline $\mathrm{O}$ & $\mathrm{O}-16$ & 8016 & $9.976654 \mathrm{E}-03$ & $\mathrm{Fe}$ & $\mathrm{Fe}-58$ & 26058 & $1.151283 \mathrm{E}-07$ \\
$\mathrm{Mg}$ & $\mathrm{Mg}-24$ & 12024 & $3.403118 \mathrm{E}-07$ & $\mathrm{Ni}$ & $\mathrm{Ni}-58$ & 28058 & $8.052963 \mathrm{E}-07$ \\
$\mathrm{Mg}$ & $\mathrm{Mg}-25$ & 12025 & $4.308245 \mathrm{E}-08$ & $\mathrm{Ni}$ & $\mathrm{Ni}-60$ & 28060 & $3.101974 \mathrm{E}-07$ \\
$\mathrm{Mg}$ & $\mathrm{Mg}-26$ & 12026 & $4.743451 \mathrm{E}-08$ & $\mathrm{Ni}$ & $\mathrm{Ni}-61$ & 28061 & $1.347995 \mathrm{E}-08$ \\
$\mathrm{Al}$ & $\mathrm{Al}-27$ & 13027 & $4.204504 \mathrm{E}-02$ & $\mathrm{Ni}$ & $\mathrm{Ni}-62$ & 28062 & $4.299501 \mathrm{E}-08$ \\
$\mathrm{Si}$ & $\mathrm{Si}-28$ & 14028 & $4.111125 \mathrm{E}-05$ & $\mathrm{Ni}$ & $\mathrm{Ni}-64$ & 28064 & $1.094743 \mathrm{E}-08$ \\
$\mathrm{Si}$ & $\mathrm{Si}-29$ & 14029 & $2.088652 \mathrm{E}-06$ & $\mathrm{Cu}$ & $\mathrm{Cu}-63$ & 29063 & $4.954219 \mathrm{E}-07$ \\
$\mathrm{Si}$ & $\mathrm{Si}-30$ & 14030 & $1.378407 \mathrm{E}-06$ & $\mathrm{Cu}$ & $\mathrm{Cu}-64$ & 29065 & $2.210253 \mathrm{E}-07$ \\
$\mathrm{Ti}$ & $\mathrm{Ti}-46$ & 22046 & $9.612225 \mathrm{E}-08$ & $\mathrm{Th}$ & $\mathrm{Th}-230$ & 90230 & $1.516932 \mathrm{E}-08$ \\
$\mathrm{Ti}$ & $\mathrm{Ti}-47$ & 22047 & $8.668829 \mathrm{E}-08$ & $\mathrm{Th}$ & $\mathrm{Th}-232$ & 90232 & $1.561664 \mathrm{E}-05$ \\
$\mathrm{Ti}$ & $\mathrm{Ti}-48$ & 22048 & $8.589333 \mathrm{E}-07$ & $\mathrm{U}$ & $\mathrm{U}-233$ & 92233 & $3.282677 \mathrm{E}-09$ \\
$\mathrm{Ti}$ & $\mathrm{Ti}-49$ & 22049 & $6.303140 \mathrm{E}-08$ & $\mathrm{U}$ & $\mathrm{U}-234$ & 92234 & $2.340226 \mathrm{E}-13$ \\
$\mathrm{Ti}$ & $\mathrm{Ti}-50$ & 22050 & $6.035514 \mathrm{E}-08$ & $\mathrm{U}$ & $\mathrm{U}-235$ & 92235 & $3.127797 \mathrm{E}-11$ \\
$\mathrm{Cr}$ & $\mathrm{Cr}-50$ & 24050 & $8.941129 \mathrm{E}-09$ & $\mathrm{U}$ & $\mathrm{U}-238$ & 92238 & $4.310031 \mathrm{E}-09$ \\
$\mathrm{Cr}$ & $\mathrm{Cr}-52$ & 24052 & $1.724069 \mathrm{E}-07$ & $\mathrm{~Np}$ & $\mathrm{~Np}-237$ & 93237 & $4.988327 \mathrm{E}-03$ \\
$\mathrm{Cr}$ & $\mathrm{Cr}-53$ & 24053 & $1.955046 \mathrm{E}-08$ & $\mathrm{Pu}$ & $\mathrm{Pu}-238$ & 94238 & $2.036611 \mathrm{E}-07$ \\
$\mathrm{Cr}$ & $\mathrm{Cr}-54$ & 24054 & $4.865596 \mathrm{E}-09$ & $\mathrm{Pu}$ & $\mathrm{Pu}-239$ & 94239 & $6.727254 \mathrm{E}-08$ \\
$\mathrm{Mn}$ & $\mathrm{Mn}-55$ & 25055 & $4.765044 \mathrm{E}-07$ & $\mathrm{Pu}$ & $\mathrm{Pu}-240$ & 94240 & $8.866567 \mathrm{E}-09$ \\
$\mathrm{Fe}$ & $\mathrm{Fe}-54$ & 26054 & $2.382736 \mathrm{E}-06$ & $\mathrm{Pu}$ & $\mathrm{Pu}-242$ & 94242 & $5.862084 \mathrm{E}-09$ \\
$\mathrm{Fe}$ & $\mathrm{Fe}-56$ & 26056 & $3.740114 \mathrm{E}-05$ & & & & \\
$\mathrm{Fe}$ & $\mathrm{Fe}-57$ & 26057 & $8.636030 \mathrm{E}-07$ & total & & & $5.711547 \mathrm{E}-02$ \\
\hline & & & & & & &
\end{tabular}




\section{CONTROL ELEMENT MATERIAL COMPOSITION}

The material compositions of the control elements are changed from those used in the Cycle 400 model [4] to reflect fresh, un-irradiated, reduced-tantalum loading control elements. A few changes have been made to the previous control element design to improve their performance and in-core lifetime. With the exception of removing one set of pressure-equalization flow holes from the gray region of the control plates, the geometry model remains unmodified. The set of holes removed from the control plate is the set closest to the black region. This set of holes was removed to reduce the possibility of water coolant entering the black region and reacting with the $\mathrm{Eu}_{2} \mathrm{O}_{3}$ material, which can cause blistering of the cladding. Because the small-volume flow holes are modeled by homogenizing the water coolant with the tantalum-aluminum core region, no geometry changes are made to the Cycle 400 as-modeled control elements.

At the time this representative model was being developed and these calculations were being performed, the control cylinder (inner control element) in service (Cylinder No. 14 per [16]) was a reduced-tantalum cylinder whose gray region is $30 \mathrm{vol} \%$ tantalum in aluminum and the safety plates in service (Plates 16-1, 16-3, 16-4, and 10-2 per [16]) contain gray regions with 38 vol.\% tantalum in aluminum. Based on the available operating data and a Cycle 461 burnup of $2094.24 \mathrm{MWd}$, the end-ofcycle 461 (August 2015) exposures of plates 16-1, 16-3, 16-4, and 10-2 are 95,279.11, 97,656.11, 67,783.22, and 92,563.51 MWd, respectively. Another set of 38 vol.\% plates (17-1, 17-2, 17-3, and 17-4) located in HFIR's storage pool has an exposure of 82,698.06 MWd [16]. With a maximum lifetime of $100,000 \mathrm{MWd}$, all eight of these plates are nearing the end of their in-service lifetimes. The first set of reduced-tantalum safety plates was installed prior to the startup of Cycle 466 (June 2016). Thus, at the time this report is being written, the cylinder and safety plates in service contain reduced-tantalum gray regions.

The latest revision of the Control Plates and Cylinders specification [17] states that the tantalum loading will be reduced from $\sim 38$ vol. $\%$ to $\sim 30$ vol. $\%$ relative to previous plate-fabrication campaigns. Thus, the current control element design has gray regions that are composed of $30 \mathrm{vol} . \%$ tantalum in aluminum; whereas, the older style design uses 38 vol.\% tantalum in aluminum. All plates and cylinders fabricated to current specifications will contain reduced-tantalum gray regions. A reduction of tantalum mass in the gray regions is expected to help alleviate degradation by ensuring that the tantalum remains as a discrete powder in the $\mathrm{Ta} / \mathrm{Al}$ mixture and not forming a continuous metal pathway to the black region [18]. In addition, reducing the tantalum content will decrease the heat generation and temperatures in the gray regions during irradiation and following shutdown (i.e., decay heat); thus, helping to further mitigate degradation.

The total mass of tantalum and aluminum in one plate's gray region fabricated to the previous design (38 vol.\%) is 1297.00 and 312.03 grams, respectively [18]. For the current (30 vol.\%) design, the total tantalum and aluminum masses in one plate's gray region are 1016.00 and 355.59 grams, respectively, [17] prior to drilling the four rows of 13 pressure equalization holes $(0.25$ in OD) through them. One row of holes is located on the gray-white region interface. Thus, there are effectively $3.5 \times 13=45.5$ holes $(\sim$ $6.86 \mathrm{~cm}^{3}$ per control plate gray region) drilled through the gray region of each plate, which removes $\sim 3-$ $4 \%$ of the total Ta mass:

as-modeled inner control element plate gray region volume $=196.90 \mathrm{~cm}^{3}$

$$
100 \times(6.86 / 196.90)=3.48 \mathrm{vol} . \%
$$

as-modeled outer control element plate gray region volume $=206.20 \mathrm{~cm}^{3}$

$$
100 \times(6.86 / 206.20)=3.33 \text { vol. } \%
$$

Water passing through the pressure equalization holes penetrating the gray region, with the in-core water atomic density of $9.87816 \times 10^{-2}$ at/b-cm, is modeled by homogenizing it with the ${ }^{181} \mathrm{Ta}$ and ${ }^{27} \mathrm{Al}$ isotopes. As shown in the material compositions listed on the following page (Table 18 and Table 19), material 4005 (inner control element) and material 4111 (outer control element) contain no water because they compose the axial regions closest to the black regions, where no pressure equalization holes are drilled.

The europium and aluminum masses in the $\mathrm{Eu}_{2} \mathrm{O}_{3}-\mathrm{Al}$ black regions are also slightly changed from the previous design to the current design. The previous design called for 1922.00 and 1539.00 grams of 
europium and aluminum, respectively, in one plate's black region, whereas the current design specifies 1915.00 and 1535.22 grams, respectively $[17,18]$.

The gray and black regions of each of the two control elements are axially subdivided in the MCNP model into five equal height (and volume) zones [4]. A unique material is defined for each of the 10 gray region zones ( 2 control elements $\times 5$ gray region zones/control element) and for each of the 10 black region zones. The volumes of these regions, as provided in [4], a MATLAB script using NIST isotopic data [10], and the previously discussed data were used to generate the material compositions of the gray and black regions. The MCNP material compositions for the control element gray and black regions are provided in Table 18 - Table 21.

Table 18. Material composition data for reduced-tantalum inner control element gray material zones

\begin{tabular}{|c|c|c|c|c|}
\hline Isotope & $\begin{array}{c}\text { Isotope } \\
\text { identifier }\end{array}$ & $\begin{array}{c}\mathrm{m} 4001, \mathrm{~m} 4002, \text { and } \mathrm{m} 4003 \\
(\mathrm{at} / \mathrm{b}-\mathrm{cm})\end{array}$ & $\begin{array}{c}\mathrm{m} 4004 \\
(\mathrm{at} / \mathrm{b}-\mathrm{cm})\end{array}$ & $\begin{array}{c}\mathrm{m} 4005 \\
(\mathrm{at} / \mathrm{b}-\mathrm{cm})\end{array}$ \\
\hline $\mathrm{H}-1$ & 1001 & $3.27885 \mathrm{E}-03$ & $1.63942 \mathrm{E}-03$ & - \\
\hline O-16 & 8016 & $1.63942 \mathrm{E}-03$ & $8.19711 \mathrm{E}-04$ & - \\
\hline $\mathrm{Al}-27$ & 13027 & 3.83005E-02 & 3.93039E-02 & 4.03073E-02 \\
\hline \multirow[t]{2}{*}{ Ta-181 } & 73181 & $1.63178 \mathrm{E}-02$ & $1.67453 \mathrm{E}-02$ & 1.71728E-02 \\
\hline & Total & 5.95365E-02 & $5.85083 \mathrm{E}-02$ & 5.74801E-02 \\
\hline
\end{tabular}

Table 19. Material composition data for reduced-tantalum outer control element gray material zones

\begin{tabular}{ccccc}
\hline Isotope & $\begin{array}{c}\text { Isotope } \\
\text { identifier }\end{array}$ & $\begin{array}{c}\mathbf{m 4 1 1 1} \\
(\mathbf{a t} / \mathbf{b}-\mathbf{c m})\end{array}$ & $\begin{array}{c}\mathbf{m 4 1 1 2} \\
(\mathbf{a t} / \mathbf{b}-\mathbf{c m})\end{array}$ & $\begin{array}{c}\mathbf{m 4 1 1 3}, \mathbf{m 4 1 1 4}, \text { and } \mathbf{m 4 1 1 5} \\
(\mathbf{a t} / \mathbf{b}-\mathbf{c m})\end{array}$ \\
\hline $\mathrm{H}-1$ & 1001 & - & $1.56665 \mathrm{E}-03$ & $3.13330 \mathrm{E}-03$ \\
$\mathrm{O}-16$ & 8016 & - & $7.83326 \mathrm{E}-04$ & $1.56665 \mathrm{E}-03$ \\
$\mathrm{Al}-27$ & 13027 & $3.85182 \mathrm{E}-02$ & $3.76018 \mathrm{E}-02$ & $3.66855 \mathrm{E}-02$ \\
Ta-181 & 73181 & $1.64105 \mathrm{E}-02$ & $1.60201 \mathrm{E}-02$ & $1.56297 \mathrm{E}-02$ \\
& Total & $5.49287 \mathrm{E}-02$ & $5.59720 \mathrm{E}-02$ & $5.70152 \mathrm{E}-02$ \\
\hline
\end{tabular}

Table 20. Material composition data for reduced-tantalum inner control element black material zones

\begin{tabular}{ccc}
\hline Isotope & $\begin{array}{c}\text { Isotope } \\
\text { identifier }\end{array}$ & $\begin{array}{c}\mathbf{m 4 0 1 1}, \mathbf{m 4 0 1 2}, \mathbf{~ m 4 0 1 3}, \mathbf{~ m 4 0 1 4}, \text { and } \mathbf{m 4 0 1 5} \\
(\mathbf{a t} / \mathbf{b}-\mathbf{c m})\end{array}$ \\
\hline $\mathrm{O}-16$ & 8016 & $1.31392 \mathrm{E}-02$ \\
$\mathrm{Al}-27$ & 13027 & $3.95505 \mathrm{E}-02$ \\
$\mathrm{Eu}-151$ & 63151 & $4.18789 \mathrm{E}-03$ \\
$\mathrm{Eu}-153$ & 63153 & $4.57156 \mathrm{E}-03$ \\
& Total & $6.14492 \mathrm{E}-02$ \\
\hline
\end{tabular}


Table 21. Material composition data for reduced-tantalum outer control element black material zones

\begin{tabular}{|c|c|c|}
\hline Isotope & $\begin{array}{c}\text { Isotope } \\
\text { identifier }\end{array}$ & $\begin{array}{c}\mathrm{m} 4101, \mathrm{~m} 4102, \mathrm{~m} 4103, \mathrm{~m} 4104, \text { and } \mathrm{m} 4105 \\
(\mathrm{at} / \mathrm{b}-\mathrm{cm})\end{array}$ \\
\hline O-16 & 8016 & $1.25560 \mathrm{E}-02$ \\
\hline Al-27 & 13027 & $3.77950 \mathrm{E}-02$ \\
\hline Eu-151 & 63151 & $4.00200 \mathrm{E}-03$ \\
\hline \multirow[t]{2}{*}{ Eu-153 } & 63153 & $4.36863 \mathrm{E}-03$ \\
\hline & Total & $5.87216 \mathrm{E}-02$ \\
\hline
\end{tabular}




\section{HIGH-FIDELITY FUEL ELEMENT SIDE PLATE MODELING}

The previous HFIR MCNP model [4] approximates the fuel element side plates as smooth cylinders of Al-6061 material with a height of $60.96 \mathrm{~cm}$ (24 in). Realistically, this smooth cylinder contains fuel plate slots, which are filled by the fuel clad Al-6061 material, and weld grooves, which are filled with $\mathrm{Al}$ weld metal. Furthermore, the side plates have upper and lower extensions used to attach adapters. The previous model [4] side plate geometry is an adequate approximation for the HEU model because the fuel plate clad, weld metal, adapters, and side plates are all aluminum. But, the currently proposed HFIR LEU design $[1,6]$ uses borated IFE side plates. For consistency purposes, a high-fidelity side plate model describing the exact geometry of the side plates by including the weld grooves, fuel plate slots, and upper and lower extensions is developed for the HEU and LEU explicit representative models. These geometry updates are not applied to the simplified [4] HEU model.

\subsection{MODELING OF THE WELD GROOVES}

The inner and outer side plates of the IFE and OFE have 24 weld groove channels used for securing the fuel plates to the side plates, as illustrated in Figure 12. Weld grooves are machined along the circumference of the cylinder on the opposite side of the fuel plate slots. Weld metal is deposited in the grooves to join the fuel plates to the side plates. They are centered at regularly spaced locations (1.011 in center-to-center) from the top of the unmachined side plate (see Table 22). They are cut into the side plate at a $30^{\circ}$ angle (with respect to the vector normal to the surface of the side plate). Each weld groove is cut to a depth beyond that of the fuel plate slots to ensure access to the fuel plates through the weld groove. At full depth, the height (measurement along the axis of the cylinder) of each weld groove is $0.254 \mathrm{~cm}(0.1 \mathrm{in})$. The height of the weld groove at the surface of the side plate is larger (approximately $0.5-0.8 \mathrm{~cm}$ depending on the side plate) because of the angle and depth of the cut.

Because it is difficult to model angled weld grooves (it would require the use of conical shapes), weld grooves are modeled as flat (washer-like) grooves with a depth of the fuel plate slot radius (the fuel plate will occupy most of the volume up to the fuel plate slot radius). The fuel plate slot radii for the IFE inner, IFE outer, OFE inner, and OFE outer side plates are $6.58368 \mathrm{~cm}$ (2.592 in), $13.17625 \mathrm{~cm}$ (5.1875 in), $14.5936 \mathrm{~cm}$ (5.7455 in), and $21.4465 \mathrm{~cm}$ (8.4435 in), respectively. Because there are only 24 weld grooves and these welds are machined after fuel plate attachment, the volume of the approximate smooth cylinder occupied by weld metal is only a few percent of the total side plate volume.

Based on the nominal side plate dimensions, fuel plate slot radii, groove dimensions, and a $30^{\circ}$ entrance angle (with respect to the vector normal to the surface of the side plate), the average groove heights through the side plates are estimated to be $\sim 0.338,0.404,0.442,0.439$, and 0.406 for the IFE inner side plate, IFE outer side plate, OFE inner side plate, OFE outer side plate, and the average of the four side plates, respectively. The volume of the weld grooves is roughly conserved by modeling the height of each groove as $0.4 \mathrm{~cm}$. When considering a proposed LEU fuel assembly with neutron poisons in the IFE side plates, the use of a $0.4 \mathrm{~cm}$ height is slightly conservative for the inner side plate and consistent with the outer side plate. This conservative approach increases the size of the window ("square" window vs. "angled" window) of weld metal (Al) through which neutrons may stream freely (in the case with borated side plates). The three wall assurance grooves are not modeled, as they are less than $1 \mathrm{~mm}$ deep. An illustration of the as-modeled weld grooves in the upper region of the IFE is provided in Figure 13. 


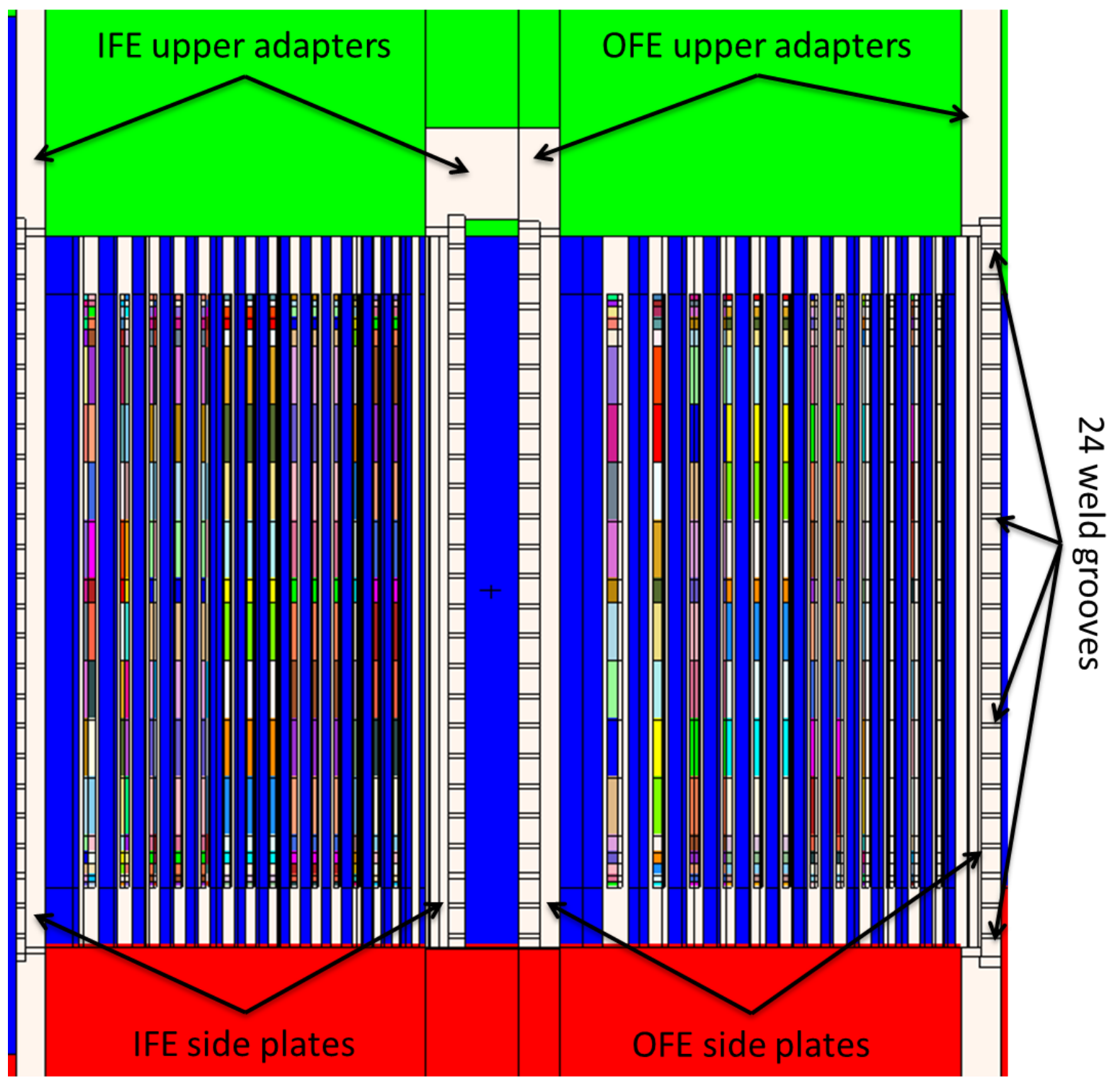

Figure 12. An r-z cross-section of the fuel element assembly as-modeled geometry. 
Table 22. Axial dimensions for the weld grooves

\begin{tabular}{crrrrr}
\hline No. & \multicolumn{2}{c}{$\begin{array}{c}\text { Distance from } \\
\text { top [cm] }\end{array}$ ([in]) } & $\begin{array}{r}\text { Distance from } \\
\text { midplane [cm] }\end{array}$ & $\begin{array}{r}\text { Top surface } \\
\text { location [cm] }\end{array}$ & $\begin{array}{r}\text { Bottom surface } \\
\text { location [cm] }\end{array}$ \\
\hline 1 & 3.81000 & $(1.500)$ & 29.53258 & 29.73258 & 29.33258 \\
2 & 6.37794 & $(2.511)$ & 26.96464 & 27.16464 & 26.76464 \\
3 & 8.94588 & $(3.522)$ & 24.39670 & 24.59670 & 24.19670 \\
4 & 11.51382 & $(4.533)$ & 21.82876 & 22.02876 & 21.62876 \\
5 & 14.08176 & $(5.544)$ & 19.26082 & 19.46082 & 19.06082 \\
6 & 16.64970 & $(6.555)$ & 16.69288 & 16.89288 & 16.49288 \\
7 & 19.21764 & $(7.566)$ & 14.12494 & 14.32494 & 13.92494 \\
8 & 21.78558 & $(8.577)$ & 11.55700 & 11.75700 & 11.35700 \\
9 & 24.35352 & $(9.588)$ & 8.98906 & 9.18906 & 8.78906 \\
10 & 26.92146 & $(10.599)$ & 6.42112 & 6.62112 & 6.22112 \\
11 & 29.48940 & $(11.610)$ & 3.85318 & 4.05318 & 3.65318 \\
12 & 32.05734 & $(12.621)$ & 1.28524 & 1.48524 & 1.08524 \\
13 & 34.62528 & $(13.632)$ & -1.28270 & -1.08270 & -1.48270 \\
14 & 37.19322 & $(14.643)$ & -3.85064 & -3.65064 & -4.05064 \\
15 & 39.76116 & $(15.654)$ & -6.41858 & -6.21858 & -6.61858 \\
16 & 42.32910 & $(16.665)$ & -8.98652 & -8.78652 & -9.18652 \\
17 & 44.89704 & $(17.676)$ & -11.55446 & -11.35446 & -11.75446 \\
18 & 47.46498 & $(18.687)$ & -14.12240 & -13.92240 & -14.32240 \\
19 & 50.03292 & $(19.698)$ & -16.69034 & -16.49034 & -16.89034 \\
20 & 52.60086 & $(20.709)$ & -19.25828 & -19.05828 & -19.45828 \\
21 & 55.16880 & $(21.720)$ & -21.82622 & -21.62622 & -22.02622 \\
22 & 57.73674 & $(22.731)$ & -24.39416 & -24.19416 & -24.59416 \\
23 & 60.30468 & $(23.742)$ & -26.96210 & -26.76210 & -27.16210 \\
24 & 62.87262 & $(24.753)$ & -29.53004 & -29.33004 & -29.73004 \\
\hline
\end{tabular}




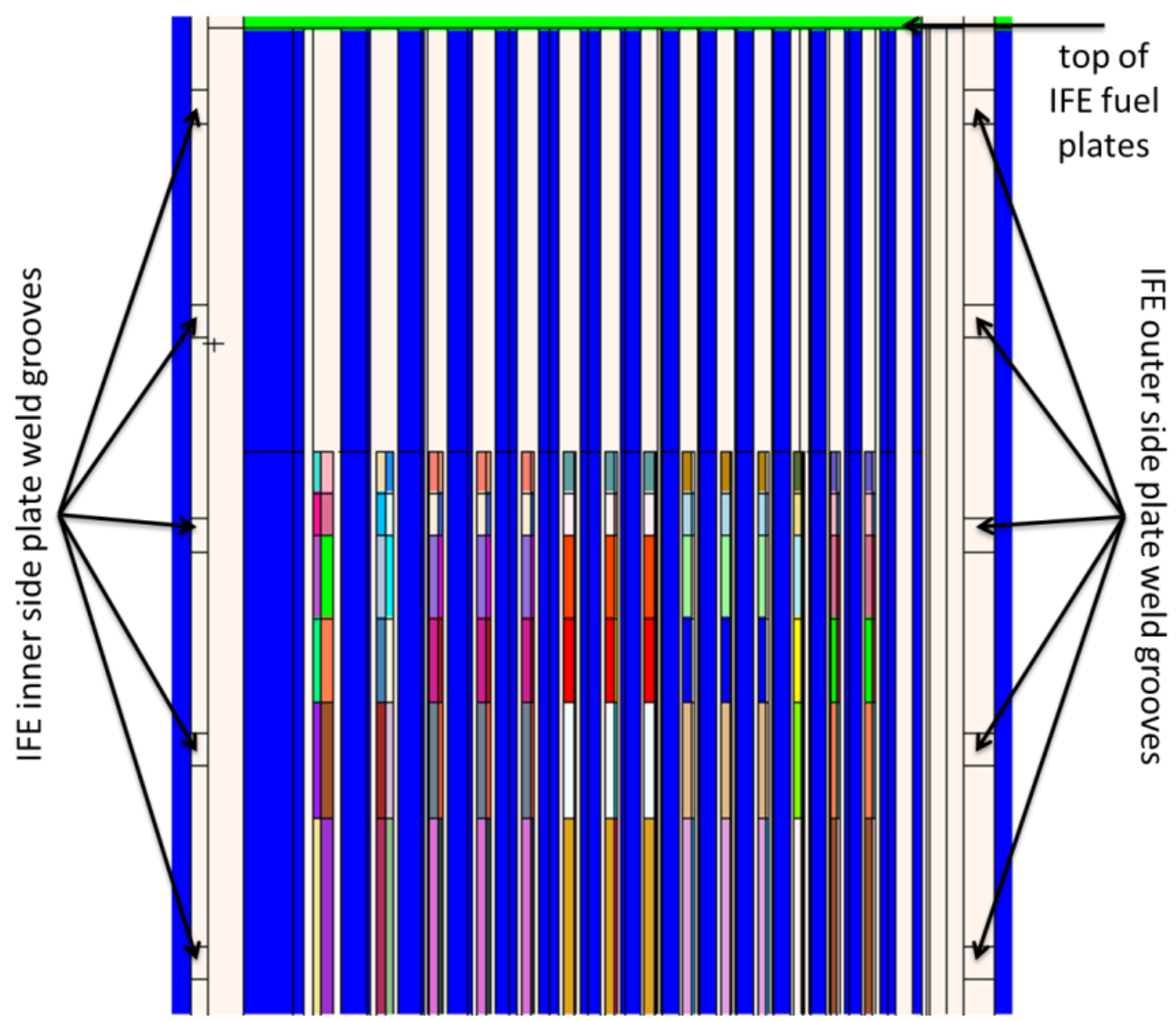

Figure 13. An r-z cross-section of the upper five as-modeled weld grooves of the inner fuel element.

\subsection{MODELING OF THE FUEL PLATE SLOTS}

The side plates of the IFE and OFE have 171 and 369 fuel plate slots, respectively. Fuel plates are placed in each slot and are welded into place from the opposite side of the side plate through the weld groove channels. Fuel plate slots are machined along the axis of the cylinder; these are located on the outside and inside of the inner and outer side plates, respectively. Fuel plate slots are cut to a height of $60.96 \mathrm{~cm}$ (24 in), to match the height of the fuel plates. The volume of the side plates occupied by the fuel plate slots is far greater than that occupied by the weld grooves (close to $25-35 \%$ of the approximate smooth side plate cylinder volume).

Fuel plate slots are modeled with the PHAME script $[4,6]$ to extend fully to the fuel plate slot radius. In reality, a cross section of this fuel plate slot is rectangular (i.e., the corners at the fuel slot depth are $90^{\circ}$ angles). This approximation, which is conservative if the side plates are poisoned, adds a slightly larger volume of fuel plate clad material (Al) to the side plate volume. The percent increase in fuel plate clad material modeled in the side plates is different for each side plate because the "additional" fuel plate clad volume modeled in the side plate is dependent on the angle at which the fuel plate meets the side plate and the radial distance between the side plate radius and the fuel plate slot radius. Based on the dimensions listed in the HFIR reference drawings and the assumption that the radii of the side plates are much larger than the fuel plot slot dimensions, which allows the curvature of the side plate across the $0.127 \mathrm{~cm}$ thick plate to be ignored, the percent increases in fuel plate clad volume modeled in the side plate volume are $~ 4.1,17.2,3.4$, and 16.9 for the IFE inner side plate, IFE outer side plate, the OFE inner side plate, and the OFE outer side plate, respectively.

The effect of this modeling approximation is a reduction in the total volume of the side plate material that is included in the model. This reduction is estimated to be $\sim 2.1,6.0,1.1$, and $4.8 \%$ for the IFE inner 
side plate, IFE outer side plate, the OFE inner side plate, and the OFE outer side plate, respectively, over the height of the plate that spans the active fuel region $( \pm 25.4 \mathrm{~cm}$ with respect to the core midplane). An illustration of the as-modeled fuel plate slots is provided in Figure 14.

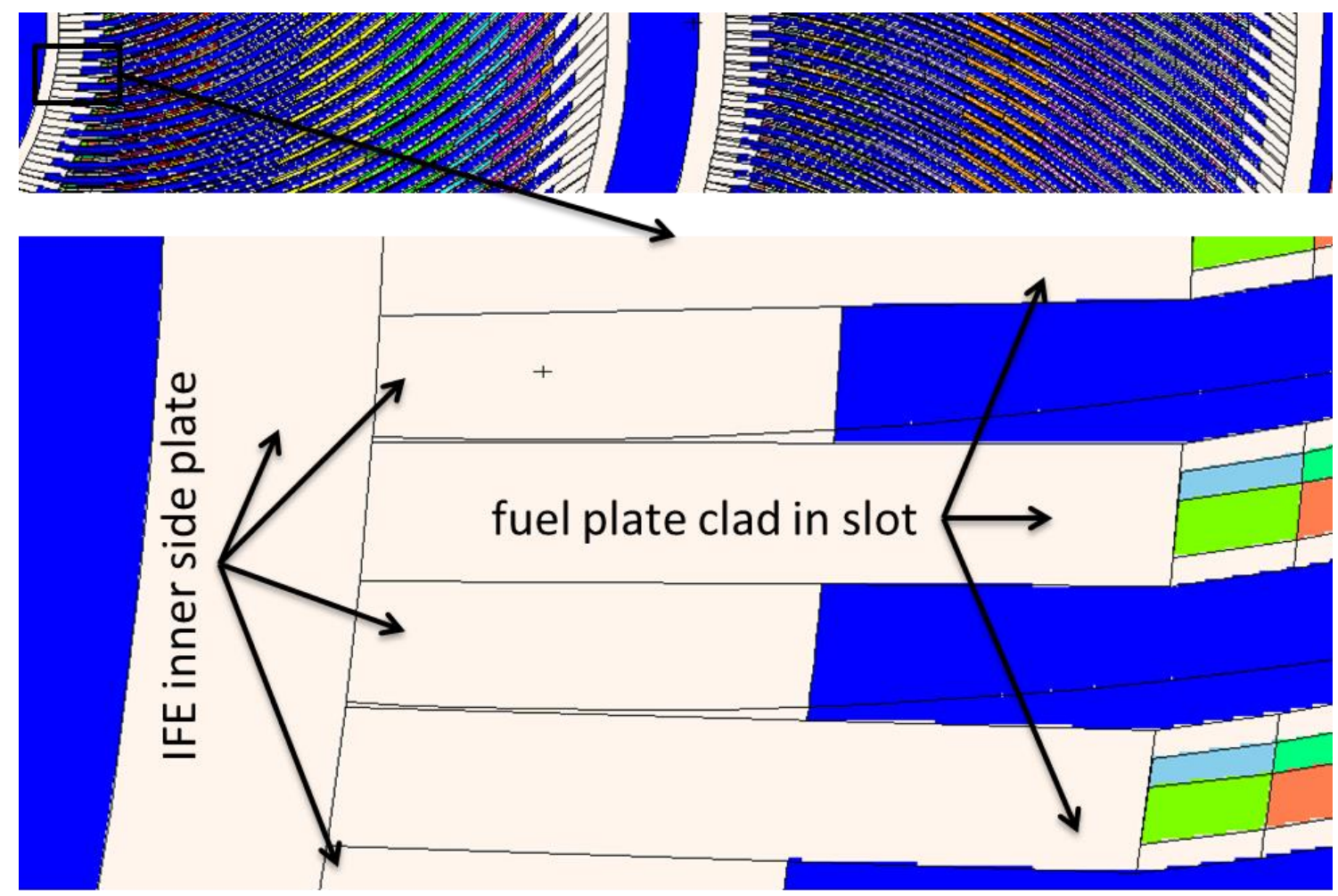

Figure 14. An $x-y$ cross-section of fuel plate and slot as-modeled geometry.

\subsection{MODELING OF THE SHOULDERS AND EXTENSIONS}

The initial height of the inner and outer side plates of the IFE and OFE (before attachment of the fuel plates) is $66.675 \mathrm{~cm}(26.25 \mathrm{in})$. The height of the thick portion of the side plates (sometimes referred to as the shoulder) measures $62.0522 \mathrm{~cm}$ (24.43 in), $62.4205 \mathrm{~cm}(24.575 \mathrm{in}), 62.103 \mathrm{~cm}(24.45 \mathrm{in})$, and $62.611 \mathrm{~cm}$ (24.65 in), for the IFE inner, IFE outer, OFE inner, and OFE outer side plates, respectively. The thick portion of these plates is not necessarily centered along the height of the side plate. The extensions are the lengths of the cylinder beyond this thick portion of the side plates.

After attaching all the fuel plates, the inside and outside of the inner and outer side plates are machined to their final radii. The ends of the inner and outer side plates are trimmed and some are machined to be fitted with aluminum adapters. Aluminum adapters are welded to the top of the IFE and OFE inner and outer side plates, the bottom of the IFE inner side plate, and the bottom of the OFE outer side plate. The adapters fit flush against the side plate shoulder to provide a smooth coolant flow. End adapters are cylindrical tube-shaped aluminum sections that are welded on the side plate ends to provide a bearing surface for the fuel elements in the reactor. An illustration of the as-modeled fuel element assembly including the side plate weld grooves, extensions, and adapters is provided in Figure 12.

The height of the extensions is measured as the distance from the shoulder to the end of the side plate. The height of the top extensions of the IFE inner and outer side plates is $0.98552 \mathrm{~cm}(0.388 \mathrm{in})$, the height of the bottom extension of the IFE inner side plate is $0.66802 \mathrm{~cm}(0.263 \mathrm{in})$, the height of the top extensions of the OFE inner and outer side plates is $0.66802 \mathrm{~cm}(0.263 \mathrm{in})$, and the height of the bottom extensions of the OFE outer side plates is $0.98552 \mathrm{~cm}(0.388 \mathrm{in})$. The ends of the extensions are machined to $30^{\circ}$. The thickness of each extension is dependent on the extension radius. For the IFE 
inner, IFE outer, OFE inner, and OFE outer side plates these radii are $6.58368 \mathrm{~cm}$ (2.592 in), 13.16546 $\mathrm{cm}$ (5.18325 in), $14.59357 \mathrm{~cm}$ (5.7455 in), and $21.43697 \mathrm{~cm}$ (8.43975 in), respectively.

The planes representing the axial tops of the shoulders are calculated by subtracting the lengths from the top of the side plates (pre-machined) to the top of the shoulders from the length from the top of the side plates (pre-machined) to the core horizontal midplane. The planes representing the axial bottoms of the IFE inner and OFE outer shoulders are calculated by subtracting the lengths from the top of the side plates (pre-machined) to the top of the shoulders from the length from the top of the side plates (premachined) to the bottom of the shoulders. The bottom of the IFE outer and OFE inner side plates are machined into the shoulder of the side plate to a distance $0.16002 \mathrm{~cm}(0.063 \mathrm{in})$ below the end of the fuel plates $(-30.64002 \mathrm{~cm}$ with respect to the core horizontal midplane). 


\section{EXPLICIT AND SIMPLIFIED MODELING OF THE FUEL ELEMENTS}

The fuel elements, as modeled in the Cycle 400 model [4] (e.g., geometry, materials, cell descriptions), were not altered in the HEU representative model. Two models were established for Cycle 400 [4] fuel, a simplified and an explicit model, also illustrated here in Figure 15 - Figure 17 for completeness.

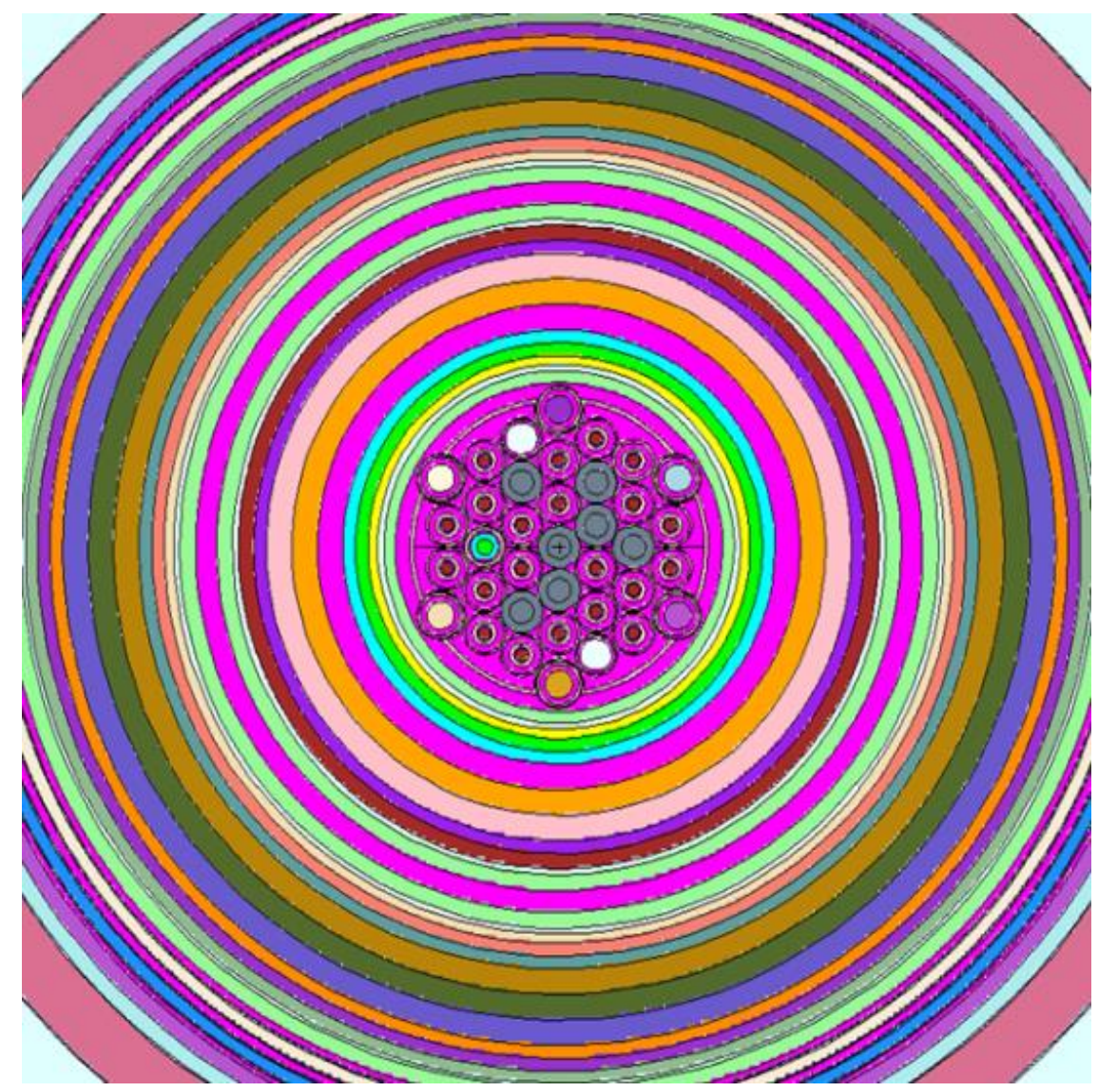

Figure 15. Modeling of the fuel elements in the simplified MCNP model.

(This figure is Fig. 18 from [4])

The ${ }^{235} \mathrm{U}$ and ${ }^{10} \mathrm{~B}$ loading does not vary significantly from cycle to cycle because the specifications and fabrication processes outlining the ${ }^{235} \mathrm{U}$ and ${ }^{10} \mathrm{~B}$ loading have not changed and are tightly controlled. The Cycle 400 input [4] makes use of 2.709 grams ${ }^{10} \mathrm{~B}$ in the IFE filler, 15.25 grams ${ }^{235} \mathrm{U}$ in each of the IFE fuel plates, and 18.52 grams ${ }^{235} \mathrm{U}$ in each of the OFE fuel plates.

Actual data available for the IFE ${ }^{235} \mathrm{U}$ loading, OFE ${ }^{235} \mathrm{U}$ loading, and IFE ${ }^{10} \mathrm{~B}$ loading for cycles 401 -461 was analyzed. Based on the as-built core data for these 61 fuel elements, the average IFE ${ }^{235} U$, OFE ${ }^{235} \mathrm{U}$, and IFE ${ }^{10} \mathrm{~B}$ loadings are $15.25,18.52$, and 2.708 grams, respectively. Thus, the use of the Cycle 400 fuel element composition is valid for use in a representative core. 


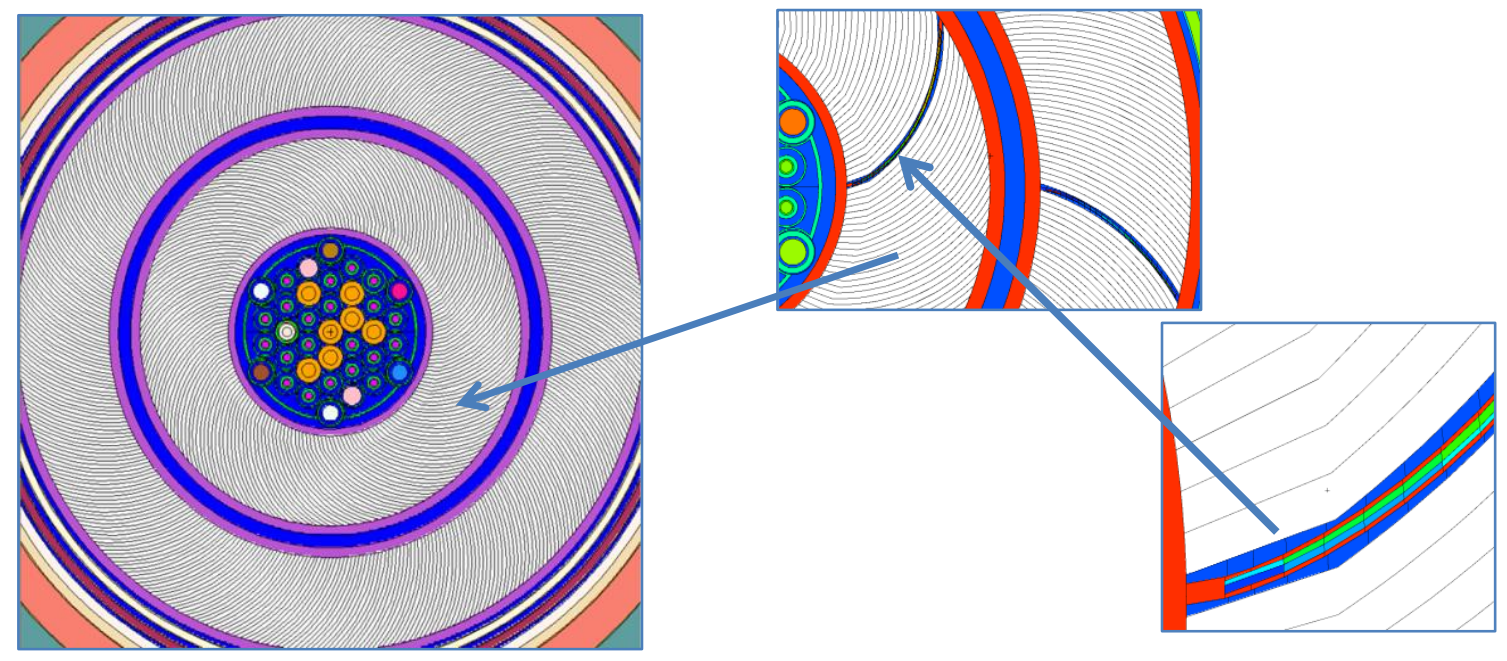

Figure 16. Modeling of the fuel elements in the explicit MCNP model.

(This figure is Fig. 19 from [4])

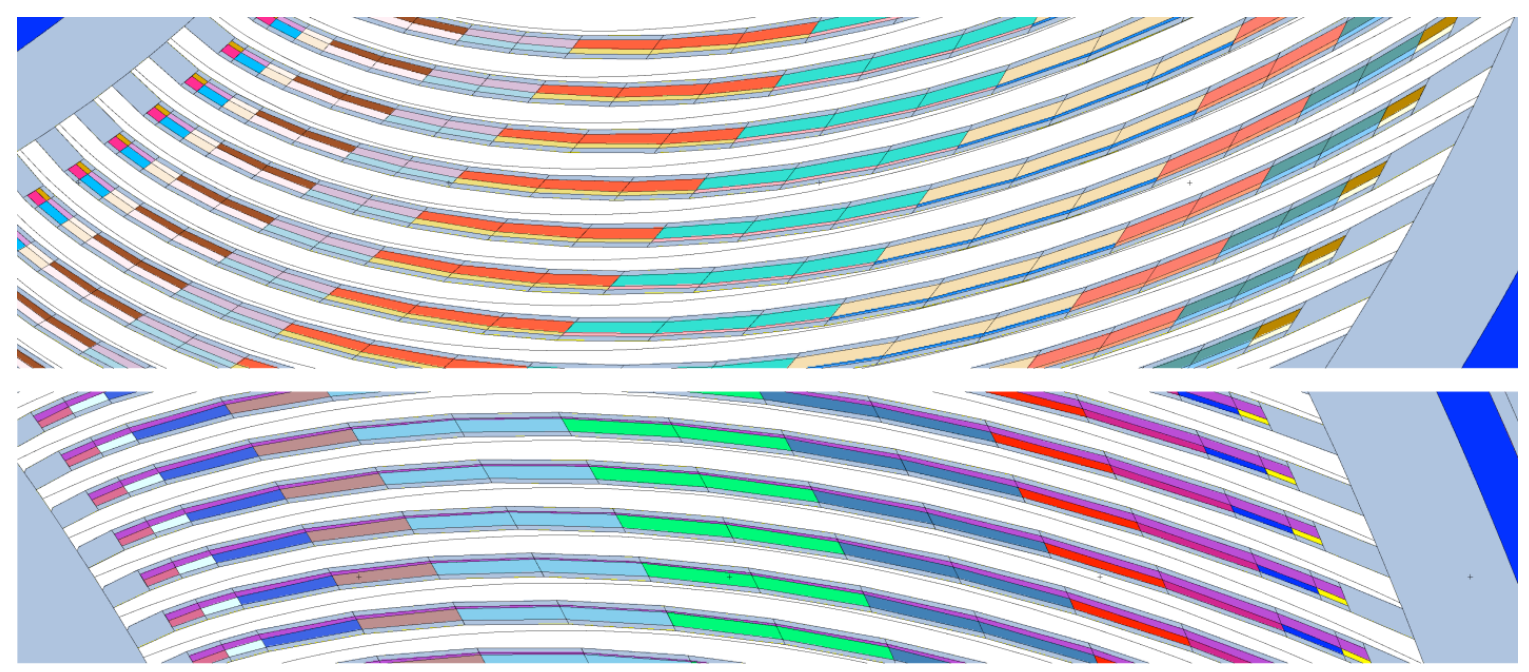

Figure 17. Approximation of the involute-shaped inner fuel element (top) and outer fuel element (bottom) via sets of hexahedra.

(This figure is Fig. 20 from [4]) 


\section{COMPUTATIONAL TOOLS AND DATA}

Version 2.0.2 of the VESTA Monte Carlo-based depletion tool [19], which is developed and maintained at Institut de Radioprotection et de Sûreté Nucléaire (IRSN)—Institute for Radiological Protection and Nuclear Safety - in France, was used to perform depletion simulations of the simplified and explicit HEU representative models. VESTA simulates fuel depletion by iteratively coupling a neutron transport solver with a point depletion and decay solver. The MCNP5 v1.51 neutron transport code [20] and the ORIGEN 2.2 point depletion code [21] were used for the VESTA analyses discussed in this report.

The depletion simulation method used in VESTA is briefly described here. At each depletion step, the transport flux solution from MCNP is used to generate the cross-section data for the ORIGEN 2.2 depletion calculation. The isotopic composition data resulting from ORIGEN 2.2 calculations are used in the subsequent MCNP transport calculation to update the isotopic compositions of the depleted materials and obtain cross-sections for the next depletion step. This iterative process continues until the desired irradiation history is complete. The fission source file containing the converged spatial distribution of fission points from the previous transport step is used as the initial source distribution for the subsequent transport calculation within the VESTA simulation. The one-group cross-sections required by ORIGEN 2.2 are obtained by weighting pre-generated pointwise cross-section data with the MCNP-calculated very fine group neutron flux data (43,000-group structure). These pointwise cross-section data are consistent with the cross-section data set used in the MCNP transport calculation as both sets are precomputed based on the same ENDF/B data files.

Compared to other Monte Carlo-based depletion simulation tools, VESTA has the advantage of providing modeling capabilities essential for HFIR analyses, such as the explicit simulation of CE movement during the reactor cycle and the depletion of nonfissile materials, which makes it possible to account for the irradiation of the CEs and nonfissile targets during the reactor cycle.

For the analyses discussed in this report, the cross-section data used with the MCNP neutron transport solver and the ORIGEN 2.2 depletion solver in VESTA are based on ENDF/B-VII.0 data [9]. All crosssections are considered at $300 \mathrm{~K}$ temperature, with the water thermal scattering data, as available from the MCNP5 release, at 293.6 K. The fission yield data and the nuclear decay data used with ORIGEN 2.2 are based on ENDF/B-VII.1 [22] evaluations. The use of these fission yield and nuclear decay libraries to replace the outdated data files released with ORIGEN 2.2 was documented in [4].

Cross-section data that are based on ENDF/B-VII.0 for use in VESTA are only available at 293.6, $300,600,900$, and $1200 \mathrm{~K}$. The $300 \mathrm{~K}$ cross-sections are used for the transport and depletion calculations because they best represent HFIR temperatures from the sets of available data. The 293.6 K water scattering kernel, $\mathrm{S}(\alpha, \beta)$, is used for these studies because corresponding ENDF/B-VII.0 data, as provided with the MCNP package, are limited to 293.6, 350, 400, 450, 500, 550, 600, 650, and $800 \mathrm{~K}$. Studies performed in [4] show these $293.6 \mathrm{~K}$ data to be appropriate for use together with the $300 \mathrm{~K}$ ENDF/BVII.0 cross-sections.

A total power of $85 \mathrm{MW}$ was used for all depletion steps, for both the simplified and explicit fuel models, and a criticality search script [6] was used to determine the symmetrical critical control element position (SCCEP) at each step into the simulation. After determining the critical position at each transport step with fewer active histories and no tallies, the transport step used to calculate the fine-group neutron flux in VESTA uses 300 active cycles, 50 inactive cycles, and 100,000 histories per cycle. The criticality search script is based on the script discussed in [5], which has been modified to improve its efficiency [6].

The fuel materials (209 per fuel element, 418 materials for both elements), IFE filler materials (homogenized with fuel materials in simplified model and 209 in explicit model), control element poison materials (20 materials), and the isotope production target materials (one ${ }^{188} \mathrm{~W}$ production material, one ${ }^{252} \mathrm{Cf}$ production material, and three ${ }^{238} \mathrm{Pu}$ production materials) are included in the depletion calculation. Thus, a total of 443 and 652 depletion materials are tracked for the simplified and explicit models, respectively. 


\section{COMPUTATIONS AND ANALYSES}

\subsection{SYMMETRICAL CONTROL ELEMENT POSITIONS AND CYCLE LENGTH}

The VESTA depletion simulations were performed with the criticality search script and 1-day each time steps. The average MCNP run time for the simplified and explicit models was approximately 69 CPU hours (4.3 hours on 16 CPUs) and 381 CPU hours (12.7 hours on 30 CPUs), respectively. Thus, the simplified model is much more computationally efficient and the cost of explicitly modeling the fuel plates and modeling the high-fidelity side plates is a $\sim 5.5$ fold increase in run time.

The symmetrical control element positions, eigenvalues $\left(\mathrm{k}_{\mathrm{eff}}\right)$, and corresponding eigenvalue statistical uncertainties $\left(\sigma_{\text {keff }}\right)$ were extracted from the MCNP output files produced by VESTA and are listed in Table 23 and Table 24 for the explicit and simplified models, respectively. The control element positions as a function of time into cycle, as calculated in the VESTA simulation, are illustrated in Figure 18 and the $\mathrm{k}_{\mathrm{eff}}$ values are shown in Figure 19. For both depletion simulations, for the simplified and the explicit models, the maximum control element withdrawal position was set to $68.58 \mathrm{~cm}$ (i.e., 27 inches withdrawn). Thus, the control elements could not be withdrawn more than $68.58 \mathrm{~cm}$ even if the core reactivity was determined to be below the criticality uncertainty band.

\subsubsection{Cycle Length Estimate for the Explicit Fuel Model}

As shown in Table 23, the $\mathrm{k}_{\text {eff }}$ calculated for the explicit model on day 27 with the control elements fully withdrawn is $443 \pm 14$ pcm subcritical. The $k_{\text {eff }}$ calculated on day 26 with the control elements only $0.208 \mathrm{~cm}$ from their fully withdrawn symmetrical positions was $45 \pm 14 \mathrm{pcm}$ subcritical. Considering these two data points and the fact that the control element differential rod worth is small when fully withdrawn, the calculated end-of-cycle is estimated to be between about 25.85 and 26.20 days based on a visual inspection of the plotted control element withdrawal curve. An end-of-cycle of 26 days and 3 hours (26.125 days) is estimated based on linear interpolation/extrapolation of the day 25 and 26 calculated data and then rounding to the nearest hour.

Based on the VESTA run files obtained for the simulations that used the criticality search script, a VESTA restart run was performed to calculate the isotopic compositions of depleted materials at 26.125 days. In this restart calculation, all data from day 0 to day 26 were the same as in the run that used the criticality search script. A new depletion step of 3 hours was added at the end of day 26 , which led to generation of a new MCNP input file, which has material composition data corresponding to 26.125 days of irradiation. Then, both the day 26 and day 26.125 MCNP inputs were executed outside VESTA after changing the control elements location in both inputs to the fully withdrawn position. The $\mathrm{k}_{\text {eff }}$ values of $0.99976 \pm 0.00013(24 \pm 13$ pcm subcritical $)$ and $0.99948 \pm 0.00014(52 \pm 14$ pcm subcritical $)$, respectively, were obtained for these two MCNP runs. Because of the nature of Monte Carlo methods, the process in determining the end-of-cycle can become quite tedious. Because the day 26 fully withdrawn $\mathrm{k}_{\text {eff }}$ is within two standard deviations of unity, and based on linear interpolation/extrapolation between these two MCNP results, the cycle length would be expected to be between 25.9 and 26.0 days:

To obtain better statistics, the MCNP input corresponding to day 26 input was rerun with 10,000 active cycles and the resulting calculated $\mathrm{k}_{\text {eff }}$ was $0.99988 \pm 0.00002(12 \pm 2 \mathrm{pcm}$ subcritical). This minimal reactivity deviation from critical is considered acceptable. Thus, the end-of-cycle is considered to be 26.0 days. The results of these sensitivity studies on the end-of-cycle estimate are listed in Table 25 . 
Table 23. Explicit model symmetrical control element position and $\mathbf{k}_{\text {eff }}$ as-calculated with VESTA and the critical search script

\begin{tabular}{cccc}
\hline Day & $\begin{array}{c}\text { Control Element } \\
\text { position }(\mathbf{c m})\end{array}$ & $\mathbf{k}_{\text {eff }}$ & $\boldsymbol{\sigma}_{\text {keff }}$ \\
\hline 0 & 44.51098 & 1.00006 & 0.00015 \\
1 & 50.61431 & 0.99923 & 0.00016 \\
2 & 51.72076 & 0.99949 & 0.00015 \\
3 & 52.14784 & 0.99966 & 0.00016 \\
4 & 52.66036 & 1.00090 & 0.00016 \\
5 & 52.72804 & 0.99976 & 0.00015 \\
6 & 53.03476 & 1.00010 & 0.00015 \\
7 & 53.07512 & 0.99876 & 0.00016 \\
8 & 53.62959 & 1.00109 & 0.00014 \\
9 & 53.71427 & 0.99965 & 0.00014 \\
10 & 54.06920 & 0.99990 & 0.00016 \\
11 & 54.37471 & 0.99945 & 0.00014 \\
12 & 54.69964 & 0.99933 & 0.00015 \\
13 & 55.25730 & 1.00006 & 0.00015 \\
14 & 55.66213 & 0.99985 & 0.00015 \\
15 & 56.21758 & 1.00002 & 0.00016 \\
16 & 56.82790 & 1.00035 & 0.00015 \\
17 & 57.48461 & 1.00057 & 0.00014 \\
18 & 58.04654 & 0.99974 & 0.00016 \\
19 & 59.06819 & 1.00100 & 0.00015 \\
20 & 59.82764 & 1.00052 & 0.00014 \\
21 & 60.86528 & 1.00086 & 0.00014 \\
22 & 61.48628 & 0.99914 & 0.00014 \\
23 & 63.02303 & 1.00031 & 0.00015 \\
24 & 64.56096 & 1.00041 & 0.00014 \\
25 & 66.38076 & 1.00028 & 0.00013 \\
26 & 68.37245 & 0.99955 & 0.00014 \\
27 & 68.58000 & 0.99557 & 0.00014 \\
\hline & & & \\
\hline
\end{tabular}


Table 24. Simplified model symmetrical control element position and $\mathbf{k}_{\text {eff }}$ as-calculated with VESTA and the critical search script

\begin{tabular}{cccc}
\hline Day & $\begin{array}{c}\text { Control Element } \\
\text { position }(\mathbf{c m})\end{array}$ & $\mathbf{k}_{\text {eff }}$ & $\boldsymbol{\sigma}_{\text {keff }}$ \\
\hline 0 & 44.13545 & 1.00093 & 0.00016 \\
1 & 50.20043 & 1.00045 & 0.00016 \\
2 & 51.44587 & 1.00191 & 0.00017 \\
3 & 51.75289 & 1.00016 & 0.00016 \\
4 & 51.83391 & 0.99892 & 0.00017 \\
5 & 52.19723 & 0.99958 & 0.00015 \\
6 & 52.52747 & 1.00032 & 0.00015 \\
7 & 52.73139 & 1.00028 & 0.00017 \\
8 & 52.97313 & 0.99975 & 0.00017 \\
9 & 53.31883 & 1.00027 & 0.00017 \\
10 & 53.67865 & 1.00052 & 0.00016 \\
11 & 53.86408 & 1.00007 & 0.00016 \\
12 & 54.25909 & 0.99973 & 0.00016 \\
13 & 54.62529 & 0.99927 & 0.00016 \\
14 & 55.16167 & 0.99966 & 0.00016 \\
15 & 55.68729 & 0.99986 & 0.00016 \\
16 & 56.51180 & 1.00146 & 0.00016 \\
17 & 56.86591 & 1.00025 & 0.00016 \\
18 & 57.57427 & 0.99987 & 0.00016 \\
19 & 58.47478 & 1.00088 & 0.00017 \\
20 & 59.27168 & 1.00077 & 0.00015 \\
21 & 60.23372 & 1.00040 & 0.00015 \\
22 & 61.22788 & 1.00043 & 0.00016 \\
23 & 62.09514 & 0.99940 & 0.00015 \\
24 & 63.56656 & 0.99994 & 0.00015 \\
25 & 65.44632 & 1.00048 & 0.00015 \\
26 & 67.01820 & 0.99922 & 0.00015 \\
27 & 68.58000 & 0.99784 & 0.00016 \\
\hline & & & \\
\hline
\end{tabular}




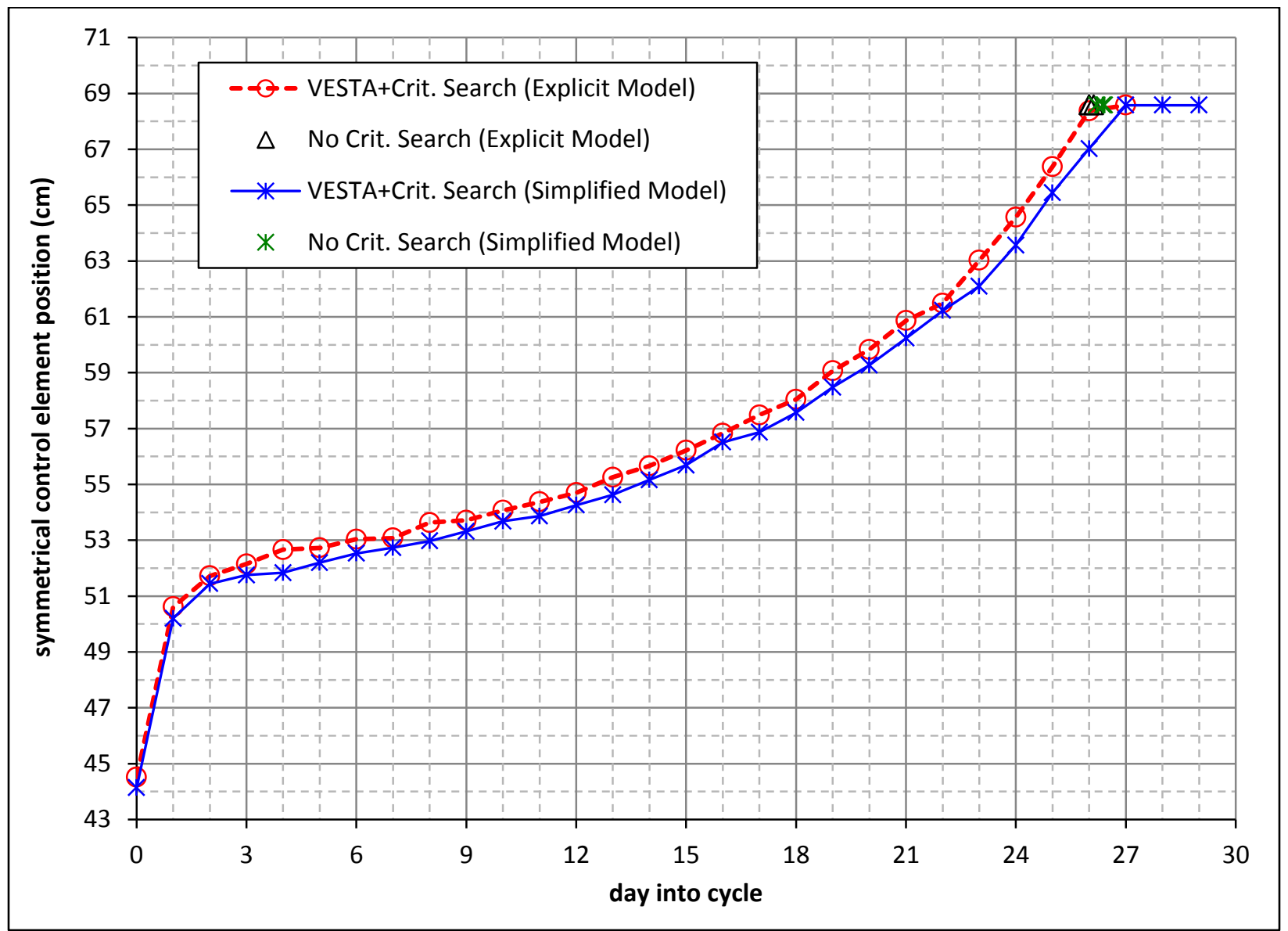

Figure 18. Symmetrical control element position curves. 


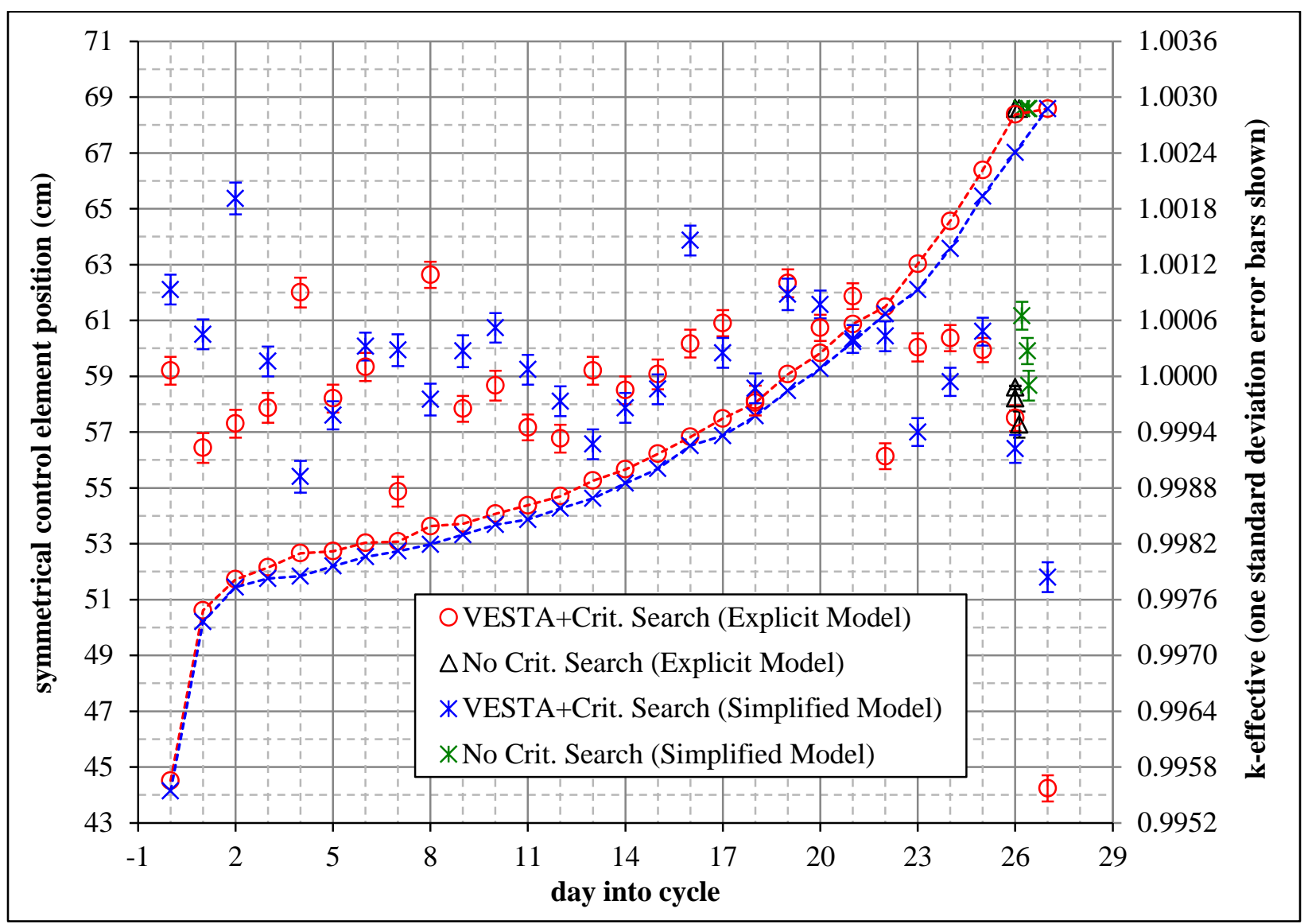

Figure 19. Variation of calculated $\mathbf{k}_{\text {eff }}$ with irradiation time and control element position.

Table 25. Explicit model $k_{\text {eff }}$ values with elements fully withdrawn

\begin{tabular}{lcccc}
\hline Day & MWd & $\begin{array}{c}\text { Control Element } \\
\text { position }(\mathbf{c m})\end{array}$ & $\mathbf{k}_{\text {eff }}$ & $\boldsymbol{\sigma}_{\text {keff }}$ \\
\hline $26.000^{\text {a) }}$ & 2210.000 & 68.580 & 0.99976 & 0.00013 \\
$26.000^{\text {b) }}$ & 2210.000 & 68.580 & 0.99988 & 0.00002 \\
$26.125^{\text {a) }}$ & 2220.625 & 68.580 & 0.99948 & 0.00014 \\
$27.000^{\text {a) }}$ & 2295.000 & 68.580 & 0.99557 & 0.00014 \\
\hline
\end{tabular}

a) 100,000 histories per cycle, 350 total cycles, 50 skipped cycles used with MCNP

b) 100,000 histories per cycle, 10,050 total cycles, 50 skipped cycles used with MCNP

\subsubsection{Cycle Length Estimate for the Simplified Fuel Model}

A similar study was performed to determine the simplified model's calculated cycle length. It is evident from the results listed in Table 24 that the calculated cycle length is between 26 and 27 days. Considering these results, and based on visual inspection of the control element withdrawal curve coupled with a few linear interpolations, it was estimated that the calculated cycle length would be between 26 days 5 hours and 26 days 15 hours. Because the control rod withdrawal curve is not linear in the last few days of the fuel cycle and because the end-of-cycle is predicted to be further beyond day 26 in 
comparison to the explicit model's cycle length estimate, simple linear extrapolation with the day 25 and day 26 data is not as appropriate for this case. The approximate fully withdrawn control rod worth and approximate day 27 SCCEP beyond fully withdrawn are estimated based on the day 27 results as follows:

$$
\begin{aligned}
& \text { worth } \approx \frac{0.99784-0.99588}{68.580000-67.716982}=2.27110 \times 10^{-03} \frac{\Delta k}{\mathrm{~cm}}=227.110 \frac{\mathrm{pcm}}{\mathrm{cm}} \\
& \operatorname{SCCEP}(\text { day } 27) \approx 67.716982+\frac{(1.00000-0.99588)(68.580000-67.716982)}{(0.99784-0.99588)}=69.531081 \mathrm{~cm}
\end{aligned}
$$

Note that the control element withdrawal position and $\mathrm{k}_{\mathrm{eff}}$ value of $67.716982 \mathrm{~cm}$ and 0.99588 are not listed in Table 24 because this position and $\mathrm{k}_{\text {eff }}$ were obtained for a case with the criticality search script where the calculated $k_{\text {eff }}$ was well below unity and the control elements were not yet fully withdrawn - it was the first pass at finding the day 27 critical position. The only differences between the two cases whose results are reflected in the above equations are the control element positions. Based on the day 26 data and this newly estimated day 27 data, the cycle length for the simplified model is estimated to be about 26 days 15 hours.

A VESTA restart run was then set up to add four 5 hour time steps beyond day 26. The MCNP input corresponding to day 26.208 (26 days and 5 hours) that was generated in this VESTA restart run was executed outside VESTA with the control elements fully withdrawn and the resulting calculated $\mathrm{k}_{\text {eff }}$ was $1.00065 \pm 0.00015$ (65 \pm 15 pcm supercritical). Linearly interpolating between the day 26.208 and day $27 \mathrm{k}_{\text {eff }}$ results yields a calculated cycle length estimate of about 26 days and $9-10$ hours.

Two VESTA restart runs were performed, without the use of the criticality search script, using the day 0 to day 26 MCNP inputs/outputs previously generated to analyze cycles with lengths of 26 days 9 hours and 26 days 10 hours. In each restart case, an additional depletion step was added after day 26, of 9 and 10 hours, respectively. The control element location at the end of these additional steps were set to the fully withdrawn position. The day 26.375 and day $26.417 \mathrm{k}_{\text {eff }}$ values, with the control elements fully withdrawn, calculated within the VESTA simulation were $1.00027 \pm 0.00014$ (27 \pm 14 pcm supercritical $)$ and $0.99990 \pm 0.00016(10 \pm 16 \mathrm{pcm}$ subcritical $)$, respectively. The calculated simplified model cycle length is therefore presumed to be 26 days and 10 hours. The results of these sensitivity studies are listed in Table 26.

Table 26. Simplified model $\mathbf{k}_{\text {eff }}$ values with elements fully withdrawn

\begin{tabular}{lcccc}
\hline Day & MWd & $\begin{array}{c}\text { Control Element } \\
\text { position }(\mathbf{c m})\end{array}$ & $\mathbf{k}_{\text {eff }}$ & $\boldsymbol{\sigma}_{\text {keff }}$ \\
\hline $26.208^{\text {a) }}$ & 2227.708 & 68.580 & 1.00065 & 0.00015 \\
$26.375^{\text {a) }}$ & 2241.875 & 68.580 & 1.00027 & 0.00014 \\
$26.417^{\text {a) }}$ & 2241.875 & 68.580 & 0.99990 & 0.00016 \\
$27.000^{\text {a) }}$ & 2220.600 & 68.580 & 0.99784 & 0.00016
\end{tabular}

a) 100,000 histories per cycle, 350 total cycles, 50 skipped cycles used with MCNP 
Typical HFIR cycle lengths range from 24 to 26 effective full power days (EFPD). So, the calculated estimates for the representative explicit and simplified models, of 26.000 and 26.417 days, are on the upper end of typical operations. However, it is important to note some arguments and uncertainties when performing and assessing cycle length estimates with a computer code and comparing them to real life operations. Below are some, but certainly not all, details to consider:

- The simplified Cycle 400 input (i.e., simplified model validation problem) end-of-cycle $\mathrm{k}_{\text {eff }}$ is 115 \pm 15 pcm above unity [4].

- The explicit Cycle 400 input (i.e., explicit model validation problem) end-of-cycle $\mathrm{k}_{\text {eff }}$ is $158 \pm 14$ pcm below unity [4].

- The representative model presented in this report uses beryllium dummy plugs in all of the RB experiment facilities, which has a positive reactivity impact in comparison to aluminum dummy plugs.

- The fissile targets loaded in the flux trap $\left({ }^{252} \mathrm{Cf}\right.$ production targets) and in the beryllium reflector $\left({ }^{238} \mathrm{Pu}\right.$ production targets) generate $\sim 0.43 \mathrm{MW}$ fission power at the end of the cycle, which reduces the fission power generated in the fuel to $\sim 84.57 \mathrm{MW}$.

- The representative MCNP model uses reduced-tantalum safety plates and a reduced-tantalum cylinder. At the time this report is being written, a set of reduced-tantalum safety plates has been in service for one full HFIR cycle (Cycle 466). However, the impact of the reduced-tantalum safety plates on cycle length cannot be made at this time because a very strong neutron absorbing experiment was installed during Cycle 466. Data from several typical operating cycles will be needed to assess whether they have an impact on cycle length.

- The calculated results are impacted by uncertainties in cross-section data.

- The calculated results are impacted by the use of $300 \mathrm{~K}$ cross-sections and $293.6 \mathrm{~K}$ water scattering data instead of data at the actual temperatures of the reactor. The temperatures of the water coolant, fuel meat, and other materials in HFIR are spatially dependent. As it is not possible to generate and utilize cross-sections and scattering data at every conceivable temperature with currently available computational tools, assumptions must be made (see [4]). For example, the primary inlet water temperature is nominally $120 \mathrm{~F}(\sim 322 \mathrm{~K})$ and the outlet temperature is $\sim 156 \mathrm{~F}(\sim 342 \mathrm{~K})$.

- Use of nominal core geometry and materials data vs. actual, as-built core geometry and materials data are affecting the results.

- No modeling of oxide build-up, thermal expansion, and other phenomena that may slightly alter the plate-to-water ratio during the cycle are affecting the results.

- Per Table 15.3.0-3 of the SAR [12], the heat power measurement error is reasonably expected to be less than $2.73 \%$ with $95.5 \%$ probability. The heat power measurement is used to estimate the cycle burnup in MWd, which in turn is used to estimate the number of EFPDs. For example, a $2.73 \%$ uncertainty on a $2210 \mathrm{MWd}$ cycle having a constant heat power measurement reading of $85 \mathrm{MW}$ for 26 days is $60.3 \mathrm{MWd}$ (or $\sim 17$ hours).

- Original computations/predictions estimated that the HFIR cycle length would be $1100 \mathrm{MWd}$ (11 days at $100 \mathrm{MW}$ ) and the actual cycle length turned out to be $2300 \mathrm{MWd}$ (23 days at $100 \mathrm{MW}$ ) [23]. 


\subsection{ISOTOPIC COMPOSITION OF IRRADIATED FUEL}

The inventory of pertinent major actinides and neutron poisons in the core at BOC and EOC, for both the explicit and simplified models, is listed in Table 27. The EOC isotopic content for the nuclides listed is consistent between the two models. For all results shown in this section, the cycle length for the explicit model is 26 days ( $2210 \mathrm{MWd}$ ) and the cycle length for the simplified model is 26 days 10 hours (2245.417 MWd). Thus, the core burnup of the simplified model is $35.417 \mathrm{MWd}$ greater than that of the explicit model. 
Table 27. Core poison and actinide inventory at end-of-cycle

\begin{tabular}{|c|c|c|c|c|c|c|c|c|c|c|c|c|}
\hline \multirow{3}{*}{ Nuclide } & \multicolumn{6}{|c|}{ Explicit Model } & \multicolumn{6}{|c|}{ Simplified Model } \\
\hline & \multicolumn{3}{|c|}{ beginning-of-cycle } & \multicolumn{3}{|c|}{ end-of-cycle } & \multicolumn{3}{|c|}{ beginning-of-cycle } & \multicolumn{3}{|c|}{ end-of-cycle } \\
\hline & IFE (g) & OFE (g) & FE $(\mathbf{g})$ & IFE (g) & OFE (g) & FE (g) & IFE (g) & OFE (g) & FE (g) & IFE (g) & OFE (g) & FE (g) \\
\hline${ }^{10} \mathrm{~B}^{(\mathrm{a})}$ & 2.709 & 0.000 & 2.709 & 0.166 & 0.000 & 0.166 & 2.709 & 0.030 & 2.739 & 0.167 & 0.005 & 0.171 \\
\hline${ }^{135} \mathrm{Xe}$ & 0.000 & 0.000 & 0.000 & 0.012 & 0.039 & 0.052 & 0.000 & 0.000 & 0.000 & 0.012 & 0.04 & 0.052 \\
\hline${ }^{149} \mathrm{Sm}$ & 0.000 & 0.000 & 0.000 & 0.091 & 0.277 & 0.369 & 0.000 & 0.000 & 0.000 & 0.09 & 0.276 & 0.366 \\
\hline${ }^{234} \mathrm{U}$ & 28.685 & 75.173 & 103.858 & 24.335 & 66.631 & 90.965 & 28.685 & 75.173 & 103.858 & 24.209 & 66.408 & 90.617 \\
\hline${ }^{235} \mathrm{U}$ & 2607.758 & 6833.889 & 9441.646 & 1623.742 & 5058.762 & 6682.504 & 2607.749 & 6833.881 & 9441.630 & 1603.211 & 5033.021 & 6636.232 \\
\hline${ }^{236} \mathrm{U}$ & 10.431 & 27.336 & 37.767 & 178.157 & 344.957 & 523.114 & 10.431 & 27.336 & 37.767 & 181.807 & 350.738 & 532.546 \\
\hline${ }^{237} \mathrm{U}$ & 0.000 & 0.000 & 0.000 & 2.258 & 3.776 & 6.034 & 0.000 & 0.000 & 0.000 & 2.389 & 3.974 & 6.363 \\
\hline${ }^{238} \mathrm{U}$ & 151.150 & 396.103 & 547.252 & 144.818 & 382.409 & 527.228 & 151.149 & 396.101 & 547.250 & 144.566 & 381.82 & 526.386 \\
\hline${ }^{239} \mathrm{U}$ & 0.000 & 0.000 & 0.000 & 0.006 & 0.013 & 0.019 & 0.000 & 0.000 & 0.000 & 0.006 & 0.013 & 0.019 \\
\hline${ }^{238} \mathrm{Pu}$ & 0.000 & 0.000 & 0.000 & 0.127 & 0.178 & 0.305 & 0.000 & 0.000 & 0.000 & 0.139 & 0.193 & 0.332 \\
\hline${ }^{239} \mathrm{Pu}$ & 0.000 & 0.000 & 0.000 & 3.355 & 8.195 & 11.550 & 0.000 & 0.000 & 0.000 & 3.457 & 8.505 & 11.962 \\
\hline${ }^{240} \mathrm{Pu}$ & 0.000 & 0.000 & 0.000 & 0.538 & 0.962 & 1.500 & 0.000 & 0.000 & 0.000 & 0.567 & 1.016 & 1.583 \\
\hline${ }^{241} \mathrm{Pu}$ & 0.000 & 0.000 & 0.000 & 0.260 & 0.405 & 0.665 & 0.000 & 0.000 & 0.000 & 0.28 & 0.438 & 0.719 \\
\hline${ }^{242} \mathrm{Pu}$ & 0.000 & 0.000 & 0.000 & 0.029 & 0.029 & 0.058 & 0.000 & 0.000 & 0.000 & 0.032 & 0.032 & 0.064 \\
\hline
\end{tabular}

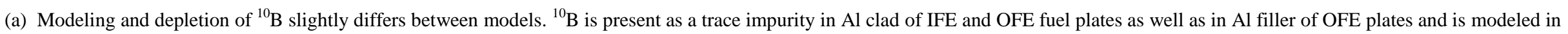

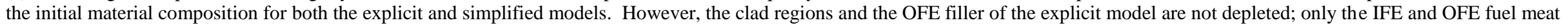

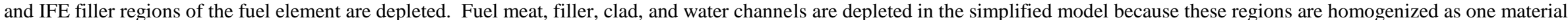

The inventory data shown in the table correspond to the depleted materials only. 


\subsubsection{Uranium-235 Depletion}

The depletion of ${ }^{235} \mathrm{U}$ and the generation of ${ }^{239} \mathrm{Pu}$ with irradiation time are illustrated in Figure 20. Table 28 lists the end-of-cycle fuel enrichment and ${ }^{235} \mathrm{U}$ depletion as calculated with both explicit and simplified models. The results from both models are in good agreement.

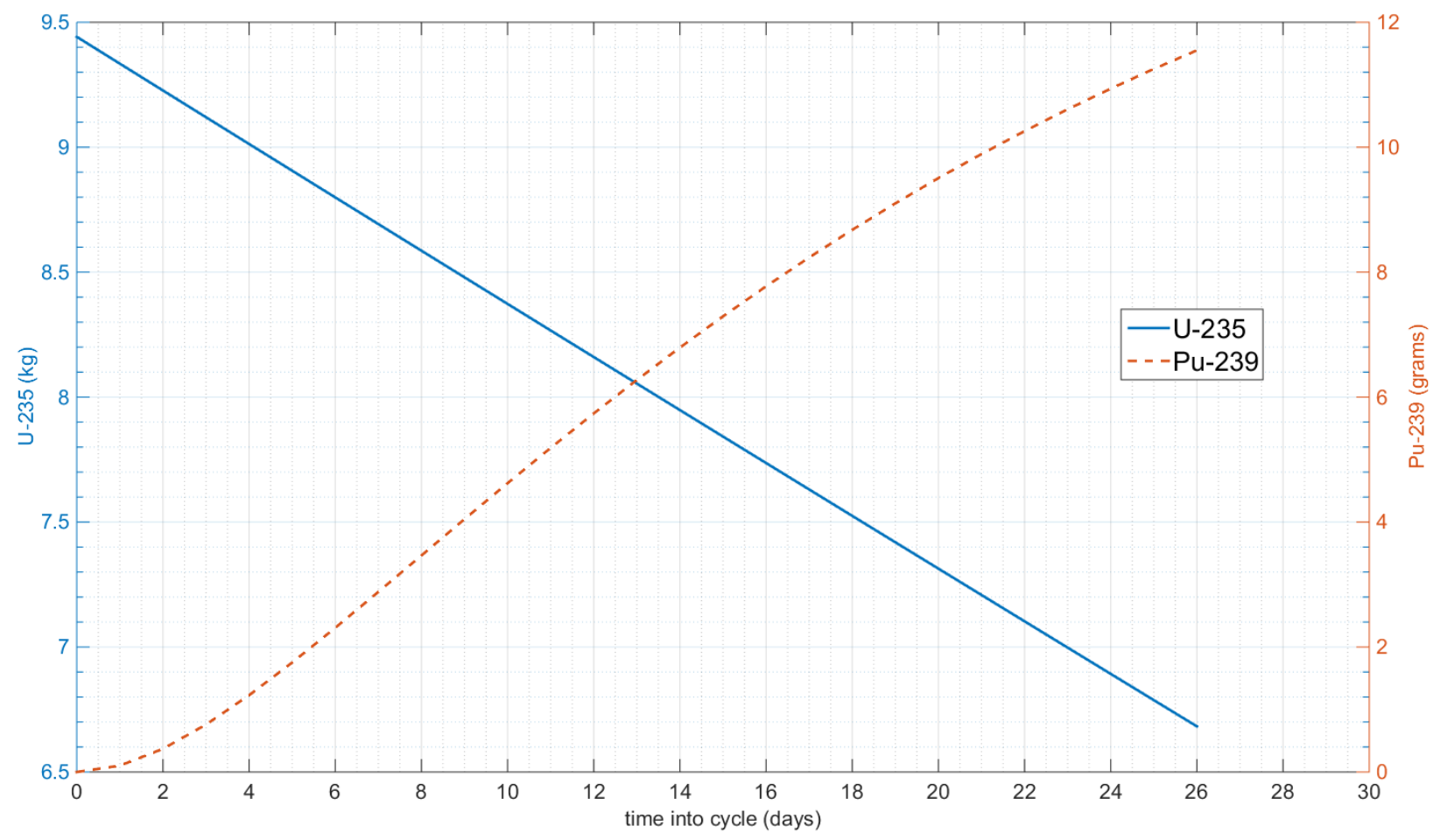

Figure 20. U-235 depletion and Pu-239 production vs. irradiation time for explicit model.

Table 28. End-of-cycle uranium enrichment and ${ }^{235} \mathrm{U}$ depletion

\begin{tabular}{lcccc}
\hline \multirow{2}{*}{$\begin{array}{l}\text { Fuel } \\
\text { Element }\end{array}$} & \multicolumn{2}{c}{ Explicit Model } & \multicolumn{2}{c}{ Simplified Model } \\
& Enrichment (\%) $^{(\mathbf{a})}$ & Depletion (\%) $^{(\mathbf{b})}$ & Enrichment (\%) $^{(\mathbf{a})}$ & Depletion (\%) $^{(\mathbf{b})}$ \\
\hline IFE & 82.28 & 37.73 & 81.96 & 38.52 \\
OFE & 86.38 & 25.98 & 86.24 & 26.35 \\
IFE+OFE & 85.35 & 29.22 & 85.17 & 29.71 \\
\hline
\end{tabular}

(a) Calculated as the ${ }^{235} \mathrm{U}$ mass divided by the total uranium mass multiplied by 100 .

(b) Calculated as the difference between the EOC and $\mathrm{BOC}{ }^{235} \mathrm{U}$ masses divided by the $\mathrm{BOC}{ }^{235} \mathrm{U}$ mass and multiplied by 100.

For the explicit model, the total ${ }^{235} \mathrm{U}$ mass decreases linearly from $9.442 \mathrm{~kg}$ at the beginning of the cycle to $6.683 \mathrm{~kg}$ on the $26^{\text {th }}$ day. Thus, approximately $29 \%$ of the total initial ${ }^{235} \mathrm{U}$ is removed while 71 $\%$ remains "unburned" at the end of the cycle. A total of $\sim 2.759 \mathrm{~kg}{ }^{235} \mathrm{U}$ is removed during the cycle and, on average, 106 grams is removed per day. Only a small amount of ${ }^{239} \mathrm{Pu}(\sim 11.55$ grams $)$ is generated in the core because the fuel is HEU and ${ }^{238} \mathrm{U}$ is in small quantity in the core.

The enrichments of the IFE, OFE, and IFE plus OFE combined, at the end of the cycle, and as calculated with the explicit model, are $82.28,86.38$ and $85.35 \%$, respectively. Enrichment as a function of irradiation time, for the IFE, OFE, and IFE plus OFE, is illustrated in Figure 21. 


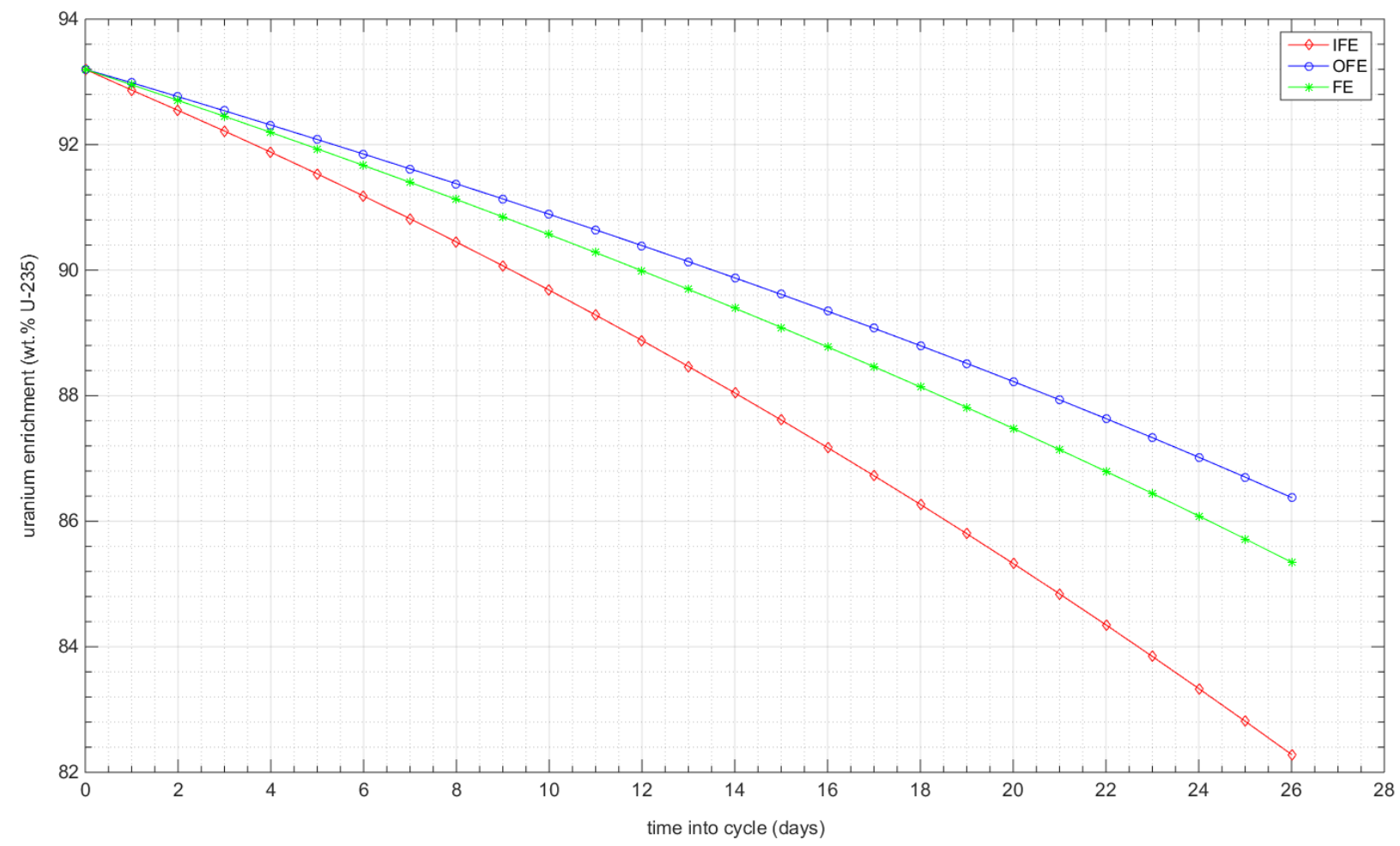

Figure 21. Variation of enrichment $\left({ }^{235} \mathrm{U} / \mathrm{U}\right)$ with irradiation time for explicit model.

A surface plot illustrating the azimuthally averaged ${ }^{235} \mathrm{U}$ depletion distribution (r-z) at EOC is provided in Figure 22. Linear plots showing the depletion profiles at various radial and axial cuts are illustrated in Figure 23; five axial and five radial profiles are provided for both the IFE and OFE. Radially dependent profiles through axial regions 1 (24.9 to $25.4 \mathrm{~cm}$ with respect to core midplane), 7 (11.0 to $16 \mathrm{~cm}$ with respect to core midplane), 10 (-1 to $1 \mathrm{~cm}$ with respect to core midplane), 16 ( -23.4 to $-22.4 \mathrm{~cm}$ with respect to core midplane), and 19 (-25.4 to $25.4 \mathrm{~cm}$ with respect to core midplane) are illustrated for both the IFE and OFE. Axially dependent profiles through radial regions $1(\mathrm{r}=7.119504-$ $7.2 \mathrm{~cm}), 3(\mathrm{r}=7.35-7.5 \mathrm{~cm}), 6(\mathrm{r}=8.5-9.5 \mathrm{~cm}), 9(\mathrm{r}=11.5-12 \mathrm{~cm})$, and $11(\mathrm{r}=12.4-12.53239 \mathrm{~cm})$ are illustrated for the IFE. Axially dependent profiles through radial regions $1(\mathrm{r}=15.11586-15.3 \mathrm{~cm})$, $3(\mathrm{r}=15.5-16.0 \mathrm{~cm}), 6(\mathrm{r}=17.5-18.5 \mathrm{~cm}), 9(\mathrm{r}=20.0-20.5 \mathrm{~cm})$, and $11(\mathrm{r}=20.75-20.87073 \mathrm{~cm})$ are illustrated for the OFE.

The distribution of ${ }^{235} \mathrm{U}$ depletion at EOC, in percent, is provided in Table 29 and Table 30, respectively, for the explicit and simplified models. The maximum depletion in the explicit model IFE is $70 \%$ and occurs in the fueled zone in the innermost radial region on the core horizontal midplane. The maximum depletion in the explicit model OFE is $59 \%$ and occurs in the fueled zone located in the outermost radial region on the core horizontal midplane. 


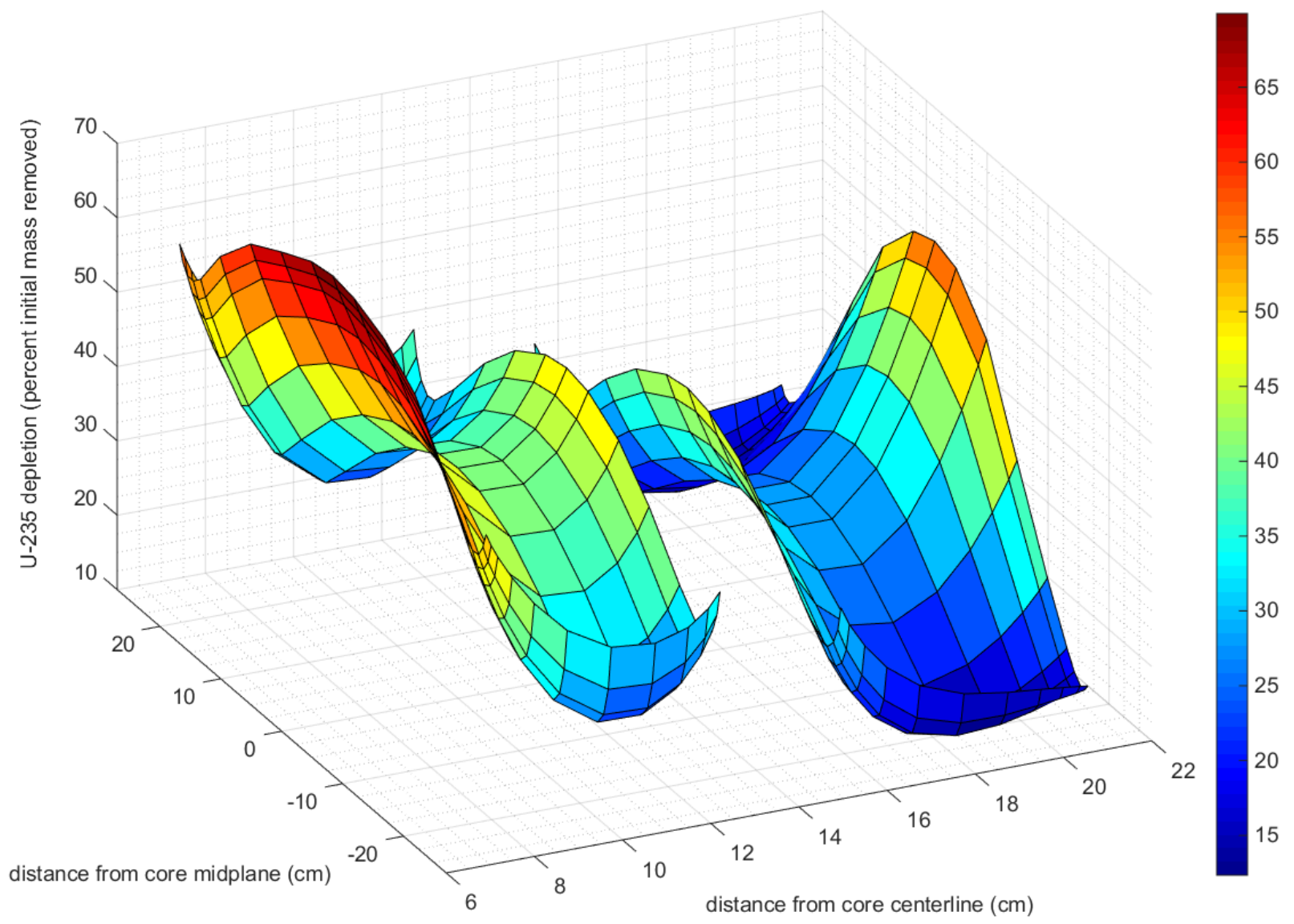

Figure 22. End-of-cycle U-235 depletion distribution for explicit model. 

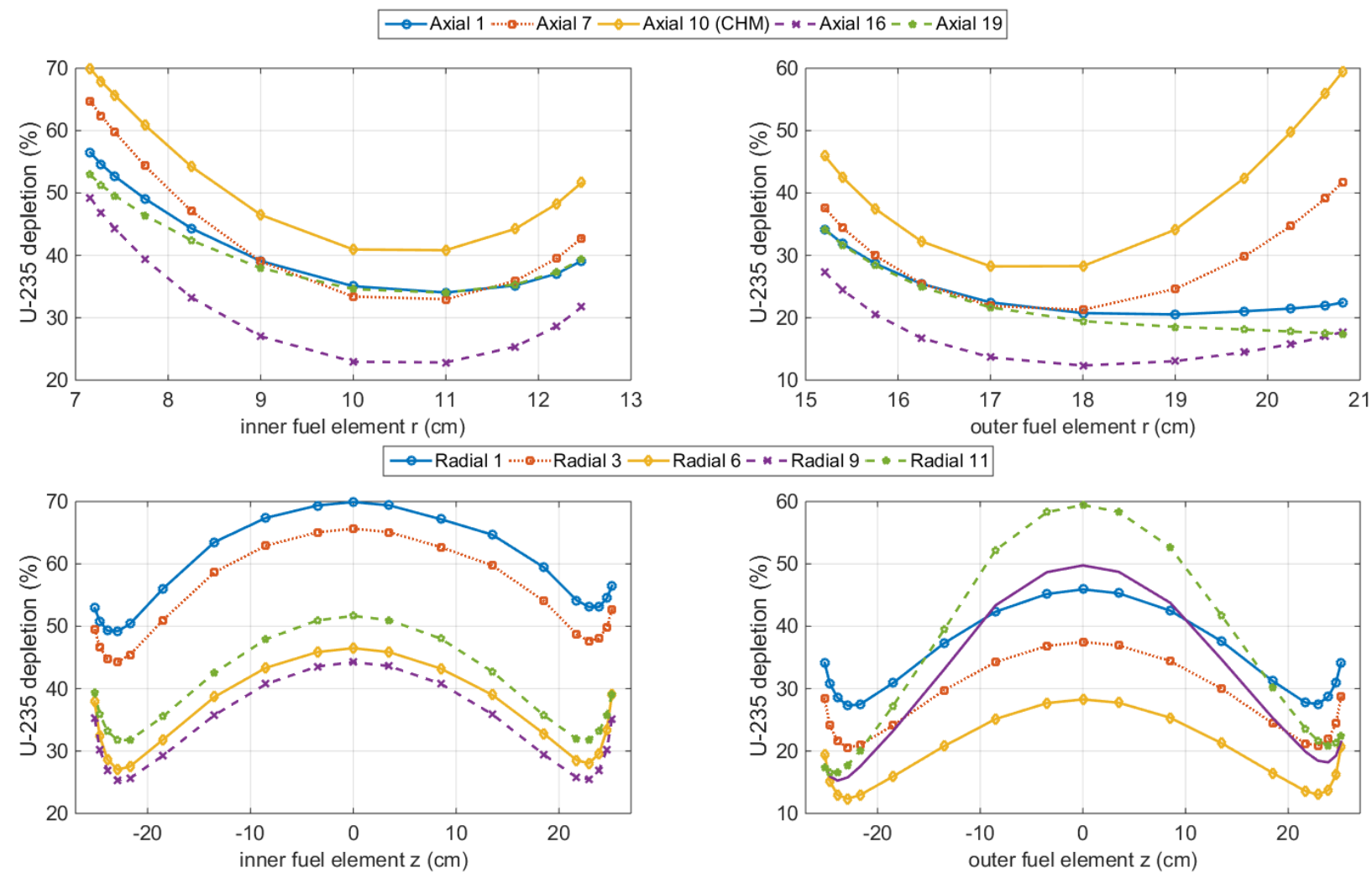

Figure 23. End-of-cycle U-235 depletion - radial and axial profiles for explicit model. 
Table 29. Explicit model end-of-cycle U-235 depletion (\%) distribution

\begin{tabular}{|c|c|c|c|c|c|c|c|c|c|c|c|c|c|c|c|c|c|c|c|c|c|c|}
\hline \multirow{2}{*}{$\begin{array}{c}\text { Axial } \\
\text { region }\end{array}$} & \multicolumn{11}{|c|}{ Inner Fuel Element } & \multicolumn{11}{|c|}{ Outer Fuel Element } \\
\hline & $\mathrm{r}=\mathbf{1}^{\text {(a) }}$ & $r=2$ & $\mathbf{r}=\mathbf{3}$ & $r=4$ & $r=5$ & $r=6$ & $r=7$ & $r=8$ & $r=9$ & $r=10$ & $r=11$ & $r=1$ & $r=2$ & $\mathbf{r}=\mathbf{3}$ & $r=4$ & $r=5$ & $r=6$ & $\mathrm{r}=7$ & $\mathbf{r}=8$ & $r=9$ & $r=10$ & $r=11$ \\
\hline 1 & 56.49 & 54.63 & 52.67 & 49.07 & 44.33 & 39.10 & 35.06 & 34.04 & 35.17 & 37.08 & 39.10 & 34.18 & 31.86 & 28.71 & 25.45 & 22.47 & 20.75 & 20.53 & 21.04 & 21.47 & 21.94 & 22.42 \\
\hline 2 & 54.50 & 52.35 & 49.84 & 45.25 & 39.56 & 33.43 & 29.06 & 28.34 & 30.23 & 33.04 & 35.81 & 30.96 & 28.18 & 24.41 & 20.68 & 17.55 & 16.21 & 16.75 & 18.04 & 19.25 & 20.40 & 21.25 \\
\hline 3 & 53.12 & 50.67 & 48.04 & 42.83 & 36.33 & 29.59 & 25.05 & 24.63 & 26.96 & 30.13 & 33.16 & 28.72 & 25.80 & 21.87 & 18.02 & 14.91 & 13.73 & 14.72 & 16.50 & 18.20 & 19.79 & 20.86 \\
\hline 4 & 53.10 & 50.45 & 47.63 & 42.10 & 35.16 & 28.02 & 23.31 & 23.01 & 25.51 & 28.78 & 31.80 & 27.54 & 24.74 & 20.90 & 17.09 & 14.07 & 13.01 & 14.21 & 16.38 & 18.44 & 20.44 & 21.66 \\
\hline 5 & 54.17 & 51.64 & 48.75 & 43.09 & 35.94 & 28.54 & 23.66 & 23.29 & 25.76 & 28.97 & 31.96 & 27.75 & 24.98 & 21.22 & 17.52 & 14.56 & 13.56 & 14.98 & 17.47 & 19.87 & 22.14 & 23.53 \\
\hline 6 & 59.48 & 56.97 & 54.09 & 48.29 & 40.83 & 32.81 & 27.42 & 26.92 & 29.47 & 32.77 & 35.75 & 31.21 & 28.37 & 24.43 & 20.48 & 17.34 & 16.47 & 18.57 & 21.99 & 25.28 & 28.35 & 30.24 \\
\hline 7 & 64.69 & 62.40 & 59.76 & 54.34 & 47.12 & 39.02 & 33.40 & 32.97 & 35.90 & 39.54 & 42.76 & 37.60 & 34.44 & 30.02 & 25.49 & 21.90 & 21.27 & 24.63 & 29.84 & 34.71 & 39.13 & 41.75 \\
\hline 8 & 67.17 & 65.07 & 62.69 & 57.71 & 50.99 & 43.22 & 37.74 & 37.53 & 40.79 & 44.67 & 48.01 & 42.51 & 39.19 & 34.42 & 29.47 & 25.60 & 25.34 & 30.17 & 37.29 & 43.77 & 49.47 & 52.68 \\
\hline 9 & 69.39 & 67.36 & 65.08 & 60.23 & 53.60 & 45.85 & 40.31 & 40.19 & 43.62 & 47.59 & 50.99 & 45.29 & 41.88 & 36.91 & 31.75 & 27.75 & 27.74 & 33.42 & 41.53 & 48.73 & 54.94 & 58.33 \\
\hline 10 & 69.92 & 67.91 & 65.65 & 60.86 & 54.24 & 46.49 & 40.94 & 40.83 & 44.25 & 48.29 & 51.66 & 45.92 & 42.50 & 37.49 & 32.27 & 28.23 & 28.28 & 34.12 & 42.44 & 49.76 & 56.03 & 59.45 \\
\hline 11 & 69.36 & 67.37 & 65.06 & 60.22 & 53.61 & 45.86 & 40.32 & 40.16 & 43.55 & 47.55 & 50.94 & 45.17 & 41.76 & 36.85 & 31.68 & 27.69 & 27.68 & 33.35 & 41.47 & 48.68 & 54.89 & 58.29 \\
\hline 12 & 67.38 & 65.32 & 62.93 & 57.93 & 51.15 & 43.34 & 37.76 & 37.51 & 40.73 & 44.59 & 47.92 & 42.33 & 39.01 & 34.26 & 29.29 & 25.42 & 25.13 & 29.88 & 36.95 & 43.36 & 49.02 & 52.22 \\
\hline 13 & 63.50 & 61.27 & 58.65 & 53.41 & 46.44 & 38.67 & 33.24 & 32.85 & 35.76 & 39.36 & 42.55 & 37.30 & 34.18 & 29.76 & 25.20 & 21.58 & 20.80 & 23.84 & 28.63 & 33.10 & 37.13 & 39.49 \\
\hline 14 & 56.03 & 53.64 & 51.00 & 45.73 & 39.02 & 31.82 & 27.03 & 26.72 & 29.27 & 32.56 & 35.54 & 30.89 & 28.06 & 24.12 & 20.15 & 16.94 & 15.90 & 17.59 & 20.47 & 23.19 & 25.72 & 27.20 \\
\hline 15 & 50.39 & 48.05 & 45.44 & 40.34 & 34.05 & 27.54 & 23.27 & 23.11 & 25.63 & 28.83 & 31.78 & 27.48 & 24.70 & 20.93 & 17.18 & 14.13 & 12.95 & 13.92 & 15.76 & 17.50 & 19.10 & 20.06 \\
\hline 16 & 49.22 & 46.86 & 44.29 & 39.38 & 33.27 & 27.02 & 22.94 & 22.83 & 25.37 & 28.66 & 31.72 & 27.29 & 24.47 & 20.59 & 16.75 & 13.64 & 12.34 & 13.05 & 14.48 & 15.77 & 16.99 & 17.73 \\
\hline 17 & 49.28 & 47.21 & 44.79 & 40.12 & 34.52 & 28.62 & 24.66 & 24.44 & 26.91 & 30.14 & 33.19 & 28.56 & 25.59 & 21.59 & 17.66 & 14.42 & 12.95 & 13.34 & 14.35 & 15.26 & 16.03 & 16.55 \\
\hline 18 & 50.84 & 48.76 & 46.64 & 42.59 & 37.65 & 32.39 & 28.58 & 28.25 & 30.26 & 33.12 & 35.88 & 30.84 & 27.94 & 24.11 & 20.25 & 16.96 & 15.19 & 15.14 & 15.59 & 15.96 & 16.29 & 16.54 \\
\hline 19 & 52.91 & 51.28 & 49.58 & 46.42 & 42.41 & 37.95 & 34.59 & 34.02 & 35.33 & 37.33 & 39.32 & 34.12 & 31.65 & 28.41 & 24.94 & 21.66 & 19.45 & 18.53 & 18.12 & 17.79 & 17.53 & 17.40 \\
\hline
\end{tabular}

(a) $\mathrm{r}=\mathrm{n}$ denotes the radial region number; $\mathrm{n}$ varies from 1 to 11 for both the inner and outer fuel elements. 
Table 30. Simplified model end-of-cycle U-235 depletion (\%) distribution

\begin{tabular}{|c|c|c|c|c|c|c|c|c|c|c|c|c|c|c|c|c|c|c|c|c|c|c|}
\hline \multirow{2}{*}{$\begin{array}{c}\text { Axial } \\
\text { region }\end{array}$} & \multicolumn{11}{|c|}{ Inner Fuel Element } & \multicolumn{11}{|c|}{ Outer Fuel Element } \\
\hline & $\mathrm{r}=1^{(\mathrm{a})}$ & $\mathrm{r}=2$ & $r=3$ & $r=4$ & $r=5$ & $r=6$ & $\mathrm{r}=7$ & $\mathrm{r}=8$ & $\mathrm{r}=9$ & $r=10$ & $\mathrm{r}=11$ & $r=1$ & $r=2$ & $r=3$ & $r=4$ & $r=5$ & $r=6$ & $\mathrm{r}=7$ & $r=8$ & $r=9$ & $r=10$ & $\mathrm{r}=11$ \\
\hline 1 & 57.80 & 56.05 & 54.00 & 50.14 & 45.18 & 39.84 & 35.70 & 34.64 & 35.89 & 37.95 & 40.10 & 35.31 & 32.87 & 29.49 & 26.00 & 22.88 & 21.05 & 20.80 & 21.23 & 21.72 & 22.21 & 22.64 \\
\hline 2 & 55.69 & 53.53 & 51.02 & 46.24 & 40.24 & 33.96 & 29.46 & 28.73 & 30.73 & 33.69 & 36.59 & 31.96 & 28.92 & 24.94 & 20.96 & 17.78 & 16.34 & 16.86 & 18.06 & 19.32 & 20.52 & 21.42 \\
\hline 3 & 54.34 & 51.86 & 49.04 & 43.69 & 36.89 & 30.02 & 25.38 & 24.93 & 27.39 & 30.77 & 33.96 & 29.47 & 26.40 & 22.29 & 18.25 & 15.07 & 13.82 & 14.74 & 16.48 & 18.23 & 19.89 & 21.04 \\
\hline 4 & 54.22 & 51.75 & 48.70 & 43.01 & 35.74 & 28.42 & 23.62 & 23.29 & 25.87 & 29.34 & 32.50 & 28.26 & 25.25 & 21.25 & 17.31 & 14.22 & 13.12 & 14.26 & 16.35 & 18.48 & 20.49 & 21.78 \\
\hline 5 & 55.47 & 52.98 & 49.91 & 44.10 & 36.59 & 29.01 & 24.01 & 23.67 & 26.27 & 29.62 & 32.72 & 28.46 & 25.55 & 21.64 & 17.75 & 14.72 & 13.71 & 15.07 & 17.49 & 19.96 & 22.30 & 23.77 \\
\hline 6 & 60.86 & 58.37 & 55.37 & 49.48 & 41.63 & 33.44 & 27.90 & 27.44 & 30.11 & 33.58 & 36.70 & 32.07 & 29.06 & 24.97 & 20.82 & 17.58 & 16.68 & 18.75 & 22.14 & 25.54 & 28.71 & 30.69 \\
\hline 7 & 66.12 & 63.88 & 61.10 & 55.60 & 48.08 & 39.85 & 34.07 & 33.66 & 36.70 & 40.53 & 43.87 & 38.60 & 35.30 & 30.70 & 25.94 & 22.24 & 21.56 & 24.89 & 30.06 & 35.07 & 39.63 & 42.33 \\
\hline 8 & 68.56 & 66.51 & 64.01 & 59.01 & 52.02 & 44.15 & 38.53 & 38.36 & 41.73 & 45.81 & 49.29 & 43.66 & 40.12 & 35.17 & 29.98 & 26.02 & 25.72 & 30.54 & 37.65 & 44.35 & 50.15 & 53.49 \\
\hline 9 & 70.76 & 68.81 & 66.42 & 61.57 & 54.72 & 46.88 & 41.19 & 41.08 & 44.60 & 48.76 & 52.29 & 46.51 & 42.89 & 37.74 & 32.33 & 28.23 & 28.20 & 33.94 & 42.10 & 49.60 & 55.94 & 59.45 \\
\hline 10 & 71.31 & 69.42 & 67.02 & 62.17 & 55.33 & 47.47 & 41.77 & 41.69 & 45.27 & 49.45 & 52.97 & 47.11 & 43.51 & 38.35 & 32.88 & 28.71 & 28.73 & 34.66 & 43.04 & 50.70 & 57.10 & 60.61 \\
\hline 11 & 70.74 & 68.80 & 66.39 & 61.55 & 54.68 & 46.82 & 41.13 & 41.01 & 44.51 & 48.69 & 52.24 & 46.38 & 42.78 & 37.67 & 32.26 & 28.16 & 28.13 & 33.88 & 42.04 & 49.56 & 55.92 & 59.43 \\
\hline 12 & 68.79 & 66.74 & 64.23 & 59.20 & 52.17 & 44.23 & 38.53 & 38.31 & 41.64 & 45.69 & 49.18 & 43.46 & 39.94 & 34.99 & 29.79 & 25.79 & 25.45 & 30.20 & 37.19 & 43.82 & 49.59 & 52.88 \\
\hline 13 & 64.92 & 62.72 & 60.02 & 54.66 & 47.38 & 39.47 & 33.89 & 33.52 & 36.55 & 40.35 & 43.67 & 38.32 & 35.00 & 30.38 & 25.62 & 21.89 & 21.06 & 24.05 & 28.75 & 33.35 & 37.47 & 39.91 \\
\hline 14 & 57.36 & 55.02 & 52.21 & 46.84 & 39.80 & 32.46 & 27.52 & 27.23 & 29.90 & 33.34 & 36.45 & 31.75 & 28.72 & 24.62 & 20.47 & 17.17 & 16.10 & 17.74 & 20.56 & 23.38 & 25.96 & 27.55 \\
\hline 15 & 51.57 & 49.24 & 46.46 & 41.32 & 34.68 & 28.02 & 23.62 & 23.47 & 26.07 & 29.46 & 32.58 & 28.19 & 25.22 & 21.31 & 17.38 & 14.30 & 13.07 & 13.97 & 15.73 & 17.46 & 19.07 & 20.10 \\
\hline 16 & 50.36 & 48.06 & 45.31 & 40.21 & 33.84 & 27.43 & 23.28 & 23.14 & 25.80 & 29.25 & 32.45 & 28.02 & 24.99 & 20.97 & 16.94 & 13.77 & 12.42 & 13.05 & 14.39 & 15.71 & 16.87 & 17.66 \\
\hline 17 & 50.50 & 48.29 & 45.76 & 40.98 & 35.02 & 29.02 & 24.97 & 24.77 & 27.34 & 30.77 & 33.94 & 29.31 & 26.16 & 21.99 & 17.84 & 14.54 & 13.04 & 13.34 & 14.26 & 15.16 & 15.96 & 16.50 \\
\hline 18 & 51.91 & 49.96 & 47.68 & 43.53 & 38.25 & 32.90 & 29.04 & 28.64 & 30.74 & 33.79 & 36.73 & 31.76 & 28.68 & 24.60 & 20.55 & 17.13 & 15.32 & 15.16 & 15.53 & 15.94 & 16.27 & 16.56 \\
\hline 19 & 54.08 & 52.48 & 50.71 & 47.44 & 43.19 & 38.72 & 35.25 & 34.56 & 35.98 & 38.11 & 40.34 & 35.20 & 32.61 & 29.17 & 25.51 & 22.07 & 19.73 & 18.70 & 18.21 & 17.92 & 17.62 & 17.53 \\
\hline
\end{tabular}

(a) $\mathrm{r}=\mathrm{n}$ denotes the radial region number; $\mathrm{n}$ varies from 1 to 11 for both the inner and outer fuel elements. 


\subsubsection{Neutron Poisons}

The three major neutron-absorbing poisons in the core are ${ }^{10} \mathrm{~B},{ }^{135} \mathrm{Xe}$, and ${ }^{149} \mathrm{Sm}$. Boron- 10 , in the form of $\mathrm{B}_{4} \mathrm{C}$, is used as a burnable poison in the IFE filler. The variation with irradiation time of ${ }^{10} \mathrm{~B}$ (grams and relative concentration) in the explicit model IFE filler region is illustrated in Figure 24. Only $\sim 6 \%$ of the initial ${ }^{10} \mathrm{~B}$ in the IFE filler remains at the end of the cycle.

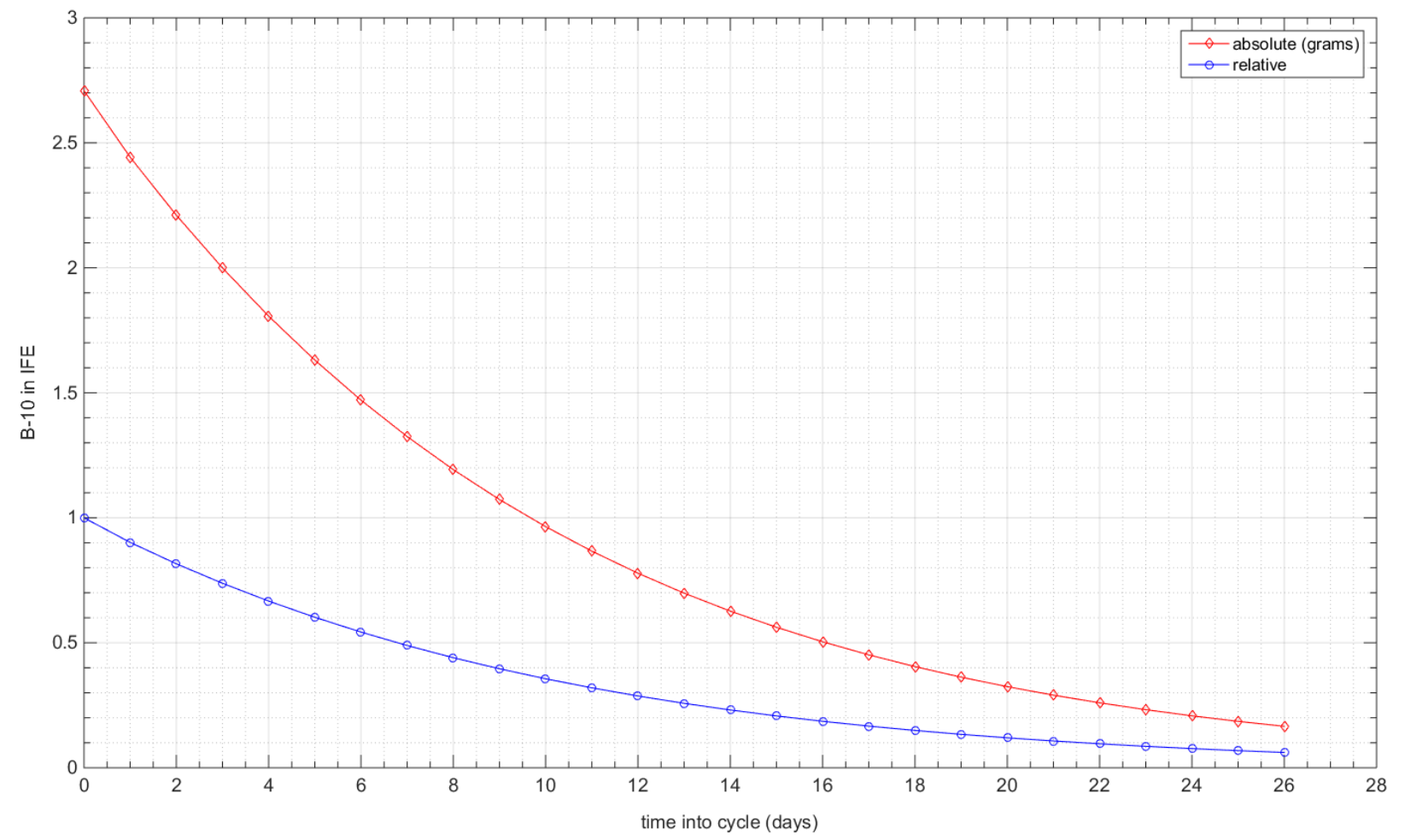

Figure 24. Variation of inner fuel element B-10 poison with time for explicit model.

The variations of the ${ }^{135} \mathrm{Xe}$ and ${ }^{149} \mathrm{Sm}$ fission product poisons as calculated with the explicit model are shown in Figure 25. These fission products account for over $90 \%$ of fission product poisoning in the core [24]. The concentration of ${ }^{135} \mathrm{Xe}$ rapidly increases with increasing time, reaches a maximum concentration of $\sim 0.074$ grams at two days into the cycle, and then decreases approximately linearly to reach $\sim 0.052$ grams at the end of the cycle. The decrease in "equilibrium" xenon, which should theoretically remain constant, is thought to be due to the consumption of ${ }^{235} \mathrm{U}$ and the spatial/spectral effects as a function of exposure in HFIR. The ${ }^{149} \mathrm{Sm}$ mass reaches a maximum amount of $\sim 0.42$ grams at approximately 12 days into the cycle and then decreases to $\sim 0.37$ grams at the end of the cycle. 


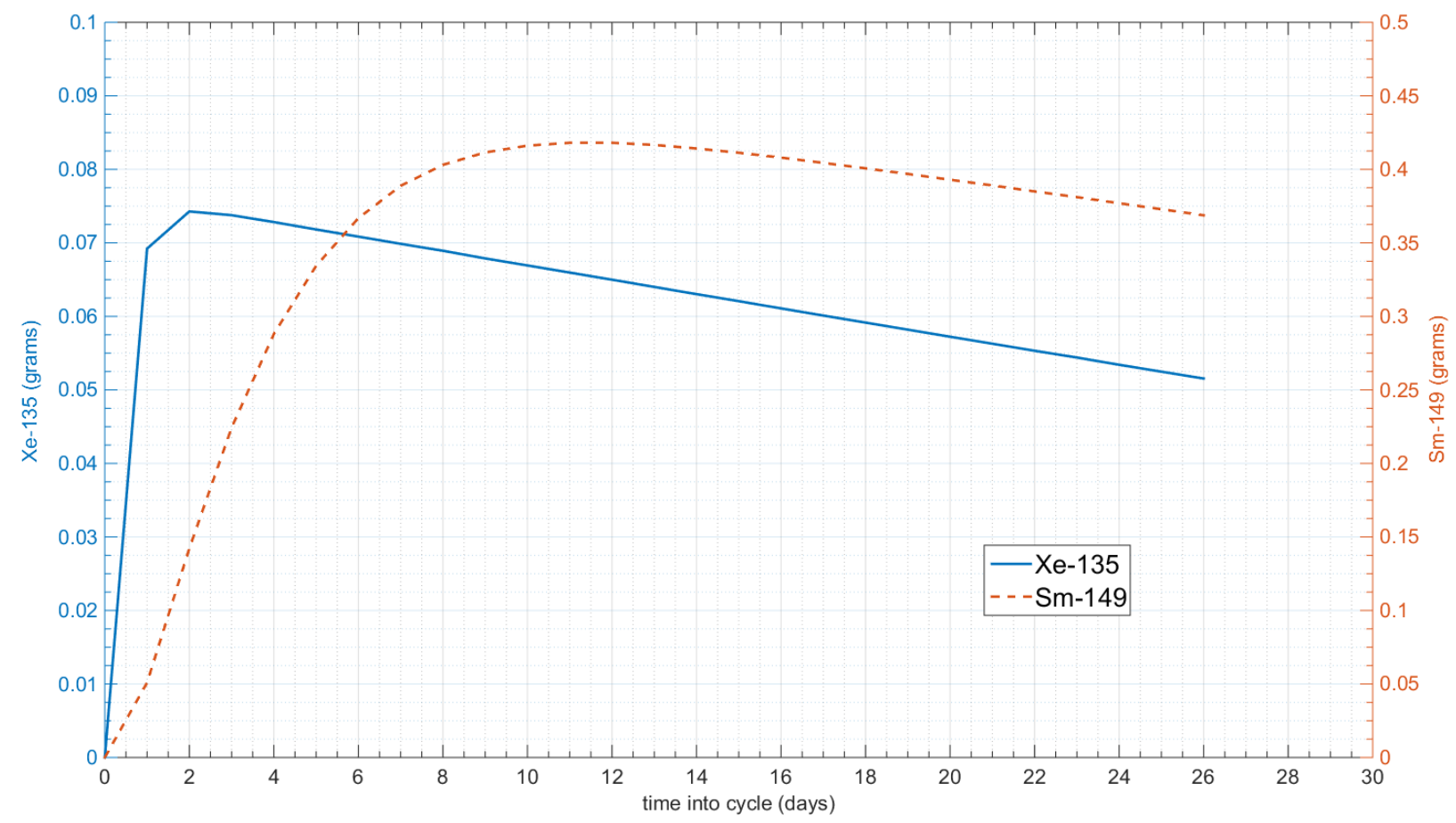

Figure 25. Buildup of Xe-135 and Sm-149 fission product poisons with time for explicit model.

\subsection{SINGLE CYCLE ISOTOPE PRODUCTION METRICS}

During the VESTA depletion simulation, ${ }^{188} \mathrm{~W}$ production target in the HT; five full length ${ }^{252} \mathrm{Cf}$ production targets in the FTT; and ${ }^{238} \mathrm{Pu}$ production targets in the inner small, outer small, and large VXFs were activated. Prior to interpreting the results shown in this section, the reader must be made aware that the results listed in this section have not been validated against measured data and strictly reflect the results as calculated with the VESTA depletion tool and corresponding nuclear data. Also, it is important to reiterate that the simplified model results reflect a 26 day 10 hour irradiation, whereas the explicit model results reflect a 26 day irradiation, which causes some differences in the calculated isotopic contents. The magnitude and relevance of these differences vary from isotope to isotope.

Based on some limited ${ }^{188} \mathrm{~W}$ production measurement data, it appears that ${ }^{188} \mathrm{~W}$ is being significantly ( 5-10 times) over-predicted. Further investigations show that this is primarily due to limitations in the cross-section data that are available for the ${ }^{187} \mathrm{~W}$ and ${ }^{188} \mathrm{~W}$ isotopes. No neutron interaction cross-section data, but only decay data, exist for ${ }^{187} \mathrm{~W}$ and ${ }^{188} \mathrm{~W}$ in any of the ENDF/B evaluations [9, 22], including in the ENDF/B-VII.0 data used with VESTA/MCNP. For cases where no cross-sections are available in the VESTA libraries, the code uses, where available, the cross-section data from the ORIGEN 2.2 library. In this case, the "pwru50.lib" ORIGEN 2.2 library is used. For the ${ }^{187} \mathrm{~W}$ capture cross-section, a value of 73.55 barns is available in pwru50.lib and is therefore used by VESTA. No cross-section data is available for ${ }^{188} \mathrm{~W}$ in the ENDF/B library or the ORIGEN 2.2 library; therefore, the only ${ }^{188} \mathrm{~W}$ removal mechanism is decay. The VESTA simulation with the explicit model estimates that $10.81 \mathrm{mg}{ }^{188} \mathrm{~W}$ and $2.74 \mathrm{mg}{ }^{188} \mathrm{Re}$ are produced in one full cycle of irradiation (Table 31). The variations of the ${ }^{188} \mathrm{~W}$ and ${ }^{188} \mathrm{Re}$ isotopes with irradiation time are illustrated in Figure 26. If ${ }^{188} \mathrm{~W}$ benchmarking is explored at a later date, future work may involve assessing the ${ }^{187} \mathrm{~W}$ and ${ }^{188} \mathrm{~W}$ neutron transport cross-sections that are available in the TENDL library [25]. 
Table 31. Single cycle $\mathrm{W}-188$ and $\mathrm{Cf}-252$ production

\begin{tabular}{ccc}
\hline Isotope & $\begin{array}{c}\text { Explicit Model } \\
(\mathbf{m g})\end{array}$ & $\begin{array}{c}\text { Simplified Model } \\
(\mathbf{m g})\end{array}$ \\
\hline${ }^{188} \mathrm{~W}^{\text {(a) }}$ & 10.810 & 11.109 \\
${ }^{188} \mathrm{Re}^{(\mathrm{a})}$ & 2.740 & 2.828 \\
${ }^{249} \mathrm{Bk}^{(\mathrm{b})}$ & 39.169 & 38.593 \\
${ }^{252} \mathrm{Cf}^{\text {(b) }}$ & 36.080 & 37.139 \\
\hline
\end{tabular}

(a) One capsule with enriched tungsten rings in the hydraulic tube. Based on available measured data, the production of ${ }^{188} \mathrm{~W}$ and ${ }^{188} \mathrm{Re}$ is being over predicted.

(b) Five full length ${ }^{252} \mathrm{Cf}$ production targets in ring 1 of the flux trap. Following this work an effort to benchmark/validate ${ }^{252} \mathrm{Cf}$ production with VESTA will be initiated.

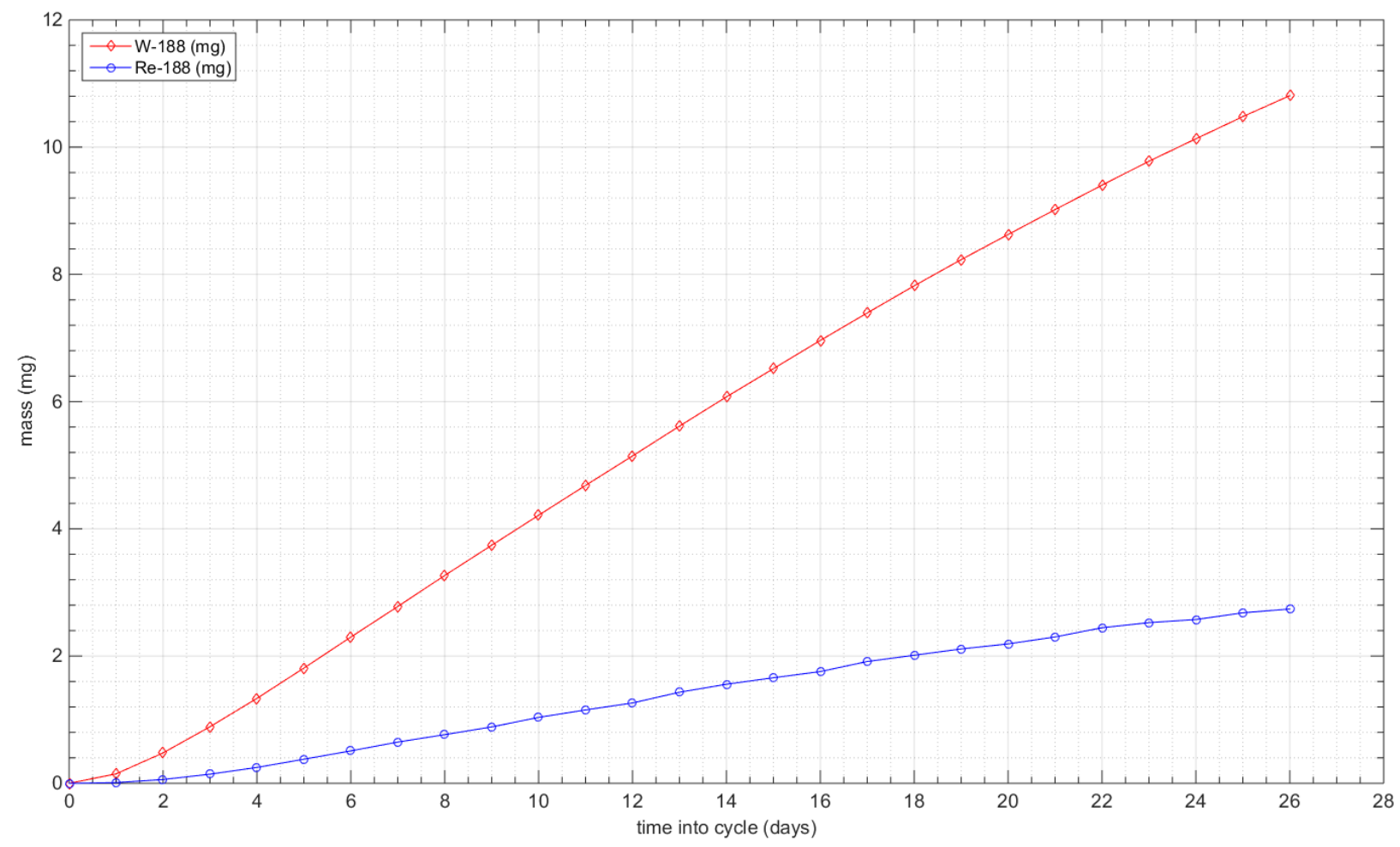

Figure 26. Single cycle W-188 and Re-188 production curves for explicit model.

As listed in Table 31 and illustrated in Figure 27, approximately $39 \mathrm{mg}{ }^{249} \mathrm{Bk}$ and $36 \mathrm{mg}{ }^{252} \mathrm{Cf}$ are generated during the single cycle VESTA simulation for the explicit model. If the first cycle ${ }^{252} \mathrm{Cf}$ production is assumed applicable for each of several consecutive cycles, which is an approximate assumption due to the continuous evolution of this target composition, a total production of $180-252 \mathrm{mg}$ ${ }^{252} \mathrm{Cf}$ is calculated over $5-7$ cycles (typical campaign lengths per [26]). These results compare fairly well to typical production goals of about $150 \mathrm{mg}$ per campaign [26]. Following this work, a study is currently planned to benchmark ${ }^{252} \mathrm{Cf}$ production with VESTA. 


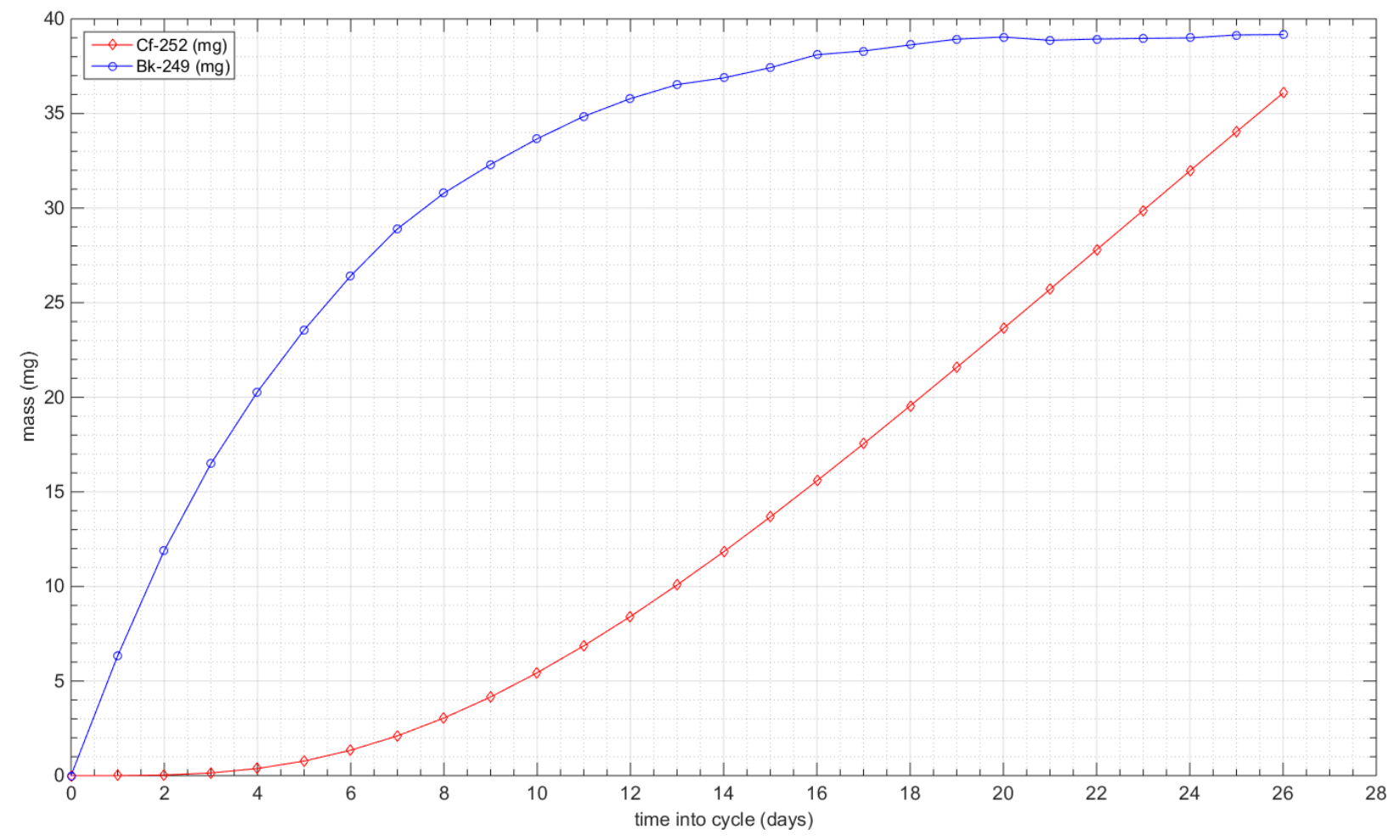

Figure 27. Single cycle Cf-252 and Bk-249 production curves for explicit model.

The ${ }^{238} \mathrm{Pu}$ production targets are expected to be irradiated in the inner small, outer small, and large VXFs for approximately $2-3,3-4$, and $5-6$ cycles, respectively. However, the purpose of the work described in this report was not to calculate the annual ${ }^{238} \mathrm{Pu}$ yield, but instead, to model a representative cycle. Pertinent metrics associated with ${ }^{238} \mathrm{Pu}$ production are listed in Table 32. The results provided are based on 15 days of decay beyond the end of the cycle to allow for the ${ }^{238} \mathrm{~Np}$ (2.117 day half-life per [27]) to decay into ${ }^{238} \mathrm{Pu}$.

The decay calculations were performed in a MATLAB post-processing script that was generated to post-process and plot the results provided in this report. With the exception of ${ }^{238} \mathrm{~Np}$, all other nuclides (within the ${ }^{238} \mathrm{Pu}$ production targets) that are discussed in this section have long half-lives relative to the 15-day decay period (e.g., ${ }^{237} \mathrm{~Np},{ }^{236} \mathrm{Pu},{ }^{238} \mathrm{Pu},{ }^{239} \mathrm{Pu}$ ). Thus, performing follow-on ORIGEN decay calculations to estimate the ${ }^{238} \mathrm{Pu}$ yields and metrics is not required. The ${ }^{238} \mathrm{~Np}$ atoms were exponentially decayed into ${ }^{238} \mathrm{Pu}$ atoms based on a ${ }^{238} \mathrm{~Np}$ half-life of 2.117 days, a ${ }^{238} \mathrm{~Np}$ mass of 238.050949 grams/mole, and a ${ }^{238} \mathrm{Pu}$ mass of 238.049561 grams/mole [19]. The masses of the longer-lived radionuclides remained constant over the 15-day decay period.

Approximately 5.8, 3.7, and $2.2 \%$ of the initial ${ }^{237} \mathrm{~Np}$ isotope is consumed during the first irradiation cycle in the inner small, outer small, and large VXFs, respectively, in order to produce $\sim 54,22$, and 37 grams of ${ }^{238} \mathrm{Pu}$. At the end of the first cycle, the quality of the $\mathrm{Pu}$ is $\sim 93,95$, and $97 \%$, respectively. The generation of ${ }^{238} \mathrm{Pu}$ with time ( 26 days irradiation plus 15 days decay) is illustrated in Figure 28 . The other metrics listed in Table 32 are plotted as a function of time in Figure 29. 
Table 32. Single cycle $\mathrm{Pu}-238$ production target metrics

\begin{tabular}{|c|c|c|c|c|c|c|}
\hline \multirow{2}{*}{ 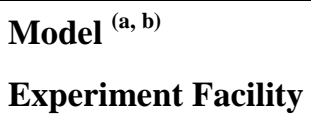 } & \multicolumn{3}{|c|}{ Explicit Model } & \multicolumn{3}{|c|}{ Simplified Model } \\
\hline & $\operatorname{ISVXF}^{(\mathbf{c})}$ & $\operatorname{OSVXF}^{(d)}$ & $\operatorname{LVXF}^{(\mathrm{e})}$ & $\operatorname{ISVXF}^{(\mathbf{c})}$ & $\operatorname{OSVXF}^{(\mathrm{d})}$ & $\operatorname{LVXF}^{(\mathrm{e})}$ \\
\hline${ }^{237} \mathrm{~Np}$ (relative) ${ }^{(\mathrm{f})}$ & 0.942 & 0.963 & 0.978 & 0.942 & 0.963 & 0.977 \\
\hline${ }^{238} \mathrm{Pu}$ (grams) & 54.079 & 21.688 & 37.264 & 54.544 & 21.912 & 37.625 \\
\hline Conversion ${ }^{(\mathrm{g})}$ & 0.050 & 0.033 & 0.021 & 0.050 & 0.034 & 0.021 \\
\hline Quality ${ }^{(h)}$ & 0.928 & 0.952 & 0.970 & 0.928 & 0.951 & 0.969 \\
\hline $\mathrm{Pu}-236(\mathrm{ppm})^{(\mathrm{i})}$ & 1.453 & 0.992 & 0.970 & 1.450 & 0.987 & 0.978 \\
\hline
\end{tabular}

(a) Both models made use of VESTA with ENDF/B-VII.0 cross-sections. The thermal ${ }^{238} \mathrm{Pu}$ capture cross-section was reduced $\sim 26 \%$ from ENDF/B-VII.0 to ENDF/B-VII.1.

(b) All results correspond to 15 days of decay following reactor shutdown. Note that only ${ }^{238} \mathrm{~Np}$ was decayed to ${ }^{238} \mathrm{Pu}$ during the 15 day decay period because all other isotopes have long half-lives relative to 15 days.

(c) Five inner small vertical experiment facilities each containing seven fully loaded targets.

(d) Three outer small vertical experiment facilities each containing seven fully loaded targets.

(e) Three large vertical experiment facilities each containing 19 fully loaded targets.

(f) Relative ${ }^{237} \mathrm{~Np}$ concentration calculated as ${ }^{237} \mathrm{~Np}$ (EOC+15 days decay) divided by ${ }^{237} \mathrm{~Np}$ (BOC).

(g) Conversion calculated as ${ }^{238} \mathrm{Pu}$ (EOC +15 days decay) divided by ${ }^{237} \mathrm{~Np}$ (BOC).

(h) Plutonium quality is calculated as the ratio of ${ }^{238} \mathrm{Pu}$ to total $\mathrm{Pu}$ after 15 days decay following reactor shutdown.

(i) ${ }^{236} \mathrm{Pu}$ content in ppm by weight in $\mathrm{Pu} 15$ days decay following reactor shutdown. Production via gamma activation was not modeled.

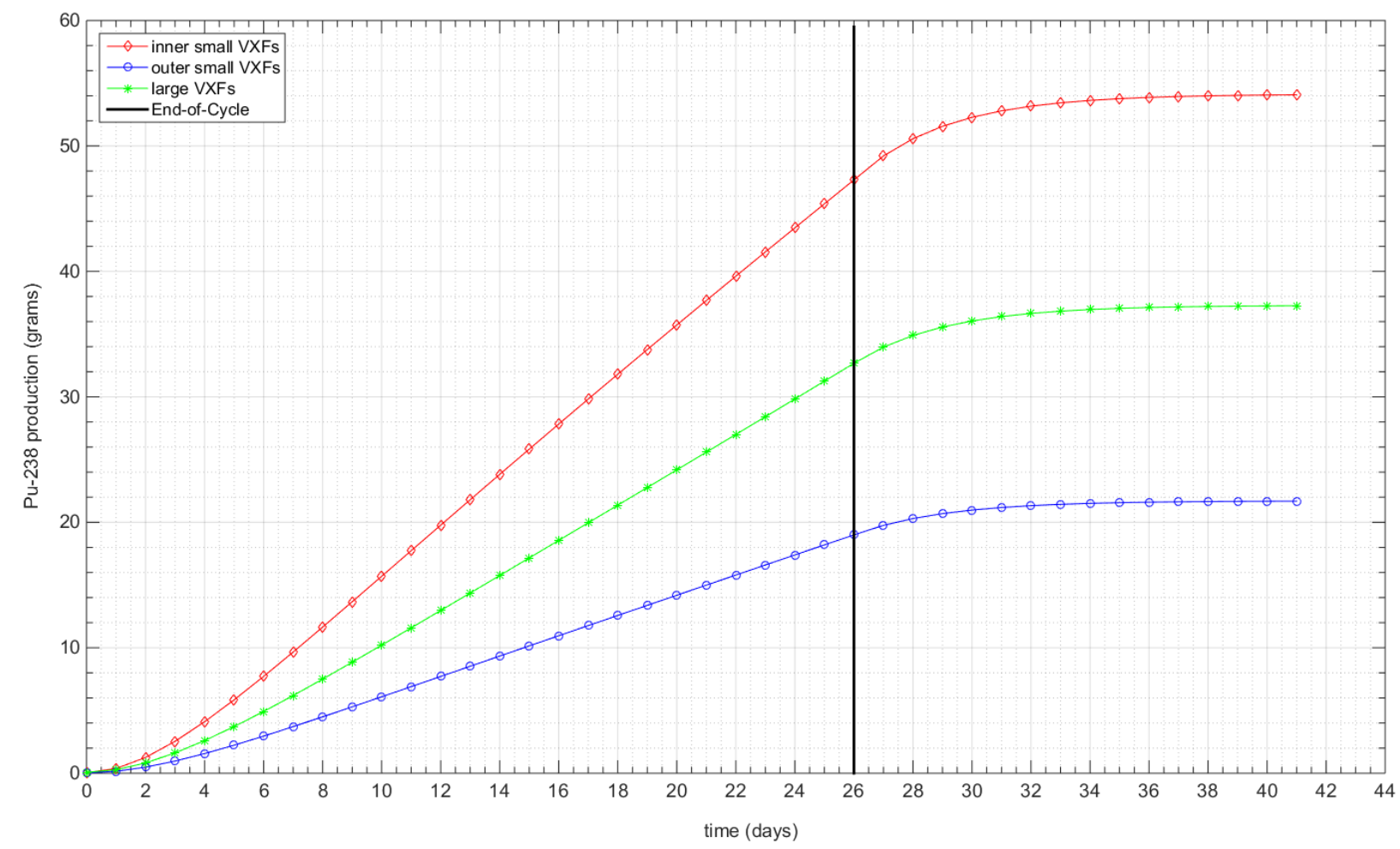

Figure 28. Single cycle Pu-238 production curves for explicit model. 

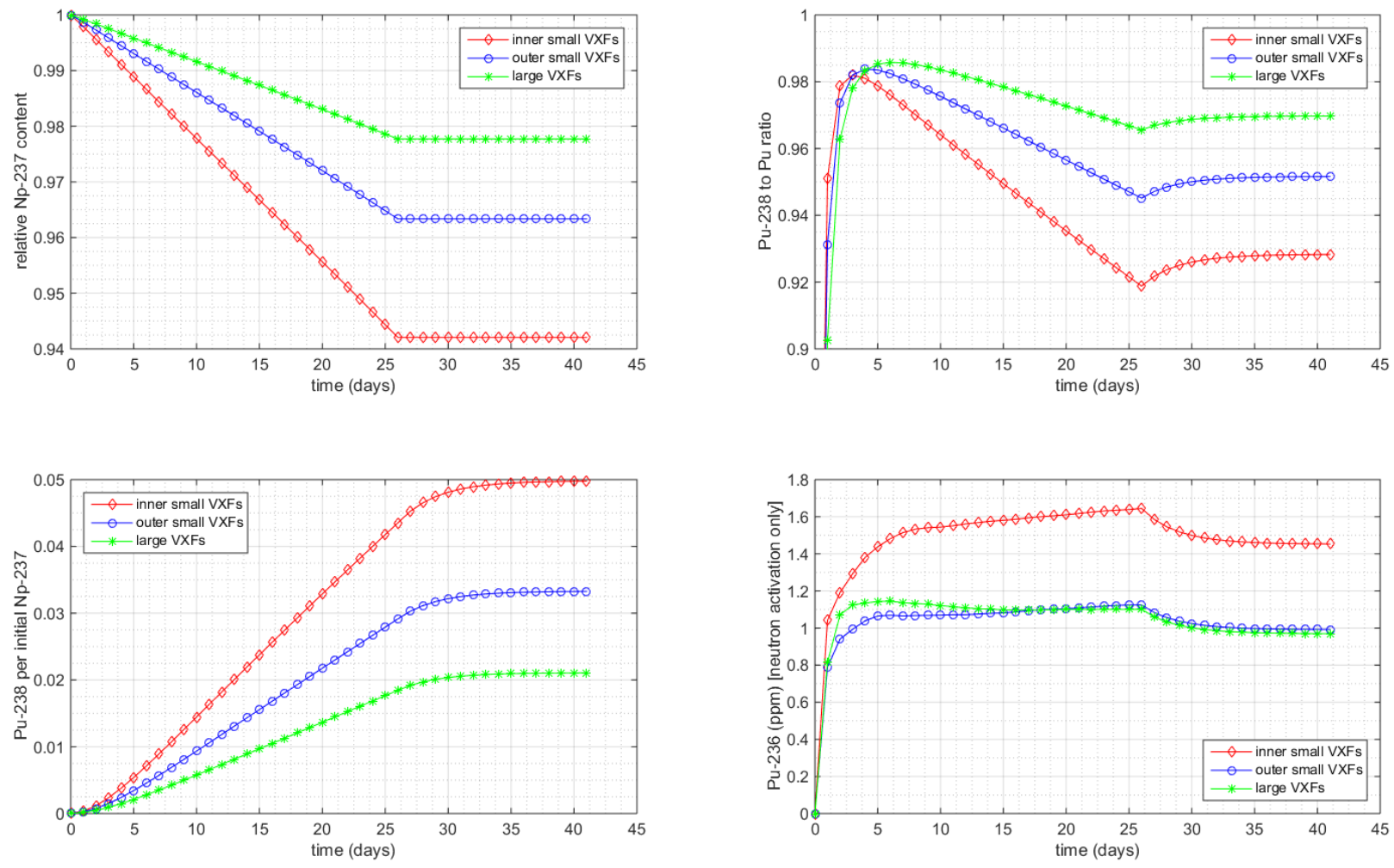

Figure 29. Single cycle Pu-238 production target metrics for explicit model.

It is again important to note that ${ }^{238} \mathrm{Pu}$ production has not yet been benchmarked, but measurements to date have generally showed good agreement in calculating the $\mathrm{Np}$ and $\mathrm{Pu}$ vectors. Irradiations to date have only been performed in the inner small VXFs; thus, no irradiations have been performed in the outer small or large VXFs. Another note to point out is that ENDF/B-VII.0 cross-sections were used in this work and that the thermal ${ }^{238} \mathrm{Pu}$ capture cross-section is reduced $\sim 26 \%$ from ENDF/B-VII.0 to ENDF/BVII.1. Refer to $[15,28]$ for more details and the impacts observed between the cross-section data sets.

The ${ }^{252} \mathrm{Cf}$ and ${ }^{238} \mathrm{Pu}$ production targets contain fissionable and fertile isotopes, and thus contribute to the total core fission power. The ${ }^{252} \mathrm{Cf}$ production targets are loaded with various $\mathrm{Am}, \mathrm{Cm}$, and $\mathrm{Pu}$ isotopes, and during the irradiation process, they transmute to other fissionable isotopes. The ${ }^{238} \mathrm{Pu}$ production targets are loaded with ${ }^{237} \mathrm{~Np}$ and breed ${ }^{238} \mathrm{~Np}$, which reaches equilibrium at approximately 10 days into the cycle, and ${ }^{239} \mathrm{Pu}$, which continuously increases in concentration with increasing irradiation time.

During the VESTA depletion simulation, the power density $\left(\mathrm{MW} / \mathrm{cm}^{3}\right)$, including the total power produced through direct fission, delayed energy, and neutron activation [19]) is calculated for each depletion material at each step into the cycle. The fission power density values provided in the VESTA output files were extracted and multiplied by the material volumes $\left(\mathrm{cm}^{3}\right)$ to attain the time-dependent material fission powers. As shown in Table 33, the targets produce $\sim 65 \mathrm{~kW}$ at BOC and $\sim 430 \mathrm{~kW}$ at EOC. The time-dependent fission powers of these targets are illustrated in Figure 30 . The ${ }^{252} \mathrm{Cf}$ production targets initially contribute $\sim 91 \%$ of the total target fission power but, at EOC, they only contribute $\sim 13 \%$. At EOC, when the ${ }^{238} \mathrm{Pu}$ production targets have the largest quantity of fissionable isotopes relative to any other time into the cycle, the targets in the inner small VXFs produce $\sim 59 \%$ of the total target fission power. 
Table 33. Beginning and end-of-cycle target fission power (MW)

\begin{tabular}{|c|c|c|c|c|}
\hline \multirow{2}{*}{$\begin{array}{l}\text { Model } \\
\text { Condition }\end{array}$} & \multicolumn{2}{|c|}{ Explicit Model } & \multicolumn{2}{|c|}{ Simplified Model } \\
\hline & $\begin{array}{c}\text { beginning-of-cycle } \\
\text { (MW) }\end{array}$ & $\begin{array}{c}\text { end-of-cycle } \\
\text { (MW) }\end{array}$ & $\begin{array}{c}\text { beginning-of-cycle } \\
\text { (MW) }\end{array}$ & $\begin{array}{c}\text { end-of-cycle } \\
\text { (MW) }\end{array}$ \\
\hline${ }^{252} \mathrm{Cf}$ targets ${ }^{(a)}$ & $5.893 \mathrm{E}-02$ & $5.728 \mathrm{E}-02$ & $5.929 \mathrm{E}-02$ & $5.651 \mathrm{E}-02$ \\
\hline ISVXF ${ }^{238} \mathrm{Pu}$ targets ${ }^{(b)}$ & $3.347 \mathrm{E}-03$ & $2.526 \mathrm{E}-01$ & 3.303E-03 & $2.531 \mathrm{E}-01$ \\
\hline OSVXF ${ }^{238} \mathrm{Pu}$ targets ${ }^{(\mathrm{c})}$ & $9.020 \mathrm{E}-04$ & $6.015 \mathrm{E}-02$ & $8.770 \mathrm{E}-04$ & $6.022 \mathrm{E}-02$ \\
\hline LVXF $^{238} \mathrm{Pu}$ targets ${ }^{(\mathrm{d})}$ & $1.742 \mathrm{E}-03$ & $5.974 \mathrm{E}-02$ & $1.704 \mathrm{E}-03$ & $6.010 \mathrm{E}-02$ \\
\hline Sum of targets & $6.492 \mathrm{E}-02$ & 4.298E-01 & $6.518 \mathrm{E}-02$ & $4.299 \mathrm{E}-01$ \\
\hline
\end{tabular}

(a) Five full length targets located in the flux trap target region.

(b) Five inner small vertical experiment facilities each containing seven fully loaded targets.

(c) Three outer small vertical experiment facilities each containing seven fully loaded targets.

(d) Three large vertical experiment facilities each containing 19 fully loaded targets.

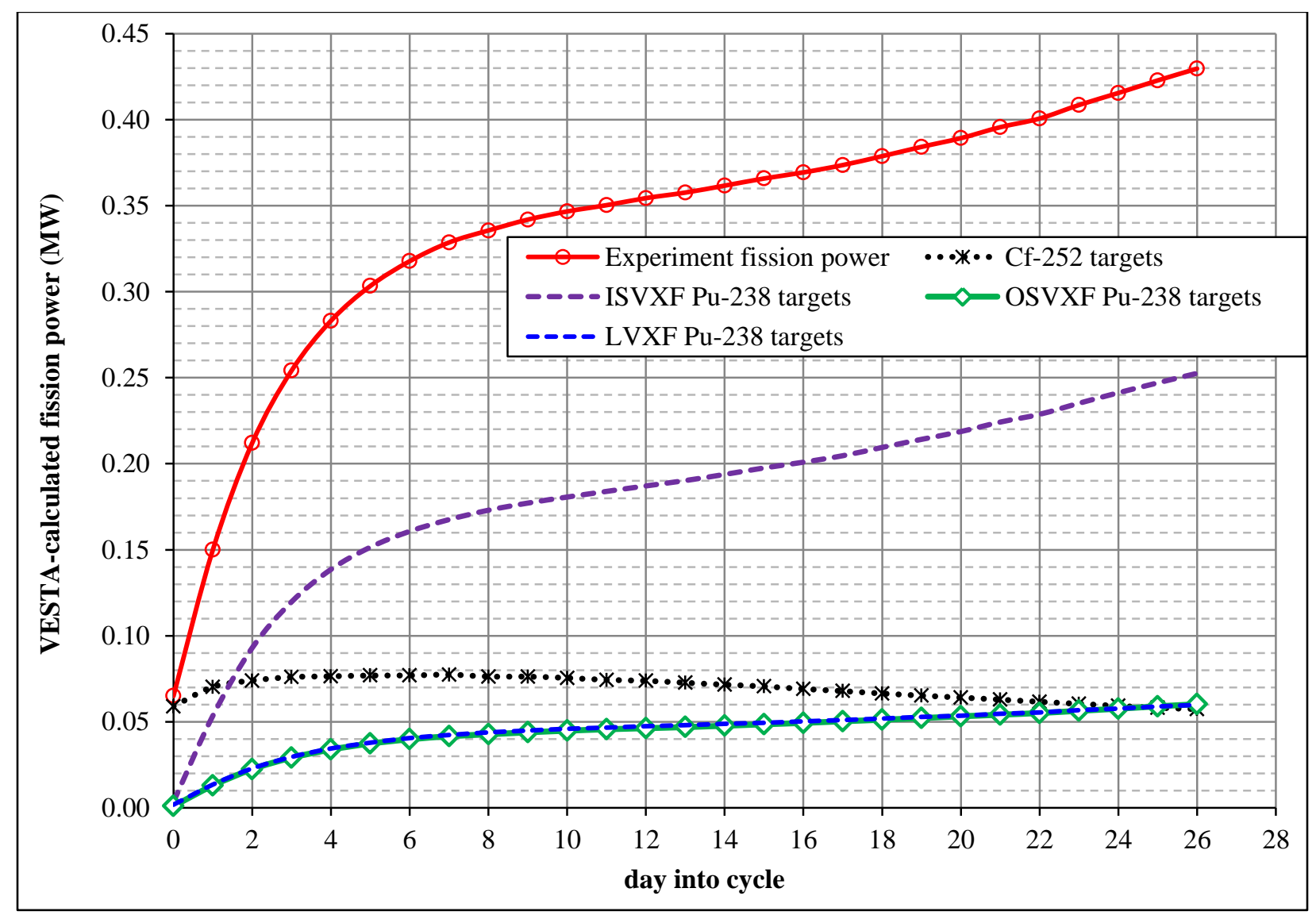

Figure 30. Single cycle target fission power curves for explicit model. 


\section{CONCLUSIONS}

This report documents a new, high-fidelity VESTA/MCNP HFIR core model with HEU fuel and a representative experiment loading to serve as a reference for LEU conversion studies, safety-basis calculations, and other research activities. The development of a representative experiment loading is described in detail. This loading adequately represents current, typical experiment loadings; whereas, the experiment loading in the Cycle 400 model is outdated and not typical of current operations. The VESTA 2.0.2, MCNP5 v1.51, and ORIGEN 2.2 codes were used to model and analyze this core configuration.

Two core models are discussed in this report, which are similar with the exception of the approach used to model the fuel elements. These two explicit and simplified models are the same as the corresponding models developed for Cycle 400 [4], except for the major improvement of the experiment loading, the detailed modeling of the fuel element side plates, and the change of initial material composition of the control elements.

The representative experiment loading that was implemented in the HEU representative model was defined based on valuable feedback from the RRD NS\&EA Group. The as-modeled FTT region contains full length ${ }^{252} \mathrm{Cf}$ production targets, ${ }^{75} \mathrm{Se}$ production capsules, ${ }^{63} \mathrm{Ni}$ production capsules, a ${ }^{188} \mathrm{~W}$ production capsule, and four shrouded dummy aluminum targets, with the remaining positions being filled with various materials irradiation targets. Five inner small VXFs, three outer small VXFs, and three large VXFs are modeled with $\mathrm{Al}$ holders containing fully loaded ${ }^{238} \mathrm{Pu}$ production targets.

The models making use of the explicit and simplified fuel plate modeling approaches predict 26 day and 26 day 10 hour cycle lengths, respectively. These estimates are slightly greater than actual cycle lengths that typically vary between 24 and 26 days. However, when considering the core modeling assumptions and potential uncertainties in nuclear data, these cycle length estimates are considered to compare fairly well to actual operations. Given the differences in modeling approaches and calculated cycle lengths, the isotopic results obtained with each of the two models are in good agreement with each other. The explicit model results indicate that $29.2 \%$ of the initial ${ }^{235} \mathrm{U}$ is depleted, with a maximum local ${ }^{235} \mathrm{U}$ depletion of $69.9 \%$. The fuel enrichment at discharge is $85.3 \mathrm{wt} . \%{ }^{235} \mathrm{U}$.

The cycle length predictions, isotopic inventories, and fuel burnup results obtained with the simplified and explicit fuel models for the HEU representative core compare well to each other. As also stated in [4] for Cycle 400, both simplified and explicit models for the HEU representative core provide adequate prediction of cycle length and isotope inventories, and can be used in calculations, depending on the computational purpose. While the explicit model is valuable for analyses focused on spatial detail in the fuel, the simplified model can be used for general purpose analyses and is more computationally efficient. 


\section{REFERENCES}

1) D. Renfro, D. Chandler, D. Cook, G. Ilas, P. Jain, and J. Valentine, "Preliminary Evaluation of Alternate Designs for HFIR Low-Enriched Uranium Fuel," ORNL/TM-2014/154, Oak Ridge National Laboratory (2014).

2) G. Ilas and R. T. Primm III, "Low Enriched Uranium Fuel Design with Two-Dimensional Grading for the High Flux Isotope Reactor,” ORNL/TM-2010/318, Oak Ridge National Laboratory (2011).

3) N. Xoubi and R. T. Primm III, "Modelling of the High Flux Isotope Reactor Cycle 400," ORNL/TM-2004/251, Oak Ridge National Laboratory (2005).

4) G. Ilas, D. Chandler, B. Ade, E. Sunny, and B. Betzler, "Modeling and Simulations for the High Flux Isotope Reactor Cycle 400," ORNL/TM-2015/36, Oak Ridge National Laboratory (2015).

5) A. Bergeron, "Review of the Oak Ridge National Laboratory Neutronic Calculations Regarding the Conversion of the High Flux Isotope Reactor to the Use of LEU Fuel," ANL/RERTR/TM-12/49, Argonne National Laboratory (2012).

6) B. Betzler, B. Ade, D. Chandler, G. Ilas, and E. Sunny, "Optimization of Depletion Modeling and Simulation for the High Flux Isotope Reactor", Joint International Conference on Mathematics and Computation, Supercomputing in Nuclear Applications and the Monte Carlo Method, Nashville, TN (April 2015).

7) R. M. Wham, "Current Status of the Plutonium-238 Production Project," Nuclear and Emerging Technologies for Space 2015, Paper 5013, Albuquerque, NM (February 2015).

8) J. McDuffee, "Tungsten Rabbit Irradiations in the HFIR Target Region," C-HFIR-2007-022 (March 2007) (archived, internal document available upon request to the division director, Research Reactors Division, Oak Ridge National Laboratory).

9) M. B. Chadwick, et. al., "ENDF/B-VII.0: Next Generation Evaluated Nuclear Data Library for Nuclear Science and Technology, Nuclear Data Sheets," 107, pp. 2931-3060 (2006).

10) National Institute of Standards and Technology (NIST), Atomic Weights and Isotopic Compositions, http://www.nist.gov/pml/data/comp.cfm.

11) W. R. Martin and J. R. Weir, "Mechanical Properties of X8001 and 6061 Aluminum Alloys and Aluminum-Base Fuel Dispersion at Elevated Temperatures," ORNL-3557, Oak Ridge National Laboratory (February 1964).

12) HFIR Safety Analysis Report, ORNL/HFIR/SAR/2344, Rev. 14 (October 2014) (archived, internal document available upon request to the division director, Research Reactors Division, Oak Ridge National Laboratory).

13) J. McDuffee, "Temperature Verification and Expansion Calculation for Nickel Specimens in a 3Hole Housing," C-HFIR-2014-013 (July 2014) (archived, internal document available upon request to the division director, Research Reactors Division, Oak Ridge National Laboratory).

14) D. Chandler and R. J. Ellis, "Neutronics Simulations of ${ }^{237} \mathrm{~Np}$ Targets to Support Safety-Basis and

${ }^{238} \mathrm{Pu}$ Production Assessment Efforts at the High Flux Isotope Reactor," Nuclear and Emerging Technologies for Space 2015, Paper 5009, Albuquerque, NM (February 2015). 
15) D. Chandler, "Activation and Heat Generation Calculations to Support Pu-238 Fully Loaded Target Irradiations in Inner Small VXFs for up to Three Cycles," C-HFIR-2015-014 (September 2015) (archived, internal document available upon request to the division director, Research Reactors Division, Oak Ridge National Laboratory).

16) J. Valentine, "Estimated Symmetrical Critical Control Element Position (ESCCEP) for Cycle 461," C-HFIR-2015-024 (July 2015) (archived, internal document available upon request to the division director, Research Reactors Division, Oak Ridge National Laboratory).

17) Control Plates and Cylinders, specification CDS-60.300-001, Rev. 2 (March 2012) (archived, internal document available upon request to the division director, Research Reactors Division, Oak Ridge National Laboratory).

18) R. T. Primm, III, "Reactor Physics Studies of Reduced-Tantalum-Content Control and Safety Elements for the High Flux Isotope Reactor," ORNL/TM-2003/65, Oak Ridge National Laboratory (November 2003).

19) W. Haeck, VESTA User's Manual - Version 2.0.0, IRSN Report, DSU/SEC/T/2008-331 Indice A, Institut de Radioprotection et de Sûreté Nucléaire (IRSN, The French Institute for Radioprotection and Nuclear Safety), France, (2009).

20) X-5 Monte Carlo Team, MCNP-A General Monte Carlo N-Particle Transport Code, Version 5, LA-CP-03-0245, Los Alamos National Laboratory (April 2003).

21) ORIGEN 2.2 Isotope Generation and Depletion Code Matrix Exponential Method, Oak Ridge National Laboratory, Oak Ridge, TN (June 2002). Available from Radiation Safety Information Computational Center at Oak Ridge National Laboratory as CCC-371.

22) M. B. Chadwick, et al., "ENDF/B-VII.1 Nuclear Data for Science and Technology: Cross Sections, Covariances, Fission Product Yields and Decay Data," Nuclear Data Sheets, 112, pp. 2887-2996 (2011).

23) R. T. Primm, III, "Reactor Physics Input to the Safety Analysis Report for the High Flux Isotope Reactor," ORNL/TM-11956, Oak Ridge National Laboratory (1992).

24) N. Xoubi, "Characterization of Exposure-Dependent Eigenvalue Drift Using Monte Carlo Based Nuclear Fuel Management," PhD diss., University of Cincinnati (2005).

25) A. J. Koning and D. Rochman, "Modern Nuclear Data Evaluation with the TALYS Code System," Nuclear Data Sheets, 113, pp. 2841-2934 (2012).

26) S. Hogle, "Optimization of Transcurium Isotope Production in the High Flux Isotope Reactor," PhD diss., University of Tennessee (2012). http://trace.tennessee.edu/utk_graddiss/1529.

27) Chart of Nuclides, National Nuclear Data Center, Brookhaven National Laboratory, http://www.nndc.bnl.gov/chart/.

28) D. Chandler, "Nuclide Inventory and Decay Heat Calculations to Support Pu-238 Fully Loaded Target Irradiations in Inner Small VXFs for up to Three Cycles," C-HFIR-2015-025 (November 2015) (archived, internal document available upon request to the division director, Research Reactors Division, Oak Ridge National Laboratory). 